\title{
Swiftboating: Misleading Advertising in Presidential Elections
}

\author{
Zhou Zhang \\ Montgomery, New Jersey
}

B.A. Mathematics and Economics, Vanderbilt University, 2007 M.A. Economics, University of Virginia, 2012

A Dissertation presented to the Graduate Faculty of the University of Virginia in Candidacy for the Degree of Doctor of Philosophy

Department of Economics

University of Virginia

May 2016 


\begin{abstract}
The term "swiftboating" arose out of advertisements aired in the 2004 presidential campaign and has now come to refer to any untrue political advertising. I develop an equilibrium model of voting behavior and candidate advertising in a presidential election with misleading and non-misleading advertising. I estimate the model using a unique dataset I created by systematically quantifying misleading statements in political advertisement videos in the 2008 election using FactCheck.org and PolitiFact.com. A candidate chooses misleading and non-misleading advertising in order to maximize his expected electoral votes in exogenously-determined battleground states.

I find that the two candidates spent over $\$ 38$ million on misleading advertising. At the levels of advertising observed in 2008, I find that the gross effect of misleading advertising is, on average across television markets, more than twice as large as the gross effect of non-misleading advertising in terms of increasing vote share. I calculate that the shadow price of one electoral vote to be $\$ 9.7$ million for McCain and $\$ 15.2$ million for Obama. In a counterfactual analysis where candidates cannot air misleading advertising, three states (Missouri, Indiana, and North Carolina) have different electoral outcomes, and the equilibrium level of advertising falls by $21 \%$, with the decrease in non-misleading advertising accounting for $26 \%$ of that change. In a second counterfactual, I repeal the laws against misleading advertising in the six battleground states that had them in place in 2008, and I find that misleading advertising in those states increases by $50 \%$, and this change leads to a different electoral winner in the state of North Carolina.
\end{abstract}

JEL Classifications: D72, L10, M37

KEYWORDS: elections, political advertising, misleading advertising, campaigns 
For my husband, Kevin, for always challenging me to be the best version of myself. 


\section{Acknowledgements}

I could not have completed this dissertation without the generous help of so many people. I am indebted to my advisors, Simon Anderson, Federico Ciliberto, and Maxim Engers for their patience, guidance, time, and support. I am proud to call myself their student. I am grateful for the support of several other faculty members, especially Steven Stern, Paul Freedman, and Leora Friedberg. Many thanks to Ken Elzinga and Lee Coppock for always providing a fresh perspective on this journey.

I also wish to thank my fellow students, from whom I have learned so much. I have benefited a great deal from conversations with Catherine Alford, Andrew Barr, Charles Murry, Michael Schreck, and everyone who has participated in the IO research meetings. Special thanks to the TAs who suffered through me being their Head TA and still letting me call them my friends. I also especially wish to thank Alicia Baik, who has been my loyal friend and partner in crime as we have gone through the challenging and rewarding experience of graduate school. To Kaitlyn Amos, for unwavering support, affirmation, garden walks, and faithful friendship - thank you.

I would like to recognize my parents, Ming and Weidong. It is their love and sacrifice that have given me the chance to live a life so rich with opportunities. Thanks to Amy and Alex, the greatest siblings in the world, for always being there with a listening ear. Lastly, to Kevin and Nate, thank you for your unconditional love and for giving me a reason to go home. Without you, I would probably still be working on this dissertation. 


\section{Contents}

1 Introduction 1

2 Literature Review $\quad 8$

2.1 Theoretical Models of Campaign Behavior . . . . . . . . . . . . 8

2.2 Empirical Models of Candidate Resource Allocation . . . . . . . . . . 13

2.3 Models of Advertising . . . . . . . . . . . . . . . 15

$\begin{array}{lll}3 & \text { Institutional Background } & 27\end{array}$

3.1 Advertising in Presidential Campaigns . . . . . . . . . . . . . 28

3.2 Swiftboating and Fact Checking . . . . . . . . . . . . . . . 30

3.3 The 2008 Campaign and Election . . . . . . . . . . . . . . . 33

4 Model $\quad 35$

4.1 Timing . . . . . . . . . . . . . . . . . . . 35

4.2 Voter Utility . . . . . . . . . . . . . . . 36

4.3 Candidate Advertising Choices . . . . . . . . . . . . . . 41

5 Data and Coding Misleading Statements 49

5.1 Data Sources . . . . . . . . . . . . . . . . . . 49 
5.2 Calculating Ideology $\ldots \ldots \ldots \ldots$

5.3 Summary Statistics . . . . . . . . . . . . . . . . . 65

6 Logit Estimation and Results $\quad 69$

$6.1 \quad$ Logit Model . . . . . . . . . . . . . . . . . . . . . . . . . . 69

6.2 Main Results . . . . . . . . . . . . . . . . . 71

6.3 Alternative Specifications . . . . . . . . . . . . . . . . 72

7 Empirical Model and Estimation $\quad 76$

7.1 Econometric Specification: Voters . . . . . . . . . . . 76

7.2 Econometric Specification: Candidates . . . . . . . . . . . . 91

$\begin{array}{lll}8 & \text { Results } & 97\end{array}$

8.1 Voters' Utility from Candidates . . . . . . . . . . . . . . . . . 99

8.2 Estimated Average Benefit of Advertising . . . . . . . . . . . . . 101

8.3 Marginal Cost Parameters . . . . . . . . . . . . . . . . . 102

9 Counterfactual Analysis $\quad 106$

9.1 No Misleading Advertising . . . . . . . . . . . . . . . . . 107

9.2 Overturn State Laws Against Misleading Advertising . . . . . . . 108

$\begin{array}{ll}10 \text { Conclusion } & 110\end{array}$

$\begin{array}{ll}\text { Bibliography } & 114\end{array}$ 


\section{Chapter 1}

\section{Introduction}

Total spending on television advertising by candidates in presidential campaigns reached $\$ 540$ million in 2012 (Andrews, Keating, and Yourish, 2012). The 2004 "swiftboat" advertisements raised the specter of misleading political advertising, and the term "swiftboating" has come to refer to an untrue political attack, usually on a candidate's character. The term comes from a series of advertisements aired by the group Swift Boat Veterans for Truth claiming John Kerry lied about his war record. The claims in these advertisements were later widely discredited by nearly all of the veterans who served alongside Kerry. ${ }^{1}$ Simultaneously, emphasis on fact-checking political advertising has grown since 2000 (Cooper, 2012), especially with the launch of third-party, fact-checking websites, Factcheck.org and PolitiFact.com, in 2003 and 2007, respectively. During the 2008 campaign, the two websites examined over one thousand claims made by politicians. PolitiFact.com also won the Pulitzer Prize for

\footnotetext{
${ }^{1}$ In this paper, "swiftboating" is a subset of what I consider misleading advertising, where misleading advertising includes all untrue political statements, whether about policy or character, and whether they are attack or self-promotional.
} 
National Reporting in 2009 for its fact-checking efforts in the 2008 campaign.

This increased attention to misleading political advertising coincides with controversy over legislation regarding political advertising; in 2014 and 2015, state laws against misleading political advertising were repealed in Ohio and Massachusetts due to lawsuits. Despite the media and policy scrutiny, little empirical work has investigated the effectiveness, either positive or negative, of misleading political advertising. Using a novel dataset of all candidate spending on misleading advertising in the 2008 campaign by television market, I develop and estimate a model of voter and candidate behavior in order to estimate the effectiveness of misleading advertising.

One reason for the lack of empirical work has been the lack of data to quantify misleading advertising. To address this issue, I create a dataset by watching all unique candidate-sponsored advertisements in 2008 and systematically coding each statement in each advertisement as misleading or non-misleading. I make use of FactCheck.org and PolitiFact.com to characterize the statements. I combine these data with advertising airing and spending data from the University of Wisconsin Advertising Project, and I find that misleading advertising in the 2008 campaign was substantial. Candidates spent over $\$ 38$ million (15.9\% of total advertising) on misleading advertising, and over half of all advertisements aired contained at least one misleading statement. Furthermore, unlike product markets, where misleading advertising is regulated by the Federal Trade Commission, political advertising is generally protected by the First Amendment, and any regulation of political advertising is at the state level. ${ }^{2}$

\footnotetext{
${ }^{2}$ In 2008, 17 states had laws against misleading political advertising (Kruse, 2001). They were: Alaska, Colorado, Florida, Louisiana, Massachusetts, Minnesota, Mississippi, Montana, Nevada, North Carolina, North Dakota, Ohio, Oregon, Tennessee, Utah, West Virginia, and Wisconsin.
} 
The prevalence of swiftboating and the associated changes in state laws concerning it raise questions about misleading advertising — do voters respond to misleading advertising differently than non-misleading advertising? Do state laws against misleading advertising affect candidate behavior? To answer these questions, I develop and estimate an equilibrium model of voter and candidate behavior in a presidential election. At the beginning of the campaign, states are divided exogenously into battleground and non-battleground states. ${ }^{3}$ Candidates simultaneously choose misleading and non-misleading advertising in battleground states in order to maximize expected electoral votes. Voters choose which candidate to vote for, or voters abstain from voting.

The voter utility model is spatial (Downs, 1957), where candidates are differentiated along two dimensions: ideology (the horizontal component) and valence (the vertical component). Ideology describes the candidate's stance on policy issues, and valence describes qualities of the candidate besides ideology that may matter to a voter-for example, competence or personal integrity. This particular type of spatial voting model, with both ideology and valence, has a long history in the political science literature, including Stokes (1963, 1992), and more recently, Ansolabehere and Snyder (2000), Adams, Merrill, and Groffman (2005) and Stone and Simas (2010).

The voter model is based on Anderson and Glomm (1992), where voters make decisions based on the difference in utility the voter receives from the two candidates, and this paper represents the first estimation of a voter model of this type. Voters vote based on the difference between the two candidates because an election differs from traditional consumer markets in that every voter must "consume" the winner of

\footnotetext{
${ }^{3}$ I use a list of battleground states provided by Nate Silver at the beginning of the campaign. I find that the results are similar using other lists of battleground states.
} 
the election. If this difference is greater than the cost of voting, a voter votes for the candidate who gives her the higher utility; otherwise, she abstains. In my model, both candidate and voter ideology are fixed, and the further away the candidate's ideology from the voter's, the less utility the voter receives from the candidate's ideology. Since voters make decisions about voting based on the difference in utilities of the two candidates, this model partitions voters into three types: those at the extremes, who are alienated; those in the middle, who are indifferent; and those close to the candidates' ideologies, who are the political base.

In order to estimate the model, I need information on voter ideology by county. I obtain this by separately estimating distributions of voter ideology as a function of demographics using data from the American National Election Studies (ANES). This procedure provides a straightforward way of incorporating voter demographics through ideology, while also preserving the simplicity of the voter-side model.

Candidates engage in two different types of advertising, misleading and nonmisleading, which have different costs to the candidate, and which enter voter utility separately. Both misleading and non-misleading advertising are persuasive and affect voter utility through valence. I estimate the parameters in voter utility, and I treat advertising decisions as endogenous by exploiting exogenous variation in geographical differences between television markets and state boundaries (Moshary, 2015). Voter utility includes a preference shock that is uncertain to a candidate and affects the candidate's probability of winning a particular state.

The candidates' objective is to maximize expected electoral votes in exogenouslydetermined battleground states plus a leftover campaign chest after the cost of advertising. Though the model does not explicitly model the candidates' objective after 
the election, it is important to allow for saving for two reasons. First, there is empirical evidence that candidates have substantial sums of money left over after Election Day. Secondly, the existence of this leftover money in the campaign chest implies that there is an opportunity cost for every dollar spent on advertising, which could be saved in the campaign chest and then be rolled over for use in a future campaign. The cost of misleading advertising for a candidate is affected by whether or not that advertisement is aired in a state with a law against misleading political advertising.

I estimate the effects of misleading and non-misleading advertising on voter choice using a discrete choice approach, in the spirit of Berry, Levinsohn, and Pakes (1995). Using the voter-side parameters, I calculate the marginal benefit of advertising and estimate the marginal cost parameters using ordinary least squares. While there is extensive work on misleading advertising, most of it centers on identification and measurement in a retail setting. ${ }^{4}$ Econometric evaluation in these papers has focused on experiments with specific advertisements, particularly in nutritional claims (Andrews, Burton, and Netemeyer, 2000)..$^{5}$ I not only quantify misleading advertising over the entirety of the 2008 presidential campaign, but I also estimate its effect on voters and its cost to candidates.

As spending on campaign advertising has increased, there has also been more empirical work examining the effect of campaign advertising (see Levitt, 1994; da Silveira and Mello, 2011; Gerber, 1998; Goldstein and Ridout, 2004). ${ }^{6}$ The closest works on presidential campaign advertising are by Gordon and Hartmann (2013, 2015), who

\footnotetext{
${ }^{4}$ See: Gardner (1975); Russo, Metcalf, and Stephens (1981); Cawley, Avery, and Eisenberg (2013).

${ }^{5}$ There is analysis of a few specific misleading statements in presidential campaigns. Using surveys, Winneg, Kenski, and Jamieson (2005) conduct a descriptive analysis of six misleading claims made in the 2004 presidential campaign.

${ }^{6}$ Gordon et al. (2012) provides a survey of the literature on political advertising.
} 
analyze advertising in the 2000 and 2004 presidential campaigns. In these two papers, Gordon and Hartmann examine the effects of advertising in presidential campaigns and model candidates' advertising choices. The main contribution of this paper is that I include detailed data on the content of advertising, distinguishing between misleading and non-misleading advertising; furthermore, I allow the two types of advertising to enter the voter utility function separately and affect a candidate's cost differently.

I find that misleading and non-misleading advertising differ in substantial ways, both for voters and for candidates. On the voter side, I find that, at the equilibrium levels of advertising in 2008, the gross effect of misleading advertising is more than twice as large as the gross effect of non-misleading advertising in terms of increasing electoral votes. This result is due to the fact that I find that candidates face an additional, non-pecuniary cost of airing misleading advertising, relative to non-misleading advertising, which is more pronounced in battleground states. This could be due to the fact that, especially in battleground states, airing misleading advertising annoys rival parties' congressional candidates, which decreases a presidential candidate's probability of passing his preferred policy in his future political career. Another possibility is that coverage of misleading statements by media and other sources in battleground states is more thorough, leading to a possible backlash in those state, increasing the cost of airing misleading advertising.

I also find that this non-pecuniary cost of misleading advertising is greater in states with laws against misleading advertising, and increases the cost of a dollar of misleading advertising by $\$ 0.63$ for McCain and $\$ 0.80$ for Obama. I calculate the shadow price of an electoral vote for each of the candidates based on the total 
cost spent on advertising, including the non-pecuniary cost of misleading advertising, which is the amount that rationalizes the amounts each candidate spends in battleground states. The price of one electoral vote is $\$ 9.7$ million for McCain and $\$ 15.2$ million for Obama.

I conduct two counterfactual analyses. In a counterfactual analysis where the six battleground states with these laws in place in 2008 overturn them, I find that misleading advertising increases by $50 \%$ in those states, which leads to a different electoral winner in North Carolina. I also find that misleading and non-misleading advertising are strategic complements. In a counterfactual analysis where misleading advertising is set to zero and candidates can only choose non-misleading advertising, total advertising falls by $21 \%$, with the decrease in non-misleading advertising accounting for $26 \%$ of that change. Moreover, misleading advertising distorts voter decisions relative to a world without it; without any misleading advertising, the electoral vote outcome would have been different for three states (Missouri, Indiana, and North Carolina) in the 2008 election. 


\section{Chapter 2}

\section{Literature Review}

This research is closely related to three somewhat related sets of literature: theoretical models of campaign behavior; empirical models of campaign behavior; and lastly, empirical models of advertising, including negative/comparative advertising and misleading advertising. In this section, I discuss the most relevant papers.

\subsection{Theoretical Models of Campaign Behavior}

The theoretical work on campaign behavior focuses on voter behavior and candidate resource allocation. In most of these models, the underlying framework is through candidate positioning, starting with Downs (1957). Voters are distributed along a line segment from 0 to 1 , where their locations represent their ideal policy positions, and a voter receives more utility from the candidate that is closer to her. In terms of modeling voters, there have been many extensions on this basic model; in particular, I focus on allowing for a "valence" characteristic and a cost of voting to affect voter choice. 
While the literature that examine voter choice mostly focuses on Downsian positiontype models, the literature on candidate resource allocation is more varied, particularly in two aspects. Firstly, there the choice of objective function-do candidates maximize the probability of winning the election or the plurality of votes? One challenge in modeling candidates as maximizing the probability of winning in a presidential election is that the Electoral College system contains winner-take-all contests at both the state and national level. Secondly, models of candidate resource allocation are also differentiated according to whether or not the model allows for uncertainty from the candidates' point of view about how voters will behave. In this section, I discuss the most relevant papers on voter and candidate choice.

Much of the work studying voter behavior finds it basis in a seminal work by Downs (1957), who was the first to model voting behavior in the framework of economic thinking. In this paper, Downs develops a flexible model for multi-party systems with voters acting as rational agents. He makes the following crucial assumptions: parties seek office solely for the power and income that accompany it, parties seek to maximize votes, a voter votes for the party that create government policy that would give him the highest utility, and there is imperfect knowledge from the voter's point of view about each party's policy differences. Together, these assumptions, the key one being imperfect knowledge, create a model that supports the existence of multiple parties, with rational politicians and rational voters.

In his model, Downs rationalizes the existence of party ideologies because they help a voter decrease the cost of being politically informed on all policies - instead, she can be informed about a party's ideology, which is correlated with its policy positions. Then, a voter can rationally vote on ideology. In this model, voters are distributed 
on a Hotelling line measuring ideology from 0 to 1 . One important distinction from the Hotelling model is that the equilibrium position of each party is determined by the distribution of voters. The Hotelling model predicts minimum differentiation in a two-party model and would not allow for more than two parties, and in the Downsian model, this would hold true if the distribution of voters had a single peak. Then, both parties would locate at that peak. However, by allowing for a flexible distribution of ideology for voters, Downs generates a model where there can be any number of parties that locate at different points. In a distribution of voters that is more polarized, then the parties would be located at different ideological positions. A voter distribution with several peaks would support the existence of multiple parties in equilibrium. This system of positioning voters and candidates according to ideology forms the foundation for most of the theoretical work today on voter choice.

The Downsian spatial framework has been adapted to include other elements of politics; most notably, Ansolabehere and Snyder (2000) include an additional dimension of "valence," which is a non-policy issue that all voters put equal weight on. This could be thought of as leadership ability or competence. In particular, Ansolabehere and Snyder (2000) derive sufficient conditions for the existence of equilibria under their framework. They show that, with the addition of a valence dimension, purestrategy Nash equilibria can exist in multidimensional spatial models. They also show that the party with the higher valence score will generally take a moderate position on positional issues; similarly, partisan realignments on positional issues often occur after large changes in valence issues.

Anderson and Glomm (1992), which the theory model in this paper is based on, adapts the Downsian framework to explain why some voters do not vote. In 
this model, candidates choose policy locations on the line, and uniformly-distributed voters have concave transportation costs as well as a positive cost of voting. The key difference between this model and the Downsian model is that voters compare the difference in utility between the two candidates. When this difference is greater than the cost of voting, the voter votes for the candidate that gives her the higher utility. Otherwise, she abstains from voting. This model leads to sections of voters that do not vote. Those in the middle, who are moderate, are indifferent - the two candidates are similar enough that the difference in utility does not outweigh the cost of voting. The voters at the extremes are alienated - on the far left or far right, both of the candidates are either too conservative or too liberal, and the cost of voting is too high to justify voting.

There are a few papers that develop theoretical models of candidate resource allocation. I focus on two models that take different approaches to examine candidate resource allocation, especially in the choice of objective function. In both of these models, there is perfect information.

Perhaps the first paper to develop a theoretical model of presidential candidate resource allocation is Brams and Davis (1974). The authors develop the " $\frac{3}{2}$ 's rule of presidential campaigning," which states that each candidate should spend money in proportion to the $\frac{3}{2}$ 's power of the number of electoral votes in the state. In this model, candidates maximize expected electoral votes among uncommitted voters in all fifty states. In each state, the number of expected electoral votes is the probability that the candidate has the plurality in that state times the state's number of electoral votes. They assume that the candidate's probability of winning is equal to the proportion of money each candidate spends in a given state. 
These assumptions about the candidate objective function are critical in order to make the problem tractable and to solve for a pure-strategy Nash equilibrium for the candidatfes. It is necessary that candidates maximize expected electoral votes (which is similar to maximizing votes, where votes are weighted by state) rather than the probability of winning. Since the Electoral College features winner-take-all competitions at the state level, there are many combinations of states that would allow a candidate to win the presidency, which means it would be very difficult (and perhaps impossible) to solve for a pure strategy equilibrium. Therefore, Brams and Davis (1974) model candidates as maximizing expected electoral votes. In order to solve explicitly for the pure-strategy Nash equilibrium, they also assume that candidates have equal budgets and match each other's spending across states.

Snyder (1989) relaxes a few of the assumptions that Brams and Davis make, most notably allowing the candidates to have different levels of strength. Under this asymmetry, Snyder shows that maximizing the expected number of seats leads to a different equilibrium than maximizing the probability of winning the majority of seats. ${ }^{1}$ In particular, maximizing the probability of winning a majority introduces the probability that the state is pivotal. He finds that if one party has more safe districts than the other, more resources will be spent in the safe district of the advantaged party than in the safe districts of the disadvantaged party. While Snyder is able to solve for a pure-strategy Nash equilibrium in a game where parties maximize the majority of seats, this structure cannot easily be applied to the Electoral College setting, where the weight of each states differs. In Snyder's model, each "seat" is a perfect substitute for another, which is not true in a presidential election for states

\footnotetext{
${ }^{1}$ In this model, each seat is an equally valued representative in government.
} 
with differing numbers of electoral votes. Moreover, his model does not allow for any "corner" equilibria, with zero spending in some districts by either party, which is seen in over half of the states in most presidential campaigns.

Both Brams and Davis (1974) and Snyder (1989) show that there are many challenges associated with modeling candidate resource allocation in a presidential election, especially with regard to the choice of objective function. This challenge also extends into the literature focusing on empirical models of campaign behavior, which I discuss in the following section.

\subsection{Empirical Models of Candidate Resource Allocation}

Most works examining candidate resource allocation are theoretical in nature, with two exceptions. Both Stromberg (2008) and Gordon and Hartmann (2015) examine candidate resource allocation in a presidential election under an Electoral College system. I discuss these two papers in details, focusing the discussion on the choice of objective function and the role of uncertainty in affecting candidates' behavior.

In Stromberg (2008), candidates choose the number of visits to make to each state in order to maximize the (approximate) probability of winning the election, where the winner in each state is determined probabilistically, based on candidates' strategies. In order to make the candidate problem tractable, Stromberg abstracts away solving strategies under the interdependence of states in the Electoral College; instead, he

assumes that candidates maximize the approximate probability of winning, which essentially reduces the objective function to maximizing expected electoral votes. The probability of winning is a function of local, state, and national shocks, which represent candidate uncertainty in the election outcome. He derives an analytical 
pure-strategy Nash equilibrium solution for this game and finds that more resources (visits) should be devoted to states that are likely to be decisive swing states, the probability of which is roughly proportional to the number of electoral votes. He also finds that more precise state-election forecasts make for a more concentrated level of resource allocation; he also finds that the presidential candidate who is lagging should try to increase the variance in electoral votes by spending more tine in large states where that candidate is behind.

Like Stromberg (2008), Gordon and Hartmann (2015) estimate a model of campaign resource allocation; however, they focus on candidate spending on advertising. Also similarly to Stromberg (2008), candidates maximize the probability of winning the Electoral College, and there is uncertainty from the candidates' point of view about voting outcomes. One of the benefits of the objective function choice is that the authors do not have to explicitly solve the equilibrium strategy for each candidate; instead, they assume that the resulting equilibrium is a unique, pure-strategy Nash equilibrium. The tradeoff is that they cannot solve for a counterfactual under an Electoral College system, and they cannot guarantee that they actual resulting equilibrium is unique or even a pure-strategy equilibrium. This tradeoff neatly exemplifies the core difficulty in empirically estimating candidate resource allocation. The obvious modeling choice, which assumes candidates maximize the probability of winning the majority of the electoral votes, comes with several tradeoffs in estimation.

In terms of estimation, the authors take a structural approach and estimate the parameters in the candidates' objective function, This includes estimating a parameter that guides how much money each candidate is willing to spend, which allows candidates to have flexible budgets and is consistent with both a fundraising model 
and a contest model. The authors also allow for uncertainty in terms of voter behavior, which is crucial for empirical estimation. This uncertainty rationalizes advertising in states that candidates lose ex post, and the amount that candidates spend in these states identifies the level of uncertainty. Candidates choose how much to spend on advertising in each DMA (television market), and there is some DMA-level shock, which candidates know the distribution of and have rational expectations about. This uncertainty can be seen as unexpected gaffes, weather, and any other factors that affect voters on Election Day that candidate cannot perfectly predict.

Their main results from Gordon and Hartmann (2015) focus on the financial strength of each candidate and the level of uncertainty across elections. In the 2000 election, Republicans had $45 \%$ greater financial strength than Democrats. In 2004, the two parties were much closer. In terms of uncertainty, the level of uncertainty in 2004 is almost half of that in 2000. They conduct a counterfactual under a Direct Vote system, and they find that in 2000, candidates would increase advertising spending by $25 \%$. This advertising would be spread more evenly across markets, with every market receiving positive levels of advertising.

\subsection{Models of Advertising}

There is an extensive literature on advertising and the role it plays in changing consumer demand. Often, a distinction is made between "persuasive" and "informative" advertising, where persuasive advertising "persuades" the consumer to prefer his product, and informative advertising provides information on the existence, price, characteristics, or quality of the product, and some argue that this distinction is important for modeling the precise mechanism through which advertising affects con- 
sumers. On the other hand, in a seminal work on advertising, Stigler and Becker (1977) eschew this distinction, arguing that:

"The distinction, if in fact one exists, between persuasive and informative advertising must be one of purpose or effect. A simple, accurately stated fact ('I offer you this genuine $\$ 1$ bill for 10 cents') can be highly persuasive; the most bizarre claim ('If Napoleon could have bought our machine gun, he would have defeated Wellington') contains some information (machine guns were not available in 1814)."

I leave aside the argument about how advertising affects voters and focus instead on the literature most pertinent to this paper-in the following sections, I describe the literature on political advertising, comparative/negative advertising, and misleading advertising.

\subsubsection{Political Advertising}

Like the theoretical work on campaign behavior, empirical models of campaign behavior also focus on two aspects: voter behavior and candidate resource allocation. On the voter side, I focus on papers that identify the causal effects of advertising on voters. The literature is very sparse in terms of empirical papers examining candidate resource allocation; I discuss the two most relevant papers.

Goldstein and Ridout (2004) provide an overview of the difficulty of measuring the true effect of advertising and discuss the relative merits and weaknesses of several types of campaign advertisement measurements, including campaign spending, advertisement buys, experimental manipulation, and individual-level recall. They propose 
a new measure of advertising exposure based on combining data on individual advertisement airings with likely exposure to that advertisement based on individual voter-level characteristics. While this measure is better than many that had been used before, they admit that the measure may also suffer from potential endogeneity of individual voters watching particular programs and potential outcomes of interest (knowledge of candidates, likelihood of voting, etc.)

da Silveira and Mello (2011) take advantage of a quasi-experimental setup in Brazil and use a differences-in-differences estimation approach to estimate the causal effect of advertising. In Brazil, gubernatorial elections occur using a two-round system. In the first round, candidates' TV time shares are determined by their coalitions' share of seats in the National Parliament. In the second round, the top two winners of the first round split TV time equally. da Silveira and Mello (2011) use the differences in advertising between the rounds to identify the causal effect of TV advertising. They find that TV advertising is effective, and increasing TV time by one percentage point increases the difference in vote share by 0.272 percentage points. They also attribute $70 \%$ of the change in vote shares between the first and second round to the changes in advertising.

The closest paper examining advertising effects is by Gordon and Hartmann. Gordon and Hartmann (2013) examine the effect of advertising on voters by using both a fixed effects estimation and an instrumental variables logit approach. They measure advertising using gross rating points (GRPs), which measures the number of exposures per capita. This variable is constructed using advertisement cost and the price per GRP by market. They model voters as making a discrete choice about which candidate to vote for, and they model advertising flexibly, without distinguish- 
ing between informative effects or prestige effects and without distinguishing between positive and negative advertising.

They estimate the effect of advertising on county-level vote share using data on presidential advertising from 2004 and 2008. They take two estimation approaches, a fixed effect approach and an instrumental variables approach. In both of these approaches, the results show that advertising is effective in affecting voters' choices. In the fixed effects approach, they estimate a DMA-party fixed effect and a year-party fixed effect, and they do not include demographic controls. In the instrumental variables approach, they include the fixed effects, controls for demographics and weather. Furthermore, they instrument for advertising, which is measured in GRPs, using the price of advertising. Under the preferred two stage least squares specification, they find the elasticity of own advertising to be about 0.03 and the elasticity of opponent advertising to be -0.01 . There are some slight differences across party, with advertising elasticity for Republicans estimated at 0.033 and advertising elasticity for Democrats estimated at 0.036. They calculate a "zero-advertising counterfactual,"

and estimate state outcomes when advertising is set to zero. Under this scenario, they find that three states (Ohio, Florida and New Hampshire) would have switched winners in 2000, and one state (Wisconsin) would have switched in 2004. In 2000, this change would have been enough to change the winner of the presidential election.

\subsubsection{Negative and Comparative Advertising}

There is a growing literature on advertising content and how it affects consumer demand. In particular, it is a much-debated question whether negative or comparative advertising differs in its effect on consumers, relative to positive advertising. This 
question has been explored at depth in the political science literature, where there is an abundance of negative advertising. In the following sections, I discuss papers that look to measure the effect of negative or comparative advertising.

While the literature on firm advertising content most often focuses on information (or lack thereof), there are a few papers that look specifically at negative and contrast advertising. Anderson et al. (2015) examine comparative advertising in the over-the-counter (OTC) analgesics industry. They model comparative advertising as having two effects: increasing the positive perception of own brand ("push") and decreasing the brand image of the targeted rival ("pull"). They estimate an equilibrium model of firm behavior, where firms choose prices, promotional advertising, and comparative advertising. They calculate diversion ratios between pairs of brans, which measure the fraction of a target's lost consumers who are diverted to the rival brand following an attack, and they find that these ratios differ across brand pairs. They also find that promotional advertising is twice as effective, relative to comparative advertising, at increasing own brand perceived quality, and they also find that comparative advertising are highly effective in decreasing a target brand's share. They also find evidence that comparative advertising effects spill over to untargeted rivals. In a counterfactual where they do not allow firms from airing comparative advertisements, they find that total advertising would fall, while prices and shares would remain about the same, increasing profits for all brands.

There is a continuing debate in the political science literature as to whether attack advertising increases or decreases voter turnout. There are arguments for both camps. If attack advertising creates more cynical voters, than the effect could be negative; on the other hand, if negative advertising raises awareness about relevant issues, this 
may increase voter turnout.

Stephen Ansolabehere and Valentino (1994) belong to the first camp, and they argue that negative campaigns generate a weakened sense of political efficacy, which may alienate voters from the political process and decrease voter turnout. They use an experimental design on message tone to examine the effect of attack advertising on voter engagement. In the experiment, they created two advertisements that differed in tone and the candidate sponsoring the advertisement. For example, one version of one of the advertisements was a positive one for Dianne Feinstein, while the other version of the advertisement was a negative one attacking Feinstein's opponent, Gray Davis. They recruited subjects to watch 15-minute videotaped recordings of local newscasts with one of the advertisements inserted in the middle, and they then questioned the subjects about their voting intentions. They find that exposure to the negative advertisement decreased the likelihood of voting by six percentage points. The authors also attempt to replicate this finding by looking at the correlation between tone and voter turnout in the 1992 Senate Elections, and they find that increased negativity was correlated with decreased turnout, echoing the results from the experiment.

Goldstein and Freedman (2002) find that, contrary to previous studies, negative campaign advertising has a stimulative effect on voter turnout. The authors take advantage of new data on the number of times an advertisement was aired; they match this data with survey data on how much people in particular media markets watch television. Combined, this gives a better measure of exposure to advertising than was previously available. They estimate the effect of exposure to advertising on likelihood of voter turnout using a logit model. They also include other demographic 
covariates in this model, including income, education, gender, race, etc. They split advertising into three types: positive, negative, and contrasting. They find that positive advertisements do not have a statistically significant effect on voter turnout, while negative and contrasting advertisements have a positive effect on the probability that a voter turns out. Being exposed to the average level of negative advertising increases the average voter's turnout probability by 2.8 percentage points.

More recently, Lau, Sigelman, and Rovner (2007) conduct a meta-analysis of the existing literature that looks at negative political advertising. In this paper, the authors look at 111 studies that examine the effect of negative political advertising, including studies of a single television advertising. ${ }^{2}$ They find that while negative campaigning does increase knowledge about the campaign and also tends to be more memorable, it is not effective in winning votes. Also, while negative campaigning tends to lower feelings of trust in government and feelings of political efficacy, it does not depress voter turnout.

\subsubsection{Misleading Advertising}

The literature on misleading advertising can be divided into two main branches: theoretical and empirical. In this section, I discuss both of these branches. In the theoretical literature, Nelson (1974) argues that misleading advertising can never occur. Barigozzi, Garella, and Peitz (2009) go one step further and allow for misleading advertising to potentially occur; however, in their model, misleading advertising never occurs in equilibrium. Lastly, Rhodes and Wilson (2015) explicitly allow for misleading advertising influencing rational buyers in equilibrium. In the following section, I

\footnotetext{
${ }^{2}$ They exclude studies of negative campaigns in nonpolitical settings, like product advertising.
} 
first discuss these three theoretical papers. I then focus on the empirical literature on misleading advertising.

In a seminal paper on advertising, Nelson (1974) develops a theoretical model where misleading advertising never occurs. He argues that in the case of "search qualities," where consumers are aware of the quality of that product through the search itself (for example, the style of dress), there are no incentives to mislead, because the consumer will know prior to purchase the difference between the actual quality and the advertised quality. In the case of "experience qualities," where consumers must experience the good before knowing the quality (for example, the taste of a brand of tuna fish), misleading advertising shouldn't exist if consumers have the power to repeat purchase that brand's goods. Nelson lays out two characteristics that are each sufficient for the nonexistence of misleading advertising: (1) consumers' belief in the truth of the statement does not increase profit from initial sales and (2) the producer can, at not cost to himself, make the advertised statement true instead of false. If either of these holds, then it is profit-maximizing for the firm to tell the truth. He then concludes that advertising works as a signal for a high-quality product.

Relatedly, Barigozzi, Garella, and Peitz (2009) develop a model where comparative advertising acts as a signal of quality. In this market, there is an imperfectly enforced ban on misleading advertising, and firms can potentially air false or misleading advertising. In the model, there are two firms, an incumbent and an entrant. The entrant's quality is determined by two things: an exogenously determined potential quality, and the firm's own effort. The entrant receives a signal about the potential quality of their product and chooses effort and the amount spent on advertising. The incumbent firm then sees the advertising choice, and both firms choose prices simul- 
taneously. After consumers decide on purchases, the incumbent firm then receives a signal of the quality of the entrant and can choose to take legal action if the entrant aired comparative advertising. This is one of the first theoretical papers to allow for the existence of misleading advertising. However, only the entrant is allowed to air comparative advertising; moreover, in equilibrium, misleading advertising never occurs, because the cost of the lawsuit is high enough that an entrant would only signal a true high quality.

Rhodes and Wilson (2015) develop a model with an equilibrium where misleading advertising occurs and influences rational buyers. In their model, a monopolist has private information about its product quality. The firm then chooses price and makes a claim about its quality, which could be false. Buyers update their beliefs based on this claim and make their purchase decisions. Finally, a policymaker instigates possible penalties. They find that the resulting equilibrium depends on the size of the penalty. If punishment is sufficiently low, there is full pooling and buyers fully discount any high advertised claim. If punishment is sufficiently high, the resulting equilibrium is fully separating, and there is no misleading advertising. If the punishment level lies between these two levels, then the equilibrium is semi-pooling. Low-quality firms make a false claim with some strictly positive probability. Since there is randomness in this false claim, advertising still contains some information, and buyers will actively update their beliefs in response to false claims. As a result of this, tougher penalties reduce the incidence of false advertising but raise their credibility, which can actually lead to a reduction in buyer welfare. This is one of the first papers to explicitly allow for the existence of misleading advertising in equilibrium.

The empirical literature on misleading advertising is sparse and mainly focuses on 
product markets. Moreover, the Federal Trade Commission (FTC) actively regulates misleading advertising in product markets. In fact, the FTC website states:

When consumers see or hear an advertisement, whether its on the Internet, radio or television, or anywhere else, federal law says that ad must be truthful, not misleading, and, when appropriate, backed by scientific evidence. The Federal Trade Commission enforces these truth-in-advertising laws, and it applies the same standards no matter where an ad appears in newspapers and magazines, online, in the mail, or on billboards or buses...

When the FTC finds a case of fraud perpetrated on consumers, the agency files actions in federal district court for immediate and permanent orders to stop scams; prevent fraudsters from perpetrating scams in the future; freeze their assets; and get compensation for victims.

Because of the FTC's involvement in regulating misleading advertising, the incentives for companies to air misleading advertising in product markets is very different than in political advertising. The literature on misleading advertising focuses on defining and identifying the existence of misleading advertising in product markets (especially in nutritional claims and over-the-counter drugs) as well as experimental studies on misleading advertising. I describe several of these studies below.

Russo, Metcalf, and Stephens (1981) discuss the characteristics that define a "misleading" advertisement, and they argue that the definition of a misleading advertisement should be based on consumers' beliefs. An advertisement is therefore considered misleading when two criteria hold: the consumer holds a false belief; and, an exposure to that advertisement increases the false belief of the consumer. The first criterion 
is necessary, but not sufficient. Under this proposed definition of misleading advertising, the authors test ten allegedly misleading statements and find that six of the statements qualify as misleading.

Andrews, Burton, and Netemeyer (2000) examines the effect of misleading advertising in nutritional claims in an experimental setting. In the experiment, shoppers were recruited and shown a print advertisement with either a misleading comparative advertisement claim about the level of sodium in soup or a control advertisement with no nutrition claim. The authors find that consumers provide more favorable (and incorrect) evaluations of nutritional content when shown the comparative ad. They also find, however, that disclosure of either: the specific amount of sodium; the amount of sodium relative to daily recommendations; or, that the sodium level is "high" relative to FDA standards decreases the effectiveness of the comparative advertisement.

Cawley, Avery, and Eisenberg (2013) are some of the first to estimate the impact of misleading advertising on consumption. They examine the over-the-counter (OTC) market for weight loss drugs, and they use individual-level data on magazine readership and television viewing to construct individual measures of exposure to certain advertisements. They find that after controlling for consumption of specific magazines and shows, exposure to print advertisements is not correlated with a higher probability of use, but exposure to deceptive television advertisements is correlated with a lower probability of use. For men, there are no correlations in terms of exposure to television advertisements, but exposure to deceptive print advertisements is associated with a higher probability of use. The authors also find evidence of spillovers - exposure to deceptive print advertisements is associated with a higher 
probability of dieting and exercise for both women and men. While Cawley, Avery, and Eisenberg are able to identify correlations between deceptive advertisement exposure and outcomes of interest, one important caveat is that these effects are not necessarily causal; a person's media consumption choices could be correlated with susceptibility to deceptive advertising. 


\section{Chapter 3}

\section{Institutional Background}

In this section, I describe the institutional background of U.S. politics, which motivates the model and counterfactuals. The U.S. President is elected through the United States Electoral College every four years. The Electoral College comprises electors from every state, where the number of electors is equal to the number of members of Congress each state is entitled to. ${ }^{1}$ These electors are intermediaries that are selected by each state's laws and who have almost always pledged to vote for a particular presidential and vice-presidential candidate. These electors are partyspecific and chosen by each party before Election Day. At the state level, with the exceptions of Maine and Nebraska, electoral votes are winner-take-all - the presidential candidate with the majority of votes in that state wins the entire state's electoral votes. The winner of the plurality of the electoral votes wins the election.

This winner-take-all system at the state level has lead to a system of classifying

\footnotetext{
${ }^{1}$ This number is a function of the state's population. In 2015, there are 538 electors, corresponding to 100 Senators, 435 members of the House of Representatives, and three electors for the District of Columbia.
} 
states as "battleground" state or "non-battleground" state. Battleground states are those in which the race between (typically) the Republican and Democratic nominee is close, and all of the state's electoral votes could be one by either party. Most states are not battleground states, and in these states, the winner of the electoral votes is mostly a foregone conclusion. While the set of battleground states changes depending on the election and the political climate, these changes generally occur gradually over election cycles.

\subsection{Advertising in Presidential Campaigns}

While advertising has been a critical component of presidential campaigns, the nature of advertising has changed dramatically over the years. The advent of television was a critical change, and Dwight D. Eisenhower was the first to air television advertisements in the 1952. These advertisements were filmed in Radio City Music Hall, and the series was called "Eisenhower Answers America," and featured Eisenhower answering questions from ordinary Americans. These advertisements are credited with helping Eisenhower earn the trust of Americans and subsequently winning the election.

In 1964, one of the most controversial commercials of all time was run by Lyndon B. Johnson. The ad, called "Daisy Girl," shows a young girl picking petals off of a daisy and counting the petals. This then changes into a voice-over of a countdown, and the screen transitions to show a nuclear explosion. The advertisement then asks you to vote for Johnson, "because the stakes are too high for you to stay home." The advertisement played on fears that Goldwater would use nuclear weapons in the war in Vietnam. Though the advertisement aired only once, it is credited with giving 
Figure 1: Spending by Candidates on TV Advertising

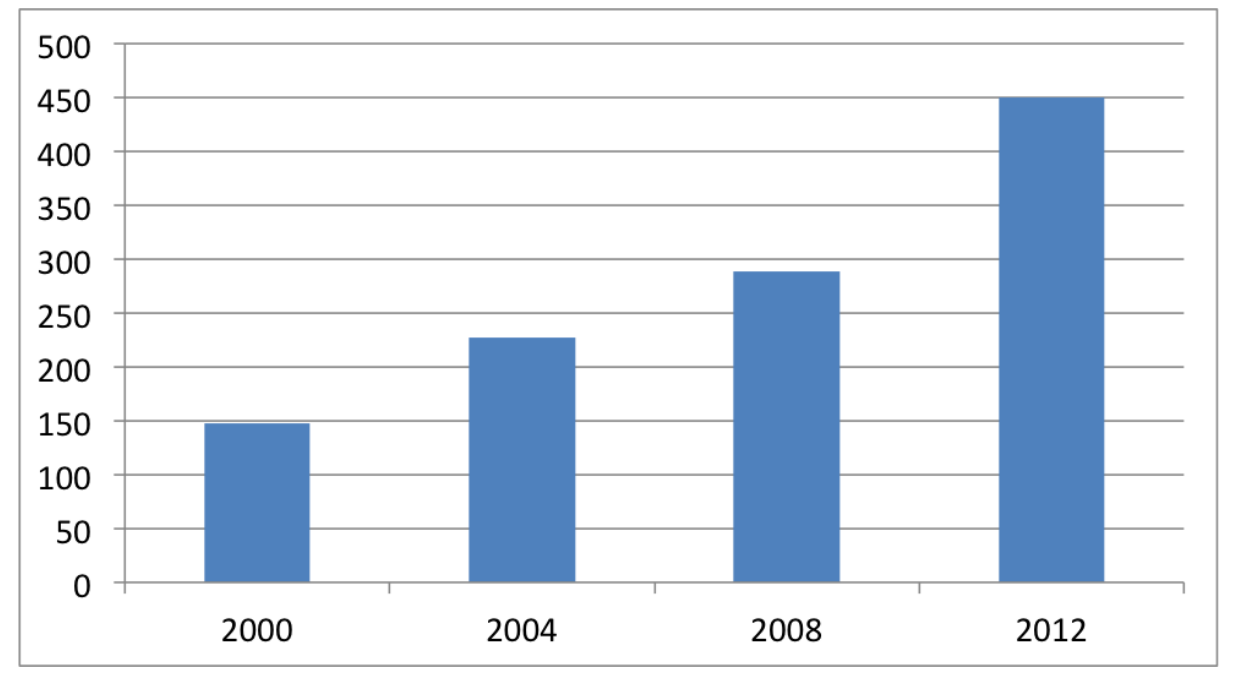

This chart shows the amount spent by candidates on television advertising from June 1 to Election Day. All amounts are normalized to 2008 dollars.

Johnson the landslide victory, in which he won 44 of the 50 states.

Spending on television advertising has only increased. In the 2000s, television advertising was the bulk of candidate advertising expenditures at 89\%, increasing from just under $\$ 150$ million in 2000 to $\$ 450$ in 2012 , as shown in Figure 1 . While spending by candidates increases in every election cycle, the campaign landscape has changed very rapidly since 2010. In 2010, the result of the Supreme Court case Citizens United v. Federal Election Commission led to the birth of the "independentexpenditure only committee," now colloquially known as Super PACs. Super PACs can raise unlimited funds from individuals, corporations, unions, etc., which has led to an explosion in third-party sponsored advertising in campaigns. The Super PACs cannot coordinate directly with candidates; however, they can and do air advertising on behalf of their preferred candidates. 


\subsection{Swiftboating and Fact Checking}

The term "swiftboating" arose from a series of advertisements aired in 2004 by the group Swift Boat Veterans for Truth (SBVT) attacking John Kerry and now have come to refer to any dishonest political advertisement. The "Swift Boat" is a class of vessel used by the U.S. Navy in the Vietnam War, and the type of vessel that Kerry served on. The SBVT members attacked Kerry's war record, calling into question his heroism in the events that led to the awarding of Bronze Star Medal and a Silver Star. One of the SBVT members did serve on the same boat as Kerry; however, nearly all of Kerry's other crewmembers have refuted the claims made by SBVT.

As a result of the swiftboat attacks on John Kerry in 2004, there has been increased media scrutiny on misleading political advertising. Two of the most well-known fact-

checking websites are FactCheck.org and PolitiFact.com. FactCheck.org describes itself in the following way:

We are a nonpartisan, nonprofit consumer advocate for voters that aims to reduce the level of deception and confusion in U.S. politics. We monitor the factual accuracy of what is said by major U.S. political players in the form of TV ads, debates, speeches, interviews and news releases. Our goal is to apply the best practices of both journalism and scholarship, and to increase public knowledge and understanding. FactCheck.org is a project of the Annenberg Public Policy Center of the University of Pennsylvania. The APPC was established by publisher and philanthropist Walter Annenberg to create a community of scholars within the University of Pennsylvania that would address public policy issues at the local, state 
and federal levels.

FactCheck.org is funded mainly by the Annenberg Public Policy Center, the Annenberg Foundation, and grants from the Flora Family Foundation. Starting in 2010, the website started accepting donations from individuals. They disclose the identity of any donor giving $\$ 1,000$ and more. Since its birth in December of 2003, FactCheck.org has posted hundreds of articles examining claims made in television advertisements.

PolitiFact.com is a project of the Tampa Bay Times (and is mostly funded by advertisements and subscriptions to the Times). They rate the accuracy of claims made by politicians in speeches, statements, and advertisements. The Times is owned by a nonprofit school of journalism called The Poynter Institute. The website has accepted donations from the Ford Foundation, the Democracy Fund, the Knight Foundation, Craigslist Charitable Fund, and the Collins Center for Public Policy. The website won the Pulitzer Prize for National Reporting in 2009 for its fact-checking efforts in the 2008 election.

One unique feature of the website is that they rate individual statements on a "Truth-O-Meter" ${ }^{\mathrm{TM}}$, which has the following rankings: Pants on Fire!; False; Mostly False; Half True; Mostly True; True. Holan (2015) shows a graphic depicting the presidential candidates (as of December 2015) and their statements as rated by PolitiFact.com starting from 2007. This graphic is reprinted below in Figure 2. 
Figure 2: PolitiFact's Falsehood Ratings

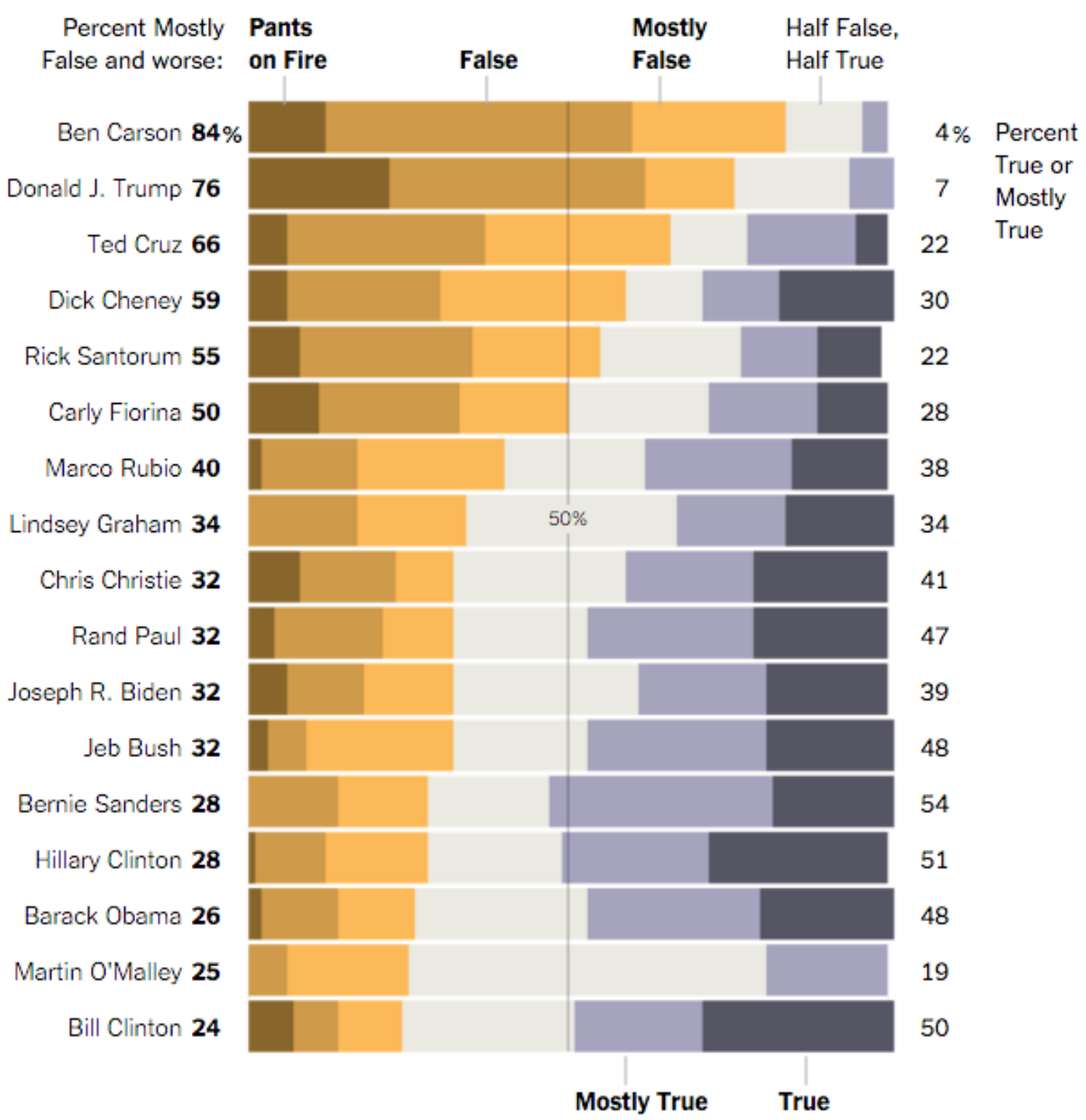

This graphic is from Holan (2015) and depicts presidential candidates ranked from most dishonest overall to least dishonest overall, as checked by PolitiFact. 


\subsection{The 2008 Campaign and Election}

In the 2008 U.S. presidential election, Barack Obama (the Democratic nominee) and running mate Joe Biden, defeated John McCain (the Democratic nominee) and running mate Sarah Palin. Obama won 365 electoral votes, while McCain won 173 electoral votes. The popular vote shows a closer election, with Obama having $52.9 \%$ of the popular vote, and McCain having $45.7 \%$ of the popular vote. There are several unique characteristics of this election. This election was the first since 1952 in which the two nominees were neither the incumbent president or vice president. ${ }^{2}$ Palin was the first woman to appear on a Republican presidential ticket, and the second woman overall to appear on a major party ticket. Similarly, Obama was the first African American to win a major party nomination and to win the presidency.

\subsubsection{The Obama Campaign}

Barack Obama served as the junior Senator for Illinois from 1997 to 2008. In June of 2008, he narrowly defeated initial-frontrunner Hillary Clinton to secure the Democratic nomination. His policies focused on ending the war in Iraq, establishing universal healthcare, and curbing global warming. His campaign raised over $\$ 650$ million, all from private citizens, breaking records for both primary and general campaigns. The Obama campaign was notable for its use of the Internet, particularly to reach young voters. The Internet allowed Obama supporters to easily reach people within their own communities, coordinate in social activities like signmaking, and campaign rallying for more Obama support. Obama's policies were all posted online and sent to subscribers via email and text, furthering his popularity among voters

\footnotetext{
${ }^{2}$ The president at the time, George W. Bush, was ineligible due to term limits.
} 
aged 18 to 29. He even announced the selection of Joe Biden, Senator from Delaware, as his running mate via text message. The campaign was also well-known for the extensive use of its logo, slogan ("Yes We Can") and its "Hope" poster. The logo and poster, in particular, have become some of the most widely recognized symbols of Obama's message. The combination of Obama's savvy technological use and recognizable campaign logo and slogan led to a successful use of grassroots fundraising and support. His inauguration in 2009 set a record for attendance at any event in Washington D.C.

\subsubsection{The McCain Campaign}

John McCain served as a Senator for Arizona starting in 1987. He ran for the Republican presidential nomination in 2000 but lost to George W. Bush. In 2008, he secured the nomination on March 4th. His policies focused on national security, education reform, and energy independence. McCain selected Governor Sarah Palin of Alaska as his running mate on August 29, 2008. The reaction to this choice was initially generally positive; however, her positions and policies became the focus of media scrutiny and later on in the campaign, voters were increasingly concerned about her qualifications. The McCain campaign participated in the public funding system, raising $\$ 380$ million; the campaign was outspent by the Obama campaign four-toone in the last two months of the campaign. The McCain campaign portrayed both McCain and Palin as mavericks and Washington outsiders. 


\section{Chapter 4}

\section{Model}

I present a model of candidate advertising decisions and voter behavior in a presidential election. Voters view political advertising; they then choose which candidate to vote for, or they choose to abstain from voting. Candidates simultaneously choose misleading and non-misleading advertising across DMAs, or television markets, in battleground states.

\subsection{Timing}

First, a Republican and Democratic candidate are nominated. Polling numbers for these two candidates are realized. Then, states are exogenously divided into "battleground" and "non-battleground" states. I assume that the winner in nonbattleground states is predetermined at this time and would not change no matter how much advertising is aired in that state. Then, candidates make advertising choices across DMAs. Finally, voters vote, and the winner of the election is determined. 


\subsection{Voter Utility}

I use a discrete choice, Hotelling framework to model voter behavior in the presence of candidate-sponsored television advertising. Voters receive utility from a candidate's ideology and a candidate's valence. Both misleading and non-misleading advertising affect the utility a voter receives from the candidate's valence. After a voter views political advertising, she compares the difference between the utilities she receives from the two candidates. If the difference is greater than the cost of voting, that voter votes for the candidate that gives her the higher utility. Otherwise, she abstains. I consider any votes for a candidate other than the Republican or Democratic candidate as equivalent to not voting.

A voter's utility of voting depends on the difference in utilities between the two candidates because an election differs from a product market - in a product market, each consumer can choose to personally consume (or not consume) any particular product. In an election, every voter will be living under the winning candidate's administration. Therefore, the voter cares about how different the two candidates are from each other. The more similar the candidates are, the less likely a voter is to vote.

\subsubsection{Utility of Voters from Candidates}

The utility that voter $i$, living in county $c$, receives from candidate $j, j=1,2$ is a function of that candidate's advertising $\left(A_{j m}, M_{j m}\right)$ in DMA $m$; other relevant county and state characteristics; the distance between the candidate's ideology, $x_{j}$, and the voter's ideology, $x_{i}$; and a candidate-preference shock, $\xi_{j c}$. Voter $i$, who lives in county $c$ in state $s$ receives the following utility from candidate $j$ : 


$$
\begin{aligned}
u_{i j c}= & \beta_{0 j}+\beta_{1} \log \left(1+A_{j m}\right)+\beta_{2} \log \left(1+M_{j m}\right) \\
& +\beta_{3} \text { Party }_{j s}+\beta_{4} \text { Poll }_{j s}+t \log \left(\left|x_{i}-x_{j}\right|+1\right)+\xi_{j c}
\end{aligned}
$$

There are two types of advertising: non-misleading advertising and misleading advertising. Both affect voter utility through the voter's perception of the candidate's valence. I follow Stigler and Becker (1977) in modeling advertising; in their model, an increase in advertising means "the household is made to believe - correctly or incorrectly - that it gets a greater output of the commodity from a given input of the advertised product." Similarly in my model, an increase in either misleading or non-misleading advertising causes the voter's perception of the candidate's valence to increase. $^{1}$

$A_{j m}$ indicates non-misleading advertising aired by candidate $j$ in DMA $m$, where county $c$ is in DMA $m$. Similarly, $M_{j m}$ indicates misleading advertising aired by candidate $j$ in DMA $m$. A DMA is a television market, which is a geographical area defined by Nielsen; each DMA comprises several counties, and in general, a state contains several DMAs. I assume that both types of advertising have diminishing returns and use a $\log (\cdot)$ functional form for advertising.

To capture persistence in voting behavior in presidential elections for each party over time, I include Party ${ }_{j s}$, which is measured by the percentage of people in state $s$, where county $c$ belongs to state $s$, who voted for the candidate belonging to $j$ 's party in the previous presidential election. The variable Poll $_{j s}$ is candidate $j$ 's average poll

\footnotetext{
${ }^{1}$ In this paper, I do not directly model the mechanism through which advertising affects voters. There is a continuing debate in the political science literature on this topic. Some argue that campaign advertising improves voter knowledge (Freedman, Franz, and Goldstein, 2004; Hillygus, 2005), while more recently, Arceneaux and Huber (2007) and Johnston, Hagen, and Jamieson (2004) separately find evidence from the 2000 election that advertising is persuasive and does not contribute to voter knowledge. More generally, Goeree (2008) addresses the role of limited information in advertising in the personal computer industry.
} 
in state $s$ on June 1, where county $c$ is in state $s$. This measure is plausibly exogenous to advertising during the presidential campaign, since the Democratic and Republican nominations were not secured until June. This measure captures utility differences between average voters in each state for the specific candidates in the election that is not captured by the party-persistent voting behavior. For example, voters in the Republican candidate's home state may already prefer the Republican candidate for ideological reasons, but they may also prefer the Republican candidate even more because he is from that state, and polling measures capture this.

The $x$ variables, $x \in[0,1]$, measure ideology on a Hotelling line where 0 is the most liberal and 1 is the most conservative. Voter utility is a function of the difference between the candidate's ideology, $x_{j}$, and the potential voter's ideology, $x_{i}$, and $t$ measures the transport cost. When $t$ is negative, the further away a candidate is from a voter, ideologically, the less utility that voter receives from that candidate.

\subsubsection{Utility of Voters from Voting}

In traditional consumer markets, each consumer has the option to personally consume, or not consume, a specific product. In an election, each voter must "consume" the winning candidate. Therefore, I model the utility of voting as a function of the differences in utilities that a voter receives from the two candidates. The smaller this difference is, the less likely a voter is to vote.

Following Anderson and Glomm (1992), the value of voting for candidate $j$ is the difference in utilities between the two candidates less the cost of voting, which is 


$$
\begin{aligned}
V_{i 1 c}\left(\Delta \xi_{c}, e_{c}\right) & =u_{i 1 c}-u_{i 2 c}-K\left(X_{c}, e_{c}\right) \\
V_{i 2 c}\left(\Delta \xi_{c}, e_{c}\right) & =u_{i 2 c}-u_{i 1 c}-K\left(X_{c}, e_{c}\right) \\
V_{i 0 c} & =0,
\end{aligned}
$$

where $u_{i j c}$ is defined in Equation (4.2.1), and the cost of voting, $K\left(X_{c}, e_{c}\right)$ is a function of county characteristics, $X_{c}$, and a cost-of-voting shock, $e_{c}$. The value of not voting is normalized to zero. Because the decision to vote is based on the difference in utilities a voter receives from the candidates, I am only able to identify the difference in the candidate-preference shock, $\Delta \xi_{c}=\xi_{1 c}-\xi_{2 c}$. Adding a constant $d$ to both $\xi_{1 c}$ and $\xi_{2 c}$ would result in the same vote shares.

In order to estimate the model, I add idiosyncratic error terms to all three of the choices. ${ }^{2}$ This error structure is unorthodox; normally, the idiosyncratic error terms would be added to the utility received from candidates, which is presented in Equation (4.2.1). However, if I were to add the errors to candidate utility, then the voting error terms would be correlated across candidates. In order to estimate the model, it is necessary that the error terms be uncorrelated across all three voting choices (voting for candidate 1 , voting for candidate 2 , and abstention). One intuitive interpretation of this error structure is "get out the vote" efforts. With some probability, a canvasser from candidate 1's campaign knocks on a potential voter's door to persuade them to vote for candidate 1. Similarly, other canvassers work for candidate 2.

Figure 3a provides an example of how the model partitions a uniform distribution of voters under a negative transport cost. The left shaded region indicates voters that vote for candidate 1 , while the right shaded region indicates voters that vote for candidate 2 . The voters in the middle are "indifferent," as the difference between the

\footnotetext{
${ }^{2}$ I present the model without the error terms to more easily depict it and offer some intuition as to how advertising affects voters.
} 
two candidates is too small to make voting worthwhile. The voters at the extreme are "alienated" and also don't vote. This is because as a voter's ideology gets closer to 0 (1), both the liberal and conservative candidate are too conservative (liberal) for that voter to warrant voting, and the difference between the two candidates is less than the cost of voting.

Figure $3 \mathrm{~b}$ shows the effect of advertising by candidate 1 to increase his own valence. Depending on the distribution of voter ideology, the same amount of advertising will have a different effect on the candidates' vote shares. Figure 4 illustrates an example of the importance of the distribution of voter ideology, where the distribution of voters is skewed left. Figures 3 and 4 show the same change in valence; however, this same shift in valence causes different shifts in the relative vote shares of the two candidates because of the difference in voter distribution.

Figure 3: Net Utility and Effect of Advertising, Uniform Distribution of Voters

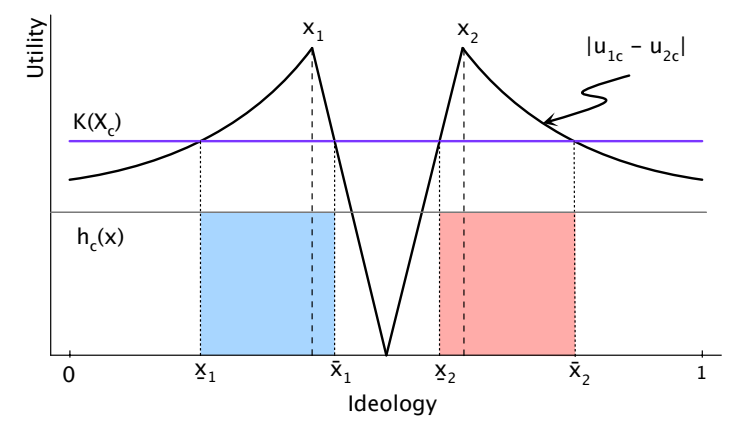

(a) Before Advertising

In this example, the candidates are located symmetrically about .5, and both candidates have the same valence. $\underline{x}_{1}$ and $\overline{\mathrm{x}}_{1}$ mark the marginal voters for candidate $1 ; \underline{x}_{2}$ and $\overline{\mathrm{x}}_{2}$ mark the marginal voters for candidate $2 . h_{c}(x)$ is the distribution of voters, and here, it is uniform.

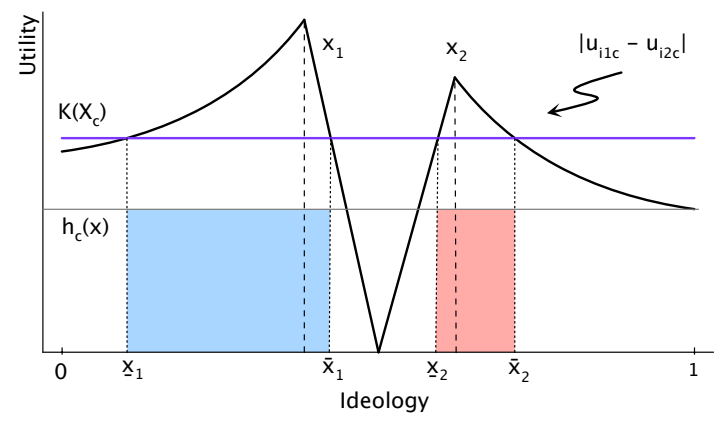

(b) After Advertising by Candidate 1

In this example, the candidates are located symmetrically about .5, and candidate 1 has a higher valence than candidate $2 . \underline{\mathrm{x}}_{1}$ and $\overline{\mathrm{x}}_{1}$ mark the marginal voters for candidate $1 ; \underline{\mathrm{x}}_{2}$ and $\overline{\mathrm{x}}_{2}$ mark the marginal voters for candidate $2 . h_{c}(x)$ is the distribution of voters, and here, it is uniform. 
Figure 4: Net Utility and Effect of Advertising, Skewed Distribution of Voters

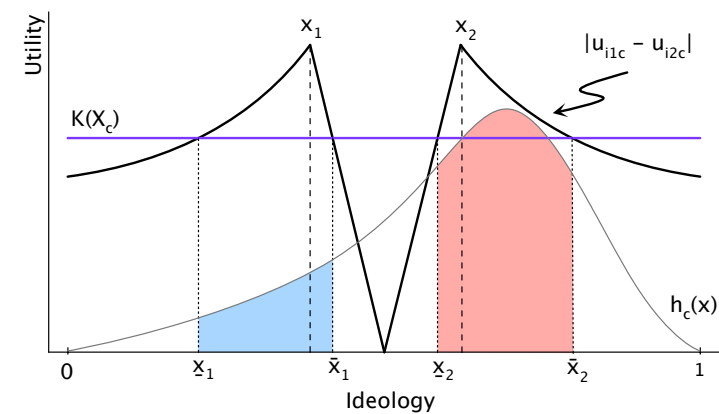

(a) Before Advertising

In this example, the candidates are located symmetrically about .5 , and both candidates have the same valence. $\underline{x}_{1}$ and $\bar{x}_{1}$ mark the marginal voters for candidate $1 ; \underline{\mathrm{x}}_{2}$ and $\overline{\mathrm{x}}_{2}$ mark the marginal voters for candidate $2 . h_{c}(x)$ is the distribution of voters, which is skewed left.

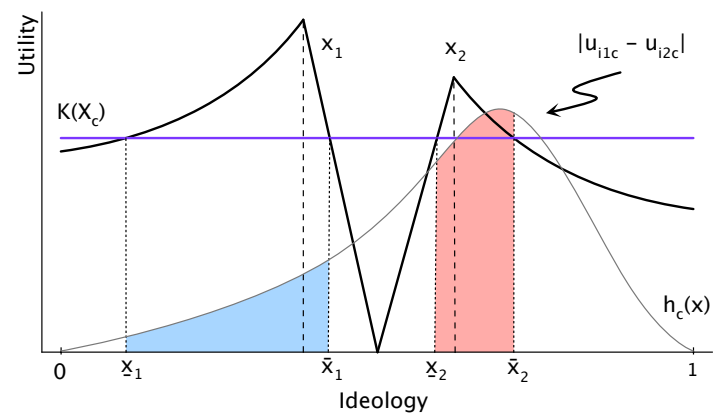

(b) After Advertising by Candidate 1

In this example, the candidates are located symmetrically about .5 , and candidate 1 has a higher valence than candidate $2 . \underline{x}_{1}$ and $\overline{\mathrm{x}}_{1}$ mark the marginal voters for candidate $1 ; \underline{\mathrm{x}}_{2}$ and $\overline{\mathrm{x}}_{2}$ mark the marginal voters for candidate $2 . h_{c}(x)$ is the distribution of voters, which is skewed left.

\subsection{Candidate Advertising Choices}

In battleground states, candidates maximize expected electoral votes plus a campaign chest leftover after the cost of advertising. This objective function is additive across states. The campaign chest represents the opportunity cost of spending on advertising, as money saved in the campaign chest can be used in future campaigns. Table 1 shows how much money candidates have saved in past elections. The cost of advertising is linear in advertising and also separable across DMAs. I follow Gordon and Hartmann (2015) and allow for uncertainty from the candidates' point of view about the candidate-preference shock. 


\subsubsection{Candidate Objective Function}

At the beginning of the campaign, states are exogenously divided into battleground and non-battleground states. ${ }^{3}$ In estimation of the candidate-side model, I ignore non-battleground states and assume that the votes in non-battleground states are guaranteed for a particular candidate, regardless of how much advertising is aired in that state. ${ }^{4}$ In battleground states, the set of which is denoted $S^{b}$, the candidate maximizes expected electoral votes plus a leftover campaign chest after the cost of advertising. ${ }^{5}$ For ease of notation, let $\operatorname{Ads}_{j m}=\left(A_{j m}, M_{j m}\right)$, and let $\mathbf{A d s}_{s}$ be a vector of advertisements aired by both candidates in DMAs contained in state $s$. Let $\theta$ be the parameters in the voter utility function, and let $\pi_{j s}$ be candidate $j$ 's probability of having the plurality of votes in state $s$, and therefore winning states $s$ 's electoral votes. Candidate $j$ has an exogenous budget $B_{j}$, and the candidate has three options for every dollar: spend on misleading advertising, spend no non-misleading advertising, or save in the campaign chest. Candidate $j$ 's objective function is

$$
\begin{aligned}
\max _{\operatorname{Ads}_{j m}} \Pi_{j}= & R_{j} \sum_{s \in S^{b}} \text { ElecVotes }_{s} \times \pi_{j s}\left(\mathbf{A d s}_{\mathbf{s}} ; \theta\right) \\
& + \text { CampaignChest }_{j}-(\text { Non-pecuniary Cost of Ads })
\end{aligned}
$$

\footnotetext{
${ }^{3}$ In non-battleground states, advertising is considered to be ornamental. Shaw (2006) defines "ornamental" advertising as not geared toward winning electoral votes but advertising that is instead designed to appease contributors or bolster congressional candidates.

${ }^{4}$ For example, I assume that the Republican candidate will always win Mississippi, even if the Democratic candidate were to buy all of the advertising spots in Mississippi.

${ }^{5}$ Each battleground state has an independent value that does not depend on any other battleground state, so this model does not allow for complementarities between states. Shaw (2006), a consultant in the 2000 and 2004 campaigns for George W. Bush, supports this assumption, and reports about the 2000 campaign, "Rove, Dowd, and others were thinking in more dichotomous terms: states were either in play or not. States that Dole had carried would get minimal resources, while states that had gone Democratic in 1996 but designated battlegrounds for 2000 would get significant attention."
} 
subject to

$$
\sum_{m \in s, s \in S^{b}} \operatorname{Ads}_{j m} N_{m}+\text { CampaignChest }_{j}=B_{j}
$$

where

$$
\pi_{j s}\left(\mathbf{A d s}_{\mathbf{s}} ; \theta\right)=\operatorname{Pr}\left(\operatorname{Votes}_{j s}\left(\mathbf{A d s}_{\mathbf{s}} ; \theta\right)>\operatorname{Votes}_{-j s}\left(\mathbf{A d s}_{\mathbf{s}} ; \theta\right)\right)
$$

and

$$
\text { Non-pecuniary Cost of Ads }=\sum_{m \in s, s \in S^{B}} \operatorname{Ads}_{j m}\left(W_{j m} \gamma_{j}+\omega_{j m}\right)
$$

$R_{j}$ is a constant and candidate-specific shadow price of one electoral vote in a battleground state, and its estimated values rationalize the observed amounts spent on advertising by each candidate. It is also a scaling parameter that translates electoral votes into dollar terms so that both electoral votes and costs are measured in the same units. One useful interpretation of $R_{j}$ is in the relative values for the two candidates. For example, if $R_{1}$ is twice as large as $R_{2}$, then candidate 1's willingness to pay for one electoral vote is twice as large as candidate 2 's. ${ }^{6}$

ElecVotes $_{s}$ is the number of electoral votes in state $s$, and $\pi_{j s}$ is the probability that candidate $j$ wins state $s$. This probability is a function of voter preferences for advertising and the candidates' uncertainty over the candidate-preference shock, which is described in detail in Section 4.3.2. Equation (4.3.2) gives the non-pecuniary cost of advertising in dollar terms, which is a function of exogenous and observable

\footnotetext{
${ }^{6}$ There are a few possible explanations as to why a single electoral vote has value to a candidate. One possible explanation is that each expected electoral vote increases the candidate's future monetary stream by $R_{j}$ in the form of campaign contributions or speaking fees. Another possible explanation, analogous to the contest literature, is the "hunger" for each expected electoral vote: each candidate doesn't want to just win the election by a few electoral votes, he wants to win by a large margin. In the contest literature, the parameter $R_{j}$ is referred to as the "prize" associated with winning the election. Baron (1989) offers a few different explanations of $R_{j}$ : the "hunger" for office, preferences for the candidate's policy outcomes, or monetary gain.
} 
DMA characteristics, including whether or not that DMA is in a state with a law against misleading political advertising, and an observable candidate- and DMAspecific shock. CampaignChest ${ }_{j}$ is candidate $j$ 's campaign chest, which is the amount of money that candidate $j$ has after the election.

$N_{m}$ is the number of potential voters in DMA $m$. Since $A_{j m}$ and $M_{j m}$ are measured in dollars per voter, $\operatorname{Ads}_{j m} N_{m}$ is the pecuniary cost of advertising - the total dollar amount spent on advertising by candidate $j$. All costs are measured relative to this campaign chest, and the interpretation of the cost of a dollar spent on advertising is the benefit of a dollar in the campaign chest. I am agnostic about the purpose of the campaign chest, and the only assumption that I impose is that the marginal benefit of a dollar in the campaign chest is constant. ${ }^{7}$ Empirically, the amount of money in the campaign chest for the 2008 campaign is positive. In the 2008 campaign, each candidate had over $\$ 32$ million of cash on hand after Election Day. Table 1 lists the amount of cash on hand for each candidate after Election Day in the 2000, 2004, 2008, and 2012 campaigns.

Rewriting the candidate objective function by substituting the budget constraint and the non-pecuniary cost of advertising into the candidate's objective function, Equation (4.3.1) becomes

$$
\begin{aligned}
\max _{\operatorname{Ads}_{j m}} & \Pi_{j}=B_{j}+R_{j} \underbrace{}_{\sum_{\text {Expected electoral votes in battleground states }} \text { ElecVotes }_{s} \times \pi_{j s}\left(\mathbf{A d s}_{\mathbf{s}} ; \theta\right)} \underbrace{\left(\operatorname{Ads}_{j m} N_{m}\right.}+\underbrace{\operatorname{Ads} s_{j m}\left(W_{j m} \gamma_{j}+\omega_{j m}\right.}_{\text {Non-pecuniary cost of ads }})) .
\end{aligned}
$$

\footnotetext{
${ }^{7}$ Common uses of leftover campaign money are: transfers to the party's committee, refunds to donors, and contributions to charity; federal regulations restrict this leftover money to be used for candidates' personal use.
} 
Table 1: Candidates' Cash at the End of November

\begin{tabular}{lllccc} 
Candidate & Year & Party & $\begin{array}{c}\text { Total Ad Spending } \\
\text { (Millions) }\end{array}$ & $\begin{array}{c}\text { Cash on Hand } \\
\text { (Millions) }\end{array}$ & $\begin{array}{c}\text { Cash on Hand } \\
\text { (\% of Ad Spending) }\end{array}$ \\
\hline Mitt Romney & 2012 & Rep & $\$ 147$ & $\$ 12.9$ & $8.78 \%$ \\
Barack Obama & 2012 & Dem & $\$ 333$ & $\$ 5.4$ & $1.62 \%$ \\
John McCain & 2008 & Rep & $\$ 103$ & $\$ 32.8$ & $31.84 \%$ \\
Barack Obama & 2008 & Dem & $\$ 187$ & $\$ 32.7$ & $17.49 \%$ \\
George W. Bush & 2004 & Rep & $\$ 97.6$ & $\$ 22.1$ & $22.66 \%$ \\
John Kerry & 2004 & Dem & $\$ 188$ & $\$ 25.7$ & $13.86 \%$ \\
George W. Bush & 2000 & Rep & $\$ 75.3$ & $\$ 8.5$ & $11.42 \%$ \\
Al Gore & 2000 & Dem & $\$ 77.1$ & $\$ 14.9$ & $19.29 \%$ \\
\hline
\end{tabular}

"Cash on Hand" is the sum of the candidate's committees' "Cash on Hand" according to reports by the FEC. The reports are a snapshot of the candidate's financial position as of: November 26, 2012; November 24, 2008; November 22, 2004; and November 27, 2000.

Since the candidate's budget, $B_{j}$, is constant, this objective function is equivalent to maximizing expected electoral votes less the cost of advertising, which has two parts: a pecuniary portion and a non-pecuniary portion.

\subsubsection{Candidate Uncertainty}

There are two types of shocks in the voter-side model: the cost-of-voting shock, $e_{c}$, and the candidate-preference shock, $\Delta \xi_{c}$. Candidates know the realizations of the cost-of-voting shock, $e_{c} \cdot{ }^{8}$ Similarly to Gordon and Hartmann (2015), candidates form beliefs about the voter-side candidate-preference shocks as follows:

$$
\Delta \xi_{c}=\Delta \bar{\xi}_{c}+\Delta \xi_{s}, \quad \Delta \xi_{s} \sim N\left(0, \sigma^{2}\right)
$$

where $\Delta \bar{\xi}_{c}$ is the expectation of the shock. The candidates' level of ex-ante uncertainty, measured by $\sigma$, affects each candidate's probability of winning, $\pi_{j s} . \Delta \xi_{s}$

\footnotetext{
${ }^{8}$ I have estimated a model that allows for candidate uncertainty in the cost-of-voting shock as well; this adds substantial computational burden and does not materially change the results.
} 
represents factors that are realized to the voters after viewing advertising but are unknown to the candidates when they set advertising. In estimation, I set candidates' expectations of the county-specific portion of the voter-preference shock equal to the realized shocks recovered from the model, and $\Delta \bar{\xi}_{c}=\Delta \xi_{c}{ }^{9}$

The probability of winning for candidate 1 (2) is the probability that the draw of the state-specific portion of the candidate-preference shock, $\Delta \xi_{s}$, is less than (greater than) the critical value of $\Delta \xi_{s}^{*}$, where $\Delta \xi_{s}^{*}$ is such that

$$
\operatorname{Votes}_{j s}\left(\mathbf{A d s}_{\mathbf{s}}, \Delta \xi_{s}^{*} ; \theta\right)=\operatorname{Votes}_{-j s}\left(\mathbf{A d s}_{\mathbf{s}}, \Delta \xi_{s}^{*} ; \theta\right)
$$

and sets the number of votes for each candidate equal in state $s$. Votes $j s$ is the number of votes candidate $j$ receives in state $s$ and is determined by the voter-side model.

Formally, the probability of winning is

$$
\begin{aligned}
& \pi_{1 s}=1-\Phi\left(\Delta \xi_{s}^{*}\right) \\
& \pi_{2 s}=\Phi\left(\Delta \xi_{s}^{*}\right)
\end{aligned}
$$

where $\Phi$ is the normal cumulative distribution function. The candidates' probabilities of winning change as the candidates' uncertainty changes. For example, suppose that at the beginning of the election and before candidate advertising is aired, polling numbers show that candidate 2 has a lead in state $s$ and $\Delta \xi_{s}^{*}=0.6$. Then, as $\sigma$ decreases, the variance of the shock decreases, there is less uncertainty, and candidate 1 has a higher probability of winning the state, since there is a higher probability that the realization of $\Delta \xi_{s}$ will be below 0.6. At the extreme, if $\sigma=0$, then candidates

\footnotetext{
${ }^{9} \mathrm{As}$ in Gordon and Hartmann (2015), this means that the realized $\Delta \xi_{s}$ is always 0 . However, this is unknown to candidates when they make advertising choices, which implies a positive probability for each candidate of winning each battleground state.
} 
have no uncertainty, and, given advertising levels for both candidates, both candidates know with certainty who will win that state's electoral votes. With uncertainty from the candidates' point of view of the voter-preference shock, even given advertising levels, candidates only know the probability of winning a state. Table 16 shows how the probability of winning changes for certain values of $\sigma$.

Given a particular level of candidate uncertainty, $\sigma$, advertising changes the candidate's probability of winning through the change in the critical value of $\Delta \xi_{s}^{*}$. Suppose that before advertising is aired, polling numbers show that the two candidates are exactly even, with $\Delta \xi_{s}^{*}=0$, and each candidate has a $50 \%$ chance of winning. Then, as candidate 1 increases his advertising, the critical value of $\Delta \xi_{s}^{*}$ falls, and the probability that candidate 1 wins, $\pi_{1 s}$ increases, because it is more likely that the realized value of $\Delta \xi_{s}$ falls above the new, lower critical value.

\subsubsection{Equilibrium}

The equilibrium solution to the candidate game is a pure-strategy Nash equilibrium, which is defined as an action for each candidate such that no candidate can unilaterally increase his payoff. Let $\mathbf{A d s}_{j}^{*}$ be a vector of misleading and non-misleading advertising choices $\left(A_{j}^{*}, M_{j}^{*}\right)$ across all DMAs in battleground states. Then, a pair of strategies $\mathbf{A d s}_{1}^{*}$ and $\mathbf{A d} \mathbf{s}_{1}^{*}$, form a Nash pure-strategy equilibrium if

$$
\Pi_{1}\left(\mathbf{A d s}_{1}^{*}, \mathbf{A d s}_{2}^{*}\right) \geq \Pi_{1}\left(\mathbf{A d s}_{1}, \mathbf{A d s}_{2}^{*}\right)
$$

for $\mathbf{A d s}_{1} \in\left[0, B_{1}\right]$ and

$$
\Pi_{2}\left(\mathbf{A d s}_{1}^{*}, \mathbf{A d s}_{2}^{*}\right) \geq \Pi_{1}\left(\mathbf{A d s}_{1}^{*}, \mathbf{A d s}_{2}\right)
$$

for $\mathbf{A d s}_{2} \in\left[0, B_{2}\right]$. Szidarovszky and Okuguchi (1997) prove the uniqueness of equilibrium in a related model, where agents compete to win a prize, and the probability of 
winning the prize is a function of all agents' effort. I do not prove that the equilibrium in my model is unique. To address the issue of multiple equilibria empirically, I use different starting guesses of strategies to check for other solutions, and I find that the routine always converges to the observed equilibrium. After estimating the model's parameters, I plug in different starting points for candidate advertising choices. I then solve for the equilibrium using a fixed-point method. Fist, I guess a vector of advertising choices for the entire state. Second, I solve for the optimal amount of misleading advertising for candidate 1 in DMA 1 and plug that in. Then, I solve for the optimal amount of advertising in the next observation (e.g. misleading advertising by candidate 1 in DMA 2). I repeat this until the entire vector of first order conditions hold. 


\section{Chapter 5}

\section{Data and Coding Misleading Statements}

I use data from the 2008 election between Barack Obama (the Democratic candidate) and John McCain (the Republican candidate). I use data from several different sources, including self-coded content data on misleading advertising. In this section, I describe what data sources I use, provide a detailed description of how I coded misleading advertising using Factcheck.org and PolitiFact.com, and explain how I construct the variables I use in estimation, including simulated ideology measures. I then provide a discussion of some summary statistics.

\subsection{Data Sources}

Data on advertisement airings and costs are from Campaign Media Analysis Group (CMAG), provided through the University of Wisconsin Advertising Project. CMAG records every instance of political advertising, the DMA in which it is aired, and the 
estimated cost of the ad. I supplement this dataset with self-coded data on advertising content, which I describe in Section 5.1.1. Data on county demographics are from the United States Census. Vote share data is from Dave Liep's Atlas of U.S. Presidential Elections. Data on past turnout is from the United States Election Project. Polling data is from Real Clear Politics, a polling aggregator. ${ }^{1}$ I simulate distributions of voter ideology for each county, a process I discuss in detail in section 5.2. Casndidate ideology measures are from Poole and Rosenthal's NOMINATE scores, which are lifetime scores based on roll-call voting behavior of each candidate.

To define battleground states, I use the states listed by Nate Silver as "Tipping Point States" as of June 9, 2008, which are listed in the first column of Table 2. ${ }^{2}$ Table 2 lists battleground states as determined by The New York Times, The Washington Post, and Nate Silver; of the eighteen states listed, the three sources agree on ten of the states, which are listed in bold. I use Nate Silver's list because he is transparent about the methodology he uses to create it. ${ }^{3}$ Silver's list is also consistent with the top 15 states in terms of total advertising spending in 2008, with the exceptions of including New Jersey and excluding Minnesota.

Data used to estimate the relationship between demographics and ideology are from the American National Election Studies (ANES). The ANES is a series of surveys of a representative sample of the American electorate. Of the 21 surveys done in 2008, 10 surveys contained questions about politics. Of those 10 surveys, 5 contained questions about the respondent's ideology. In these 5 surveys, ideology was recorded

\footnotetext{
${ }^{1}$ www.realclearpolitics.com

${ }^{2}$ Nate Silver, the founder of fivethirtyeight.com, is a statistician who analyzes elections. Silver become well-known in 2008 after he correctly predicted the outcome of the presidential election in 49 of 50 states.

${ }^{3}$ See Silver's website FAQ for details about his methodology. The model results do not materially change when using the union or intersection of the states in Table 2 instead.
} 
Table 2: Battleground States

\begin{tabular}{lccc} 
State & $\begin{array}{c}\text { Nate Silver } \\
\text { (This Paper) }\end{array}$ & $\begin{array}{c}\text { The Washington } \\
\text { Post }\end{array}$ & $\begin{array}{c}\text { The New York } \\
\text { Times }\end{array}$ \\
\hline Colorado & 1 & 1 & 1 \\
Florida & 1 & 1 & 1 \\
Indiana & 1 & 0 & 0 \\
Iowa & 1 & 1 & 1 \\
Michigan & 1 & 1 & 1 \\
Minnesota & 0 & 1 & 1 \\
Missouri & 1 & 1 & 0 \\
New Hampshire & 1 & 1 & 1 \\
New Jersey & 1 & 1 & 0 \\
New Mexico & 1 & 1 & 1 \\
Nevada & 1 & 0 & 1 \\
North Carolina & 1 & 1 & 0 \\
Ohio & 1 & 1 & 1 \\
Oregon & 0 & 1 & 1 \\
Pennsylvania & 1 & 1 & 1 \\
Virginia & 1 & 1 & 1 \\
Washington & 0 & 0 & 1 \\
Wisconsin & 1 & 1 & 1 \\
\hline
\end{tabular}

Battleground states as defined by: Nate Silver on fivethirtyeight.com as of June 9, 2008; The Washington Post in an article on June 8, 2008; The New York Times in an article on May 11, 2008. Historical information from fivethirtyeight.com was retrieved from archived pages using www. archive.org/web/. 
on a seven-point scale, with 1 being the most liberal and 7 being the most conservative. ${ }^{4}$ The first of these surveys was done in January of 2008 and the fifth was done in October of 2008.

\subsubsection{Coding Misleading and Non-Misleading Statements}

I divide each advertisement into statements and code each statement as misleading or non-misleading. To do this, I rely on two nonpartisan, third-party, fact-checking websites, FactCheck.org and PolitiFact.com. ${ }^{5}$ The goal of these two websites is to monitor the factual accuracy of statements made by political candidates in debates, statements and, most importantly for this paper, advertisements. Using analysis from these two websites, I code each statement as misleading or not misleading. These two categories are mutually exclusive and exhaustive.

For example: on Oct 23, 2008, Barack Obama first ran "Erratic," an attack advertisement against John McCain. The advertisement states that McCain supports tax policies that give "almost nothing to the middle class." Factcheck.org posted an analysis of this ad the very next day, reporting:

Actually, the Tax Policy Center report says McCain's plan would deliver a fair amount of tax relief to the middle class, just not as much as Obama's...

That hardly strikes us as "nothing" for the middle class, as the Obama ad says.

\footnotetext{
${ }^{4} 1$ = Extremely Liberal, $2=$ Liberal, $3=$ Slightly Liberal, $4=$ Moderate, 5 = Slightly Conservative, $6=$ Conservative, $7=$ Extremely Conservative.

${ }^{5}$ FactCheck.org is a project by the Annenberg Public Policy Center at the University of Pennsylvania and is funded by grants from the Annenberg Foundation, grants from the Flora Family Foundation and donations from individuals. PolitiFact.com was launched in April 2007 by the Tampa Bay Times and won the Pulitzer Prize for National Reporting for their coverage of the 2008 elections. More information on these two websites can be found in Section 3.2.
} 
PolitiFact.com comes to the same conclusion when analyzing a similar statement made by Joe Biden that McCain's tax plan provides "virtually nothing to the middle class." PolitiFact.com ranks the claim as "Mostly False," saying:

The analysis backs up Obama's broad contention that McCain's tax policy is weighted to give the largest benefit to higher-income taxpayers. However, it's wrong to say McCain's plan would provide no relief to middleclass Americans.

Given the FactCheck.org analysis and the PolitiFact.com rating of "Mostly False", I code the statement "McCain's tax policies give almost nothing to the middle class" as misleading. I consider a statement misleading only if both websites rate the statement as misleading. Of all statements that both websites post an analysis of, they only disagree on one statement, one that accounts for $1.2 \%$ of misleading statements aired. ${ }^{6}$ Each statement in each advertisement is coded using this same methodology.

\section{Misleading Statement Variants}

For the purposes of measuring statement count, misleading statements that are not identical but express the same sentiment are considered the same statement. Table 3 lists one example of this, where each statement is considered a variant of Obama's misleading claim that "McCain's tax plan gives tax breaks for big oil."

\footnotetext{
${ }^{6}$ One of Obama's advertisements said "Big oil's filling John McCain's campaign with $\$ 2$ million in contributions." PolitiFact rates this statement as "Mostly True", while Factcheck calls this claim an "overstatement... based on a mistaken calculation."
} 
Table 3: Statement Variants

\begin{tabular}{ll}
\hline Ad Name & Statement \\
\hline Embrace & "The money: billions for oil and drug companies." \\
More & "Billions more in tax breaks for oil companies." \\
New Energy & "McCain will give more tax breaks to big oil." \\
Rearview Mirror & "He wants four billion dollars in new tax breaks for big oil." \\
\hline
\end{tabular}

\subsubsection{Attack and Promote}

A statement can be a promotional statement or an attack statement (Anderson et al., 2015; Geer, 2006). In order to classify the statement, I assume that Democratic advertisements promote Obama and attack McCain, and vice-versa for Republican advertisements. I code the subject of the statement: Obama or McCain. Any statement in a Democratic advertisement that has Obama as the subject is classified as a promotional statement, while a statement in a Democratic advertisement with McCain as the subject is classified as an attack statement. ${ }^{7}$ The opposite is true for statements in Republican advertisements.

\subsubsection{Ideology and Valence}

A statement can be a statement about a candidate's ideology, a candidate's valence, or neither. In order to determine if the statement is about ideology or valence, I create two separate word lists, similarly to Gentzkow and Shapiro (2010). The ideology list contains words such as "economy," "taxes," and "Iraq." The valence list contains words that describe a candidate's character, such as "trust," "hero," and "candor." I then count the number of ideology words and the number of valence

\footnotetext{
${ }^{7}$ For analytical purposes, I ignore statements that do not have a clear subject - for example, the statement, "Michigan is hurting."
} 
words in each statement. Statements that have a greater number of ideology words are coded as targeting ideology, while statements that have a greater number of valence words are coded as targeting valence. When statements have a non-zero, equal number of ideology words and valence words, I randomly assign ideology or valence to that statement. Ideology words are listed in Table 4 and valence words are listed in Table 5.

\subsubsection{Data Notes}

I drop Spanish advertisements, which account for 1.2\% of total spending (and 1.5\% of number of advertisements aired) after June 1. I drop advertisements without videos; this accounts for $1.4 \%$ of total spending (and $1.3 \%$ of number of advertisements aired) after June 1. I also drop all counties for which the Census does not provide vote share data, which are all of the counties in Alaska and the county of Kalawao, HI. I also drop Clifton Forge, VA, South Boston, MA and Yellowstone NP, since the Census does not contain information on these counties. I calculate the number of potential voters in a county using data on voter registration from the Census. For those counties without voter registration data, I use the average voter registration within that state. For those states without voter registration data, I use $68 \%$ of the total population, the average voter registration cross the United States. I use data from the Wisconsin Advertising Project to calculate the 2004 congressional spending instruments. Since the Wisconsin Advertising Project only includes a subset of DMAs in the 2004 spending data, I estimate the parameters using only counties for which there is advertising data for both 2004 and 2008 . 
Table 4: Ideology Words

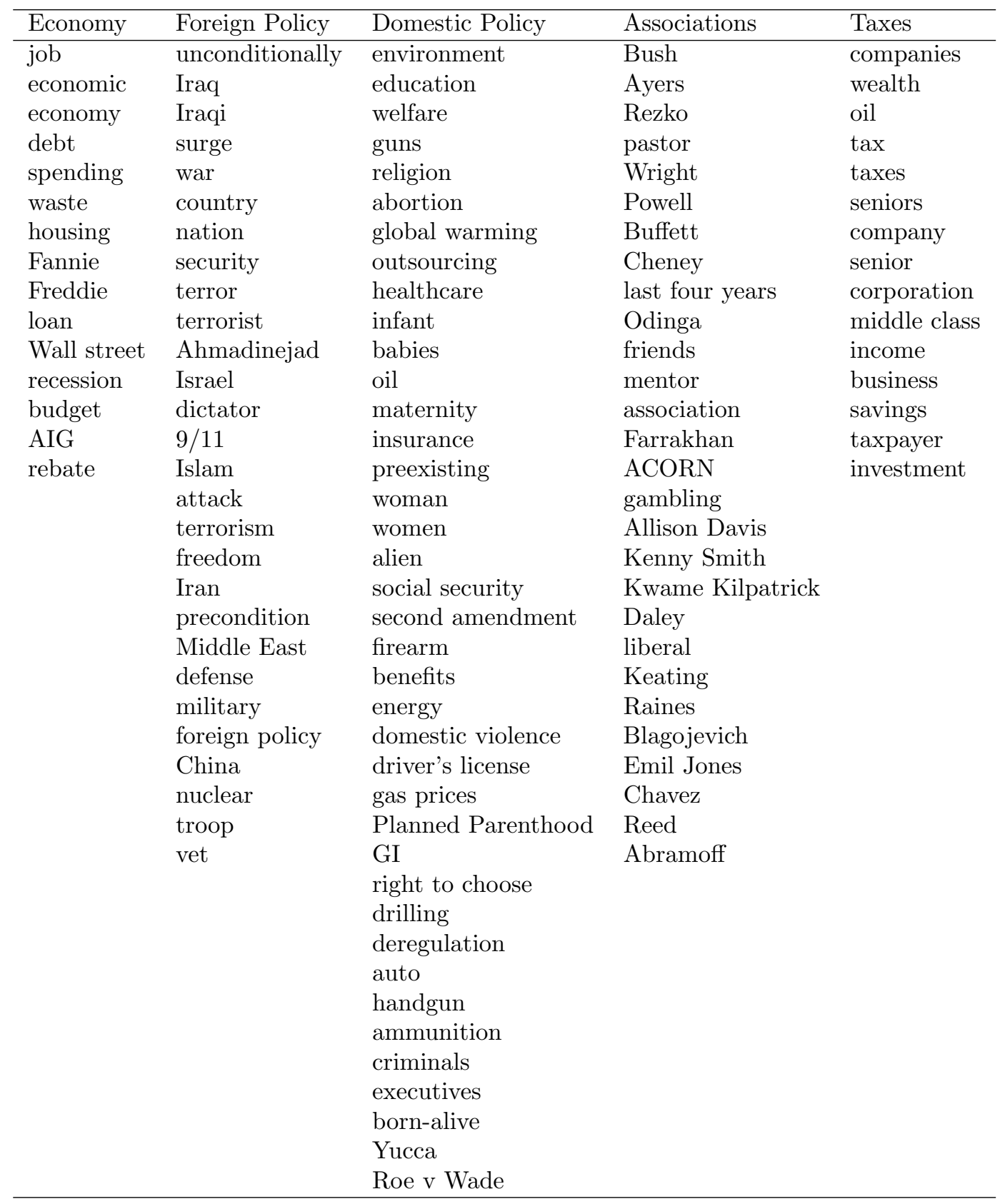

This table indicates all of the words used to categorize a statement as targeting ideology. The words are divided into groups for clarity; in the coding of the data, I do not distinguish between the different categories. 
Table 5: Valence Words

\begin{tabular}{lllll}
\hline Insider & Honesty & Experience & Personality & Campaign \\
\hline Washington & truth & experience & understand & negative \\
lobbyists & scandal & inexperience & judgment & smear \\
maverick & lying & leadership & courage & scare tactics \\
pork & candor & unprepared & hero & polls \\
bridge to nowhere & trust & risky & commitment & \\
Republican & trick & proven & listen & \\
Democrat & honorable & lead & tough & \\
change & true & & father & \\
reform & corrupt & & celebrity & \\
partisan & lie & & POW & \\
celebrity & hypocrite & & Christian & \\
& & & looking out for & \\
& & & irresponsible & \\
\hline
\end{tabular}

This table indicates all of the words used to categorize a statement as targeting valence. The words are divided into groups for clarity; in the coding of the data, I do no distinguish between the different categories.

\subsubsection{Construction of Advertising Variables}

I code statements along three dimensions: misleading or non-misleading; attack or promote; targeting ideology or targeting valence. This coding methodology allows for eight types of advertising. However, I focus on two types of statements, and I aggregate statements at the misleading/non-misleading level. To measure advertising, I calculate the amount spent per eligible voter by each candidate in each DMA. To do this, I first construct a measure of the effective length of the advertisement by summing the time spent on all of the statements in the ad, after I drop the statements that cannot be coded along all three dimensions. ${ }^{8}$ I then multiply the percentage of the effective time that is spent on misleading statements by the cost of the ad, and I sum this dollar amount over all advertisements aired in a DMA. I then divide by

\footnotetext{
${ }^{8}$ The most common example of a dropped statement is the "Stand by Your Ad" provision statement. This is the statement at the end of the advertisement in which the candidate announces, "I'm [candidate name], and I approve this message." The effective length of the advertisement is weakly less than the actual advertisement length.
} 
the number of eligible voters in the DMA to obtain $M_{j m}$, where $M_{j m}$ is the total amount spent on misleading advertising per eligible voter by candidate $j$ in DMA $m$. Analogously, I calculate $A_{j m}$ as the total amount spent on non-misleading advertising per eligible voter by candidate $j$ in DMA $m$.

\subsection{Calculating Ideology}

I estimate the relationship between demographics and self-reported ideology first, outside of the main estimation. I then simulate individuals using county demographic distributions and predict individual ideology based on the aforementioned estimates and treat $x_{i}$ as observable in the model estimation. The parameter $t$ captures the transport cost in ideology; when $t$ is negative, the utility the voter receives from a candidate decreases as that candidate's ideology is further from the voter's ideology. I measure candidate ideology using Poole and Rosenthal's NOMINATE scores. ${ }^{9}$ NOMINATE scores measure ideology from -1 to 1 on a liberal-conservative scale for all congresspeople using roll-call data. After normalizing to a $[0,1]$ scale, Obama's lifetime NOMINATE score in 2008 was 0.319 , and McCain's was 0.689. ${ }^{10}$

As described in Chapter 4, a voter's utility depends on the difference between her ideology and the candidates' ideologies. In practice, this ideology is unobservable; therefore, I simulate ideology using voter characteristics. First, I estimate ideology as a function of people's characteristics using 2008 American National Election Studies (ANES) panel data. The ANES survey data records self-reported ideology on a seven-

\footnotetext{
${ }^{9} \mathrm{I}$ also present the results using alternative measures of candidate ideology in Tables 18 and 19.

${ }^{10}$ Scores at www. voteview. com. Ideology scores are calculated by minimizing errors in the prediction of congresspeople's voting behavior, and it is assumed that candidates vote sincerely according to their ideology.
} 
point scale, where 1 is the most liberal and 7 is the most conservative $(1=$ Extremely Liberal, $2=$ Liberal, $3=$ Slightly Liberal, $4=$ Moderate, $5=$ Slightly Conservative, $6=$ Conservative, $7=$ Extremely Conservative).

I use an random effects ordered probit model to estimate the relationship between demographics and ideology because the dependent variables is measured categorically and the categories are increasing in conservativeness. I use random effects because the panel dataset shows that individuals show persistence in ideology over time that cannot be accounted for solely by demographics. The results are reported in Table 6. The independent variables are demographic variables that exist both in the ANES and in the Census data. These estimates are used the establish a relationship between demographics and voter ideology. In this estimation, I drop all observations of panelists that cross more than three categories on the seven-point scale. These observations compose less than $4 \%$ of the total sample.

The predicted ideology is latent and has support on the real line, and the cut points indicate where this predicted ideology would be categorized on the seven-point scale. All values below the first cut point would be categorized as $1=$ Extremely Liberal, and the values between the first and second cut points would be categorized as 2 $=$ Liberal, and so on. The independent variables are all measured using indicator variables, and the coefficients indicate the predicted effect on latent ideology. A positive (negative) coefficient for a characteristic indicates that that characteristic increase (decreases) the conservativeness of the voter. For examples, blacks are likely to be less conservative than white, and those over the age of 65 are likely to be more conservative than those between the ages of 18 to 25 .

The results from this regression are as expected. Females tend to be less con- 
Table 6: Random Effects Ordered Probit Results

\begin{tabular}{|c|c|c|}
\hline$\overline{\text { Variables }}$ & Effect on Ideology & Cut Point \\
\hline female & $\begin{array}{c}-0.346^{* * *} \\
(0.0580)\end{array}$ & $\begin{array}{c}-3.553^{* * *} \\
(0.177)\end{array}$ \\
\hline black & $\begin{array}{c}-1.982^{* * *} \\
(0.112)\end{array}$ & $\begin{array}{c}-1.688^{* * * *} \\
(0.173)\end{array}$ \\
\hline asian & $\begin{array}{l}-1.494^{* * *} \\
(0.125)\end{array}$ & $\begin{array}{c}-0.628^{* * *} \\
(0.172)\end{array}$ \\
\hline hispanic & $\begin{array}{c}-0.406^{* * *} \\
(0.100)\end{array}$ & $\begin{array}{c}1.055^{* * *} \\
(0.172)\end{array}$ \\
\hline northeast & $\begin{array}{l}0.0915 \\
(0.0873)\end{array}$ & $\begin{array}{c}1.835^{* * *} \\
(0.173)\end{array}$ \\
\hline midwest & $\begin{array}{l}0.251^{* * *} \\
(0.0799)\end{array}$ & $\begin{array}{cc}\text { cut } 6 & 3.970^{* * *} \\
& (0.178) \\
\end{array}$ \\
\hline south & $\begin{array}{c}0.455^{* * *} \\
(0.0764)\end{array}$ & $\begin{array}{l}\text { Standard errors in parentheses } \\
* * * \mathrm{p}<0.01, * * \mathrm{p}<0.05, * \mathrm{p}<0.1\end{array}$ \\
\hline high school & $\begin{array}{l}-0.183 \\
(0.113)\end{array}$ & \\
\hline some college & $\begin{array}{l}0.0908 \\
(0.108)\end{array}$ & \\
\hline college & $\begin{array}{c}-0.603^{* * *} \\
(0.123)\end{array}$ & \\
\hline graduate school & $\begin{array}{l}-1.865^{* * *} \\
(0.140)\end{array}$ & \\
\hline age $25-29$ & $\begin{array}{c}0.145 \\
(0.173)\end{array}$ & \\
\hline age $30-39$ & $\begin{array}{c}0.447^{* * *} \\
(0.150)\end{array}$ & \\
\hline age $40-49$ & $\begin{array}{c}0.520^{* * *} \\
(0.140)\end{array}$ & \\
\hline age $50-64$ & $\begin{array}{c}0.369^{* * *} \\
(0.142)\end{array}$ & \\
\hline age $>64$ & $\begin{array}{c}0.773^{* * *} \\
(0.136)\end{array}$ & \\
\hline income $10 \mathrm{k}-20 \mathrm{k}$ & $\begin{array}{c}1.255^{* * *} \\
(0.149)\end{array}$ & \\
\hline income 20k-30k & $\begin{array}{c}0.816^{* * *} \\
(0.137)\end{array}$ & \\
\hline income $30 \mathrm{k}-40 \mathrm{k}$ & $\begin{array}{c}1.070^{* * *} \\
(0.135)\end{array}$ & \\
\hline income $40 \mathrm{k}-50 \mathrm{k}$ & $\begin{array}{c}0.792^{* * *} \\
(0.139)\end{array}$ & \\
\hline income $50 \mathrm{k}-75 \mathrm{k}$ & $\begin{array}{c}1.222^{* * *} \\
(0.129)\end{array}$ & \\
\hline income $75 \mathrm{k}-100 \mathrm{k}$ & $\begin{array}{c}0.876^{* * *} \\
(0.173)\end{array}$ & \\
\hline income $100 \mathrm{k}-125 \mathrm{k}$ & $\begin{array}{c}1.083^{* * *} \\
(0.153)\end{array}$ & \\
\hline income $125 \mathrm{k}-150 \mathrm{k}$ & $\begin{array}{c}1.783^{* * *} \\
(0.176)\end{array}$ & \\
\hline income $>150 \mathrm{k}$ & $\begin{array}{c}1.366^{* * *} \\
(0.145)\end{array}$ & \\
\hline s.d. of RE & 2.49 & \\
\hline Observations & 9,206 & \\
\hline
\end{tabular}


servative than miles. Blacks and Asians tend to be less conservative than whites. Hispanics, on average, are less conservative than non-Hispanics. Conservativeness decreasing in education; particularly, those with a graduate degree are much less conservative than those with lower levels of education. The geographic variables are as expected, where people in the West are more liberal than those in the South or the Midwest. There is no statistically significant difference between those living in the West and those living in the Northeast, on average. People over the age of 30 tend to be more conservative than those under the ate of 30 , and people over the age of 65 tend to be even more conservative. The effect of income on conservativeness is harder to interpret; there does not appear to be a linear trend. While those with an income under $\$ 10,000 /$ year are the most liberal, there are no discernible trends in conservativeness as above that income level.

The cut points give the margins at which each category is determined. For example, a latent value less than the first cut point value, -3.55 , would be in the first category, "Extremely Liberal." Any latent value of ideology between -3.55 and -1.69 would be in the second category, "Liberal." The cut points are estimated in the model and not forced to be equidistant from each other, which is a benefit of using the ordered probit model. The results indicate that the distance between the "Extremely Liberal" ("Extremely Conservative") and "Liberal" ("Conservative") categories is greater than between "Liberal" ("Conservative") and "Slightly Liberal" ("Slightly Conservative"), which is unsurprising. The coefficients indicate effects on latent ideology and not the marginal effect of changing categories (which differs at different latent ideology levels). For example, an increase in latent ideology by 1.3 would be enough to move predicted ideology from category 3 ("Slightly Liberal") to category 
Figure 5: Ideology Distributions

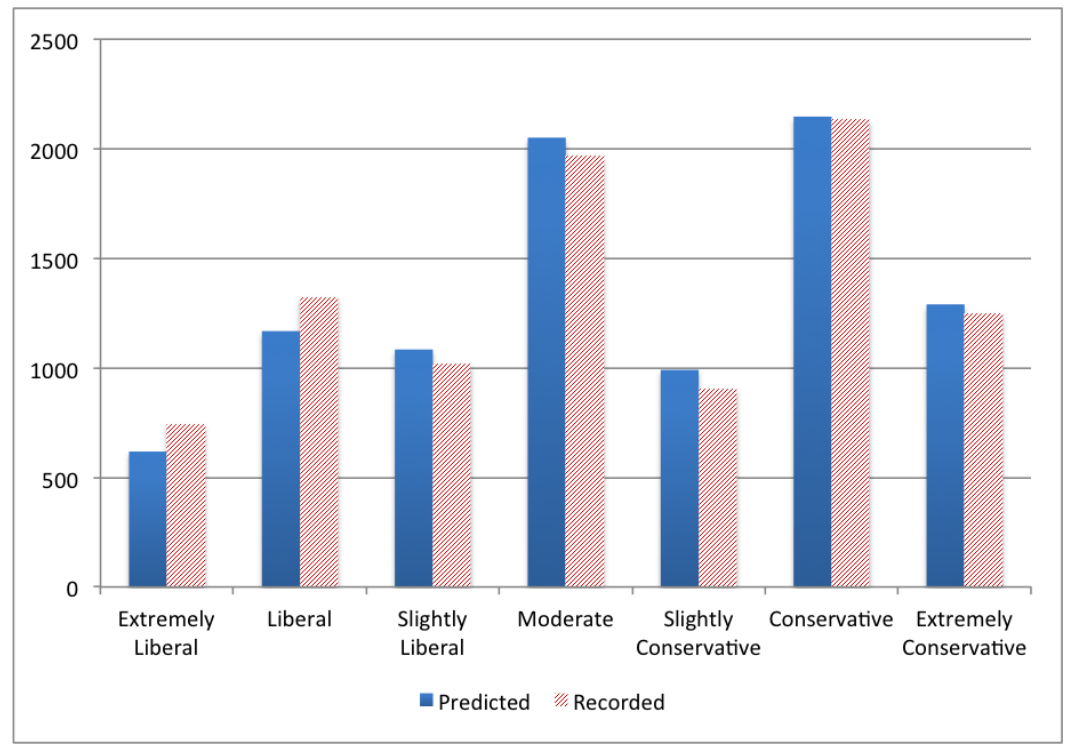

This graph shows the distribution of ideology on the seven-point scale used by the ANES. The left (blue) bar shows the number of individuals who reported that ideology for each category, and the right (red) bar shows the number of individuals I predict to be in that category using individual demographics.

4 ("Liberal") - but it is not necessarily enough to move an individual from Category 2 ("Liberal") to Category 3 ("Slightly Liberal").

In order to use the random effects ordered probit parameters to predict voter ideology on a $[0,1]$ scale, I must convert the predicted values of latent ideology, $y^{*}$, which has support on the real line, to $[0,1]$. To do this, I first predict latent ideology values, $\hat{y}^{*}$, for the respondents in the ANES dataset. I transform these predicted values into voter ideology, $x_{i}$, using the normal cumulative distribution function, where $x_{i}=\Phi\left(\hat{y}^{*}\right)$. The final adjusted distribution of ANES respondents is shown in Figure 6.

In the ANES data, people's ideologies change over time. This would cause problems in my results of changes in ideology are correlated with advertising. To provide 
Figure 6: Adjusted Ideology Distribution

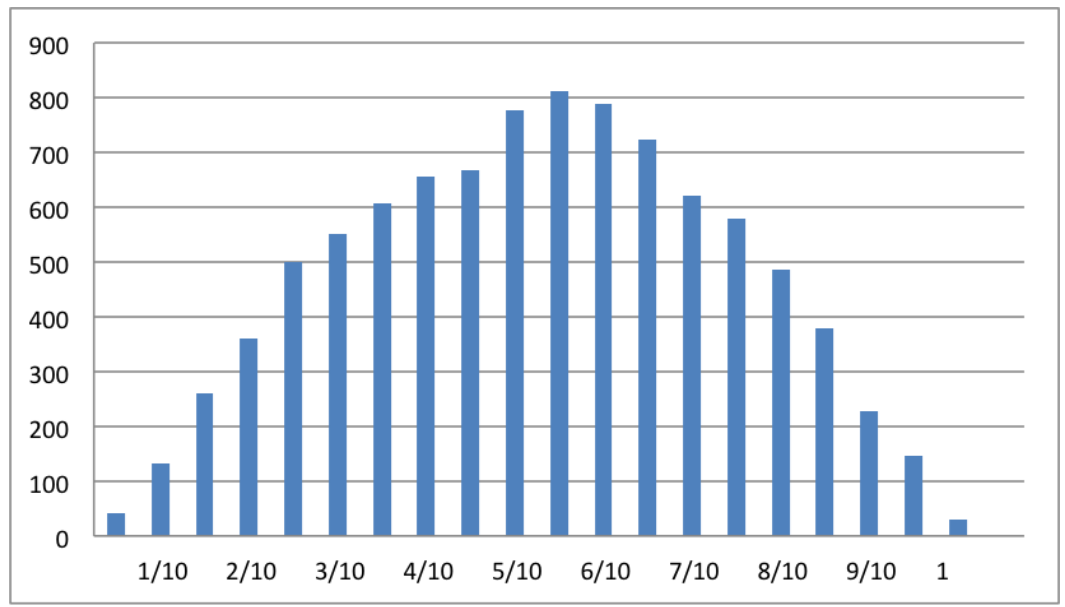

This histogram shows the predicted ideologies of the ANES respondents after conversion to a $[0,1]$ scale. 0 is most liberal, and 1 is most conservative.

evidence against this, I examine the changes in ideology from the January survey to the February survey (when there is very little presidential advertising) and compare this to the changes in ideology from the September survey to the October survey (when there is much more presidential advertising). The transition matrices of ideology changes from these two time periods are shown in Table 7 . There seem to be no systematic differences between the changes from January to February, in Table 7a, and from September to October, in Table 7b. This supports the hypothesis that ideology changes are uncorrelated with advertising. Further evidence of this hypothesis is the large standard deviation of the random effect, which is 2.49. This suggests that a person's ideology is relatively stable over time.

Because of the strength of the random effect relative to other effects, the predictions created by the random effects ordered probit regression do not predict individual ideology very well. However, as Figure 5 shows, the prediction of the distribution of 
Table 7: Ideology Transitions

(a) January to February

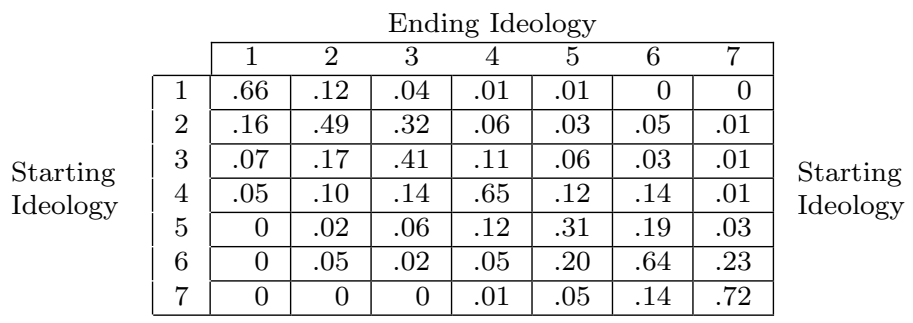

(b) September to October

\begin{tabular}{|c|c|c|c|c|r|r|r|}
\multicolumn{10}{c|}{} & \multicolumn{1}{c|}{ Ending Ideology } \\
\cline { 2 - 8 } \multicolumn{1}{c|}{} & 1 & 2 & 3 & \multicolumn{1}{c|}{5} & \multicolumn{1}{c|}{6} \\
\hline 1 & .73 & .11 & .02 & .01 & 0 & 0 & 0 \\
\cline { 2 - 8 } 2 & .19 & .60 & .27 & .07 & .02 & .03 & 0 \\
\cline { 2 - 8 } 3 & .04 & .15 & .45 & .12 & .03 & .02 & 0 \\
\cline { 2 - 7 } 4 & .01 & .05 & .17 & .70 & .15 & .06 & .01 \\
\cline { 2 - 7 } 5 & .01 & .02 & .08 & .12 & .34 & .11 & .02 \\
\cline { 2 - 8 } 6 & .02 & .04 & .04 & .14 & .35 & .63 & .14 \\
\cline { 2 - 8 } 7 & .02 & 0 & 0 & .02 & .03 & .15 & .69 \\
\hline
\end{tabular}

These two tables are the transition matrices for reported ideology from January to February 2008 and September to October 2008, according to the ANES survey. The first element of the first table, .71 indicates that $71 \%$ of people who reported an ideology of $1=$ Extremely Liberal in January also reported an ideology of $1=$ Extremely Liberal in February.

ideology is good, which is what is important for determining total vote share. 


\subsection{Summary Statistics}

Tables 8 and 9 list summary statistics for the total dollars spent in a DMA on both misleading advertising and non-misleading advertising by candidate over all states. On average, Obama spent more on non-misleading advertising, both in total dollars and in dollars per eligible voter; however, McCain spent more on misleading advertising on average, both in total dollars and dollars per eligible voter.

Tables 10 and 11 show summary statistics for total advertisement spending and spending per eligible voters in battleground states which are listed in Table 2. Unsurprisingly, both candidates spent more, on average, in the battleground states. Furthermore, the difference in spending per eligible voter on both types of advertising is greater in the battleground states. For example, over all states, McCain outspends Obama on misleading advertising, on average, by 4 cents per eligible voter, while in battleground states, McCain outspends Obama on misleading advertising, on average, by 7 cents per eligible voter.

There is also substantial variation over how much of each advertisement is misleading (by air time), which is showni n Figure 7. I find that while almost $60 \%$ of advertisements contain $0 \%$ misleading statements, the remaining $40 \%$ of advertisements are evenly distributed from $10 \%$ to $70 \%$ misleading. 
Table 8: Total Advertising Dollars

\begin{tabular}{lcccc}
\hline & Obama & McCain & Obama & McCain \\
& Non-Misleading & Non-Misleading & Misleading & Misleading \\
\hline mean & 915,404 & 428,987 & 115,265 & 137,716 \\
median & 134,289 & 869 & 9,708 & 255 \\
sd & $1,963,734$ & 983,790 & 232,248 & 312,799 \\
$\min$ & 0 & 0 & 0 & 0 \\
$\max$ & $14,329,833$ & $8,449,999$ & $1,714,640$ & $2,742,424$ \\
\hline$N$ & 181 & 181 & 181 & 181 \\
\hline
\end{tabular}

This table shows dollar amounts spent on misleading and non-misleading advertising by Obama and McCain in the 2008 presidential election. Each observation is by television market (DMA). On average, Obama spent $\$ 979,890$ per DMA on non-misleading advertising.

Table 9: Advertising Dollars per Eligible Voter

\begin{tabular}{lcccccc}
\hline & \multicolumn{3}{c}{$\log \left(1+A_{1}\right)$} & & \multicolumn{1}{l}{$\log \left(1+M_{1}\right)$} \\
& $A_{1}$ & $A_{2}$ & $-\log \left(1+A_{2}\right)$ & $M_{1}$ & $M_{2}$ & $-\log \left(1+M_{2}\right)$ \\
\hline mean & 0.85 & 0.41 & 0.22 & 0.12 & 0.13 & -0.01 \\
median & 0.43 & 0.00 & 0.04 & 0.02 & 0.00 & 0.00 \\
sd & 1.00 & 0.63 & 0.34 & 0.15 & 0.21 & 0.11 \\
$\min$ & 0 & 0 & -0.83 & 0 & 0 & -0.53 \\
$\max$ & 4.95 & 3.14 & 1.27 & 0.64 & 1.22 & 0.38 \\
\hline$N$ & 181 & 181 & 181 & 181 & 181 & 181 \\
\hline
\end{tabular}

This table shows dollars spent per eligible voter on misleading and non-misleading advertising by Obama and McCain in the 2008 presidential election. Each observation is by television market (DMA). On average, Obama spent 92 cents per eligible voter per DMA on non-misleading advertising. 
Table 10: Total Advertising Dollars, Battleground States Only

\begin{tabular}{lcccc}
\hline & $\begin{array}{c}\text { Obama } \\
\text { Non-Misleading }\end{array}$ & $\begin{array}{c}\text { McCain } \\
\text { Non-Misleading }\end{array}$ & $\begin{array}{c}\text { Obama } \\
\text { Misleading }\end{array}$ & $\begin{array}{c}\text { McCain } \\
\text { Misleading }\end{array}$ \\
\hline mean & $1,727,746$ & 819,291 & 218,568 & 263,428 \\
median & 902,954 & 371,604 & 119,504 & 135,950 \\
sd & $2,463,424$ & $1,245,218$ & 286,114 & 394,879 \\
$\min$ & 0 & 0 & 0 & 0 \\
$\max$ & $14,329,833$ & $8,449,999$ & $1,714,640$ & $2,742,424$ \\
\hline$N$ & 94 & 94 & 94 & 94 \\
\hline
\end{tabular}

This table shows dollar amounts spent on misleading and non-misleading advertising by Obama and McCain in the 2008 presidential election in battleground states only. Each observation is by television market (DMA). On average, Obama spent $\$ 1,849,389$ per DMA on non-misleading advertising.

Table 11: Advertising Dollars per Eligible Voter, Battleground States Only

\begin{tabular}{lcccccc}
\hline & \multicolumn{3}{c}{$\log \left(1+A_{1}\right)$} & & & $\log \left(1+M_{1}\right)$ \\
& $A_{1}$ & $A_{2}$ & $-\log \left(1+A_{2}\right)$ & $M_{1}$ & $M_{2}$ & $-\log \left(1+M_{2}\right)$ \\
\hline mean & 1.49 & 0.77 & 0.33 & 0.21 & 0.25 & -0.02 \\
median & 1.52 & 0.64 & 0.30 & 0.20 & 0.22 & -0.01 \\
sd & 0.96 & 0.70 & 0.38 & 0.14 & 0.23 & 0.14 \\
$\min$ & 0 & 0 & -0.83 & 0 & 0 & -0.53 \\
$\max$ & 4.95 & 3.14 & 1.27 & 0.64 & 1.22 & 0.38 \\
\hline$N$ & 94 & 94 & 94 & 94 & 94 & 94 \\
\hline
\end{tabular}

This table dollars spent per eligible voter on misleading and non-misleading advertising by Obama and McCain in the 2008 presidential election in battleground states only. Each observation is by television market (DMA). On average, Obama spent $\$ 1.60$ per eligible voter per DMA on nonmisleading advertising. 
Figure 7: Variation in Misleading Advertising

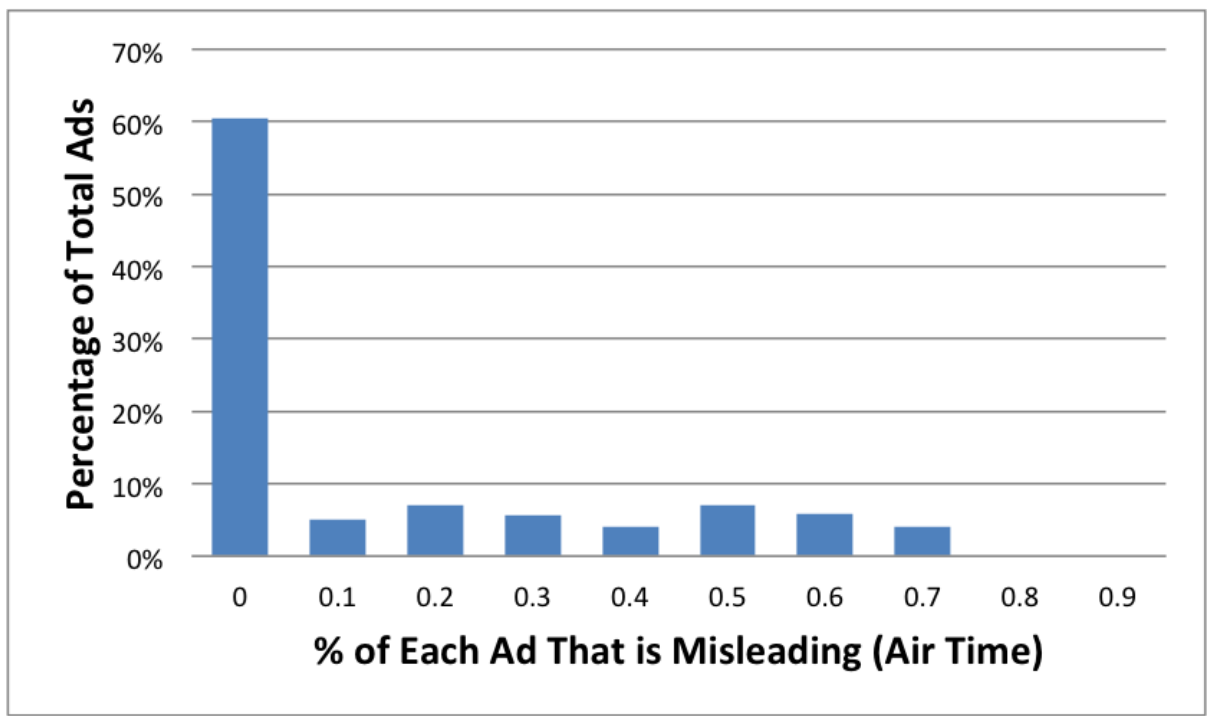

This figure shows what percentage of advertisements are misleading by air time. Almost $60 \&$ of advertisements contain $0 \%$ misleading statements. About $5 \%$ of advertisements contain $10 \%$ misleading statements. 


\section{Chapter 6}

\section{Logit Estimation and Results}

In this section, I estimate a simplified, two stage least squares version of the model presented in Chapter 4. First, I present the model specification. Then, I present the results. Finally, I show results from alternative specifications of the model.

\subsection{Logit Model}

I estimate a simplified version of the model using two stage least squares, as in Nevo (2001). The results echo the patterns in the full model. Since the logit model does not allow for individual heterogeneity in ideology, $x_{i}$, I instead use moments of the distribution of $x_{i}$ in each county as regressors. In the primary specification, I use quartiles. In this simplified model the utility a voter receives from candidate $j$ is

$$
\begin{aligned}
u_{i j c}= & \beta_{0 j}+\beta_{1} \log \left(1+A_{j m}\right)+\beta_{2} \log \left(1+M_{j m}\right)+\beta_{3} \text { Party }_{j s}+\beta_{4} \text { Poll }_{j s} \\
& +\beta_{5} \log \left(\left|x_{j}-x_{c}^{25}\right|+1\right)+\beta_{6} \log \left(\left|x_{j}-x_{c}^{50}\right|+1\right)+\beta_{7} \log \left(\left|x_{j}-x_{c}^{75}\right|+1\right)+\xi_{j c}
\end{aligned}
$$

where $x_{c}^{n}$ indicates the $n^{\text {th }}$ percentile of ideology in county $c$. The utility of voting for 
candidate $j$ is still

$$
\begin{aligned}
& V_{i 1 c}=u_{i 1 c}-u_{i 2 c}-K\left(W_{c}\right)+\epsilon_{i 1 c} \\
& V_{i 2 c}=u_{i 2 c}-u_{i 1 c}-K\left(W_{c}\right)+\epsilon_{i 2 c} \\
& V_{i 0 c}=0+\epsilon_{i 0 c}
\end{aligned}
$$

where the value of not voting is normalized to mean 0 , and $\epsilon_{i j c}$ and $\epsilon_{i 0 c}$ are idiosyncratic error terms that are distributed Type I Extreme Value. Then, aggregating over voters and integrating over $\epsilon_{i j c}$,

$$
\mathrm{vs}_{j c}=\frac{\exp \left(u_{j c}-u_{k c}-K_{c}\right)}{1+\exp \left(u_{1 c}-u_{2 c}-K_{c}\right)+\exp \left(u_{2 c}-u_{1 c}-K_{c}\right)} .
$$

For ease of notation, let $\Delta w_{c}=w_{1 c}-w_{2 c}$. I estimate the following equation:

$$
\begin{aligned}
.5\left(\log \left(\operatorname{vs}_{1 c}\right)-\log \left(\operatorname{vs}_{2 c}\right)\right)= & \Delta \beta_{0}+\beta_{1}\left(\log \left(1+A_{1 m}\right)-\log \left(1+A_{2 m}\right)\right) \\
& +\beta_{2}\left(\log \left(1+M_{1 m}\right)-\log \left(1+M_{2 m}\right)\right) \\
& +\beta_{3} \Delta \operatorname{Party}+\beta_{4} \Delta \operatorname{Poll} l_{s} \\
& +\beta_{5}\left[\log \left(\left|x_{1}-x_{c}^{25}\right|+1\right)-\log \left(\left|x_{2}-x_{c}^{25}\right|+1\right)\right] \\
& +\beta_{6}\left[\log \left(\left|x_{1}-x_{c}^{50}\right|+1\right)-\log \left(\left|x_{2}-x_{c}^{50}\right|+1\right)\right] \\
& +\beta_{7}\left[\log \left(\left|x_{1}-x_{c}^{75}\right|+1\right)-\log \left(\left|x_{2}-x_{c}^{75}\right|+1\right)\right] \\
& +\Delta \xi_{c} .
\end{aligned}
$$

There are several differences between this estimation and the estimation of the model presented in Chapter 7. Firstly, the estimation here is only of the parameters in voter utility; I do not estimate the candidate-side model. Secondly, in Equation (6.1.1), the cost-of-voting term, $K_{c}$, drops out, and so I cannot identify the parameters that determine the cost of voting. Lastly, since the logit estimation does not allow for individual heterogeneity, I cannot include individual measures of voter ideology. Instead, I proxy for these measures using moments from the county distribution of 
ideology. This gives a more flexible, though less structured, way of modeling ideology. In the main empirical specification, I assume that individuals receive less utility from the candidates the further away the individual's ideology from the candidate's. I also assume that this transport cost is concave and has a $\log (\cdot)$ functional form. In the logit model, I still assume that there is a $\log (\cdot)$ relationship, but it is only between each moment and the candidate's ideology (rather than every single individual ideology and the candidate's ideology). Moreover, I estimate a different transport cost parameter for every moment of the county ideology distribution. Therefore, the logit model would allow for more flexibility in terms of the extremity of ideology and how much that affects the voter's utility. However, as will be seen in the results below, some of these results may not make intuitive sense.

\subsection{Main Results}

The results from the primary specification of the logit model are presented in Table 12. The OLS results are presented in column (1), and the 2SLS results are presented in columns (2) through (6). Without instrumenting for candidates' advertising choices, the sign on non-misleading advertising is as expected; increasing non-misleading advertising increases a candidate's vote share. However, without instrumental variables, the effect of misleading advertising is negative, implying that greater levels of misleading advertising are correlated with lower vote share. This could be because the candidate that is behind in that DMA tends to spend relatively more on misleading advertising, leading the OLS results to imply that airing misleading advertising is detrimental to the candidate. After instrumenting for advertising, on the other hand, the instrumental variable estimates in columns (2) through (6), 
with the baseline specification in column (2), show that misleading advertising has a positive effect on vote share, and that misleading advertising is more effective than non-misleading advertising, all else equal. This echoes the results found in the full model.

I find that across the specifications, misleading advertising generally has a greater effect than non-misleading advertising on increasing relative vote share. In the preferred specification, misleading advertising is almost twice as effective as nonmisleading advertising. The estimates on Party and Poll are both positive, which is as expected. The behavior of people in that state in the previous presidential election (Party) is a good predictor of vote share in the current election. Polling numbers are also positively correlated with outcomes, which is unsurprising.

In the main specification in column (2), the transport cost parameters estimated on ideology are all negative and increasing in absolute value as ideology increases. This implies that the greater (more conservative) the $n^{\text {th }}$ percentile of ideology in the county, then Obama's vote share is relatively less. The fact that the parameter estimate increases in absolute value as ideology increases indicates that this has a greater effect at the more conservative end of ideology.

\subsection{Alternative Specifications}

Columns (3) through (6) in Table 12 use different moments from the ideology distribution. Though the signs of the parameter estimates on the advertising variables are positive through all five specifications, the magnitude of the effects is sensitive to which moments of the county ideology distribution are used. The estimation of the Party and Poll parameters do not change much over the estimation, but the estimation 
of the transport cost on ideology is very sensitive to the moments used. When more extreme moments of the ideology are used (as in columns (3) and (6)), some of the signs on the transport cost are positive, which implies that as that moment of the ideology becomes more conservative, the greater Obama's relative vote share, which does not make intuitive sense.

Table 13 shows results of the 2SLS logit regressions with different measures of candidate ideology. I use several different measures of candidate ideology from different legislative scorecards. The first column shows the baseline results using Poole and Rosenthal's NOMINATE scores. I use their methodology because it is unbiased and because the ratings are lifetime ratings based on roll-call voting behavior. The parameter estimates for advertising, Party, and Poll do not change much using the different measures. However, the transport cost estimates do differ depending on which measure of candidate ideology is used. For example, using Gentzkow \& Shapiro's method of measuring candidate ideology, the estimate of the transport cost is positive for the $25^{\text {th }}$ and $75^{\text {th }}$ percentiles. This implies that as that moment of ideology becomes more conservative (increases), then Obama's relative vote share also increases, which does not make intuitive sense.

On the one hand, it is reassuring that the parameter estimates for advertising are not very sensitive to the alternative ideology measures used. On the other hand, the transport cost parameters are very sensitive to the ideology measures used (both on the voter side and on the candidate side), because the logit model does not allow for a systematic way for individual ideology to affect utility. The estimates presented in the full model in Chapter 7 remedies this issue by assuming that the transport cost is concave. 
Table 12: Logit Results

\begin{tabular}{|c|c|c|c|c|c|c|}
\hline \multirow[b]{2}{*}{ Variables } & \multirow{2}{*}{$\begin{array}{c}\text { OLS } \\
(1) \\
\end{array}$} & \multicolumn{5}{|c|}{ 2SLS } \\
\hline & & $(2)$ & (3) & $(4)$ & $(5)$ & (6) \\
\hline \multicolumn{7}{|l|}{ Advertising Variables } \\
\hline Non-misleading & $\begin{array}{c}0.144^{* * *} \\
(0.0188)\end{array}$ & $\begin{array}{c}0.192^{* * *} \\
(0.0415)\end{array}$ & $\begin{array}{c}0.166^{* * *} \\
(0.0418)\end{array}$ & $\begin{array}{c}0.158^{* * *} \\
(0.0420)\end{array}$ & $\begin{array}{c}0.161^{* * *} \\
(0.0418)\end{array}$ & $\begin{array}{c}0.172^{* * *} \\
(0.0419)\end{array}$ \\
\hline Misleading & $\begin{array}{c}-0.304^{* * *} \\
(0.0589)\end{array}$ & $\begin{array}{c}0.381 * * * \\
(0.141)\end{array}$ & $\begin{array}{c}0.407^{* * *} \\
(0.144)\end{array}$ & $\begin{array}{c}0.464^{* * *} \\
(0.145)\end{array}$ & $\begin{array}{c}0.446^{* * *} \\
(0.144)\end{array}$ & $\begin{array}{c}0.416^{* * *} \\
(0.144)\end{array}$ \\
\hline \multicolumn{7}{|l|}{ Other Variables } \\
\hline Party & $\begin{array}{c}0.830^{* * *} \\
(0.0693)\end{array}$ & $\begin{array}{c}0.930 * * * \\
(0.0752)\end{array}$ & $\begin{array}{c}0.952^{* * *} \\
(0.0764)\end{array}$ & $\begin{array}{c}0.957^{* * *} \\
(0.0768)\end{array}$ & $\begin{array}{c}0.973^{* * *} \\
(0.0765)\end{array}$ & $\begin{array}{c}0.967^{* * *} \\
(0.0765)\end{array}$ \\
\hline Poll & $\begin{array}{l}0.186^{* *} \\
(0.0791)\end{array}$ & $\begin{array}{c}0.231 * * * \\
(0.0848)\end{array}$ & $\begin{array}{l}0.203^{* *} \\
(0.0862)\end{array}$ & $\begin{array}{l}0.188^{* *} \\
(0.0866)\end{array}$ & $\begin{array}{c}0.166^{*} \\
(0.0862)\end{array}$ & $\begin{array}{c}0.163^{*} \\
(0.0862)\end{array}$ \\
\hline \multicolumn{7}{|l|}{ Ideology Variables } \\
\hline$x^{5}$ & & & & & & $\begin{array}{c}4.994^{* * *} \\
(1.565)\end{array}$ \\
\hline$x^{15}$ & & & $\begin{array}{c}5.128^{* * *} \\
(1.018)\end{array}$ & & & \\
\hline$x^{25}$ & $\begin{array}{c}-0.173 \\
(0.208)\end{array}$ & $\begin{array}{l}-0.104 \\
(0.222)\end{array}$ & & & & \\
\hline$x^{35}$ & & & & & $\begin{array}{c}-1.439 * * * \\
(0.297)\end{array}$ & \\
\hline$x^{45}$ & & & & $\begin{array}{c}-2.212^{* * *} \\
(0.511)\end{array}$ & & \\
\hline$x^{50}$ & $\begin{array}{c}-1.134^{* * *} \\
(0.238)\end{array}$ & $\begin{array}{c}-1.107^{* * *} \\
(0.252)\end{array}$ & $\begin{array}{c}-2.286^{* * *} \\
(0.164)\end{array}$ & $\begin{array}{c}0.692 \\
(0.717)\end{array}$ & $\begin{array}{l}-0.529 \\
(0.406)\end{array}$ & $\begin{array}{c}-1.871^{* * *} \\
(0.184)\end{array}$ \\
\hline$x^{55}$ & & & & $\begin{array}{c}-1.198^{* *} \\
(0.506)\end{array}$ & & \\
\hline$x^{65}$ & & & & & $\begin{array}{c}-0.842^{* *} \\
(0.328)\end{array}$ & \\
\hline$x^{75}$ & $\begin{array}{c}-2.936^{* * *} \\
(0.282)\end{array}$ & $\begin{array}{c}-3.020^{* * *} \\
(0.299)\end{array}$ & & & & \\
\hline$x^{85}$ & & & $\begin{array}{l}-2.294^{*} \\
(1.245)\end{array}$ & & & \\
\hline$x^{95}$ & & & & & & $\begin{array}{c}7.880^{* * *} \\
(1.908)\end{array}$ \\
\hline Constant & $\begin{array}{c}0.768^{* * *} \\
(0.0889)\end{array}$ & $\begin{array}{c}0.828^{* * *} \\
(0.0946)\end{array}$ & $\begin{array}{c}2.255^{* * *} \\
(0.498)\end{array}$ & $\begin{array}{l}-0.0197 \\
(0.0405)\end{array}$ & $\begin{array}{l}-0.0624 \\
(0.0752)\end{array}$ & $\begin{array}{c}-0.773 \\
(0.688)\end{array}$ \\
\hline \multicolumn{7}{|l|}{ Endogenous Variables } \\
\hline Non-misleading Advertising & & $\mathrm{X}$ & $\mathrm{X}$ & $\mathrm{X}$ & $\mathrm{X}$ & $\mathrm{X}$ \\
\hline Misleading Advertising & & $\mathrm{X}$ & $\mathrm{X}$ & $\mathrm{X}$ & $\mathrm{X}$ & $\mathrm{X}$ \\
\hline Observations & 1,953 & 1,953 & 1,953 & 1,953 & 1,953 & 1,953 \\
\hline R-squared & 0.497 & 0.436 & 0.419 & 0.411 & 0.415 & 0.415 \\
\hline
\end{tabular}

This table reports the OLS and 2SLS estimates of Equation (6.1.1). The first column presents the OLS estimates, while the second through seventh columns present different specifications of the 2SLS estimates. The baseline specification is presented in column 2 . 
Table 13: Logit Results: Differing Candidate Ideology Measures

\begin{tabular}{|c|c|c|c|c|c|c|}
\hline & $\begin{array}{c}(1) \\
\text { NOMINATE } \\
\text { Scores } \\
\end{array}$ & $\begin{array}{c}(2) \\
\text { Gentzkow } \\
\text { \& Shapiro }\end{array}$ & $\begin{array}{c}\quad(3) \\
\text { American Civil } \\
\text { Liberties Union }\end{array}$ & $\begin{array}{c}(4) \\
\text { Americans for } \\
\text { Democratic Action }\end{array}$ & $\begin{array}{c}(5) \\
\text { American } \\
\text { Conservative Union }\end{array}$ & $\begin{array}{c}(6) \\
\text { National } \\
\text { Taxpayers Union }\end{array}$ \\
\hline \multicolumn{7}{|c|}{ Candidate Ideologies } \\
\hline$x_{\text {obama }}$ & 0.319 & 0.45 & 0.295 & 0.213 & 0.10 & 0.09 \\
\hline$x_{\text {mccain }}$ & 0.689 & 0.55 & 0.79 & 0.90 & 0.814 & 0.83 \\
\hline \multicolumn{7}{|l|}{ Variables } \\
\hline Non-misleading & $\begin{array}{c}0.192^{* * *} \\
(0.0415)\end{array}$ & $\begin{array}{c}0.171^{* * *} \\
(0.0420)\end{array}$ & $\begin{array}{c}0.168^{* * * *} \\
(0.0424)\end{array}$ & $\begin{array}{c}0.164^{* * *} \\
(0.0421)\end{array}$ & $\begin{array}{c}0.164^{* * *} \\
(0.0421)\end{array}$ & $\begin{array}{c}0.164^{* * *} \\
(0.0421)\end{array}$ \\
\hline Misleading & $\begin{array}{c}0.381^{* * *} \\
(0.141)\end{array}$ & $\begin{array}{c}0.430^{* * *} \\
(0.143)\end{array}$ & $\begin{array}{c}0.443^{* * *} \\
(0.144)\end{array}$ & $\begin{array}{c}0.445^{* * *} \\
(0.144)\end{array}$ & $\begin{array}{c}0.446^{* * *} \\
(0.144)\end{array}$ & $\begin{array}{c}0.446^{* * *} \\
(0.144)\end{array}$ \\
\hline Party & $\begin{array}{c}0.930^{* * *} \\
(0.0752)\end{array}$ & $\begin{array}{c}0.946^{* * *} \\
(0.0763)\end{array}$ & $\begin{array}{c}0.965^{* * *} \\
(0.0769)\end{array}$ & $\begin{array}{c}0.960^{* * *} \\
(0.0766)\end{array}$ & $\begin{array}{c}0.961^{* * *} \\
(0.0766)\end{array}$ & $\begin{array}{c}0.961^{* * *} \\
(0.0766)\end{array}$ \\
\hline Poll & $\begin{array}{c}0.231^{* * *} \\
(0.0848)\end{array}$ & $\begin{array}{c}0.190^{* *} \\
(0.0859)\end{array}$ & $\begin{array}{c}0.168^{*} \\
(0.0866)\end{array}$ & $\begin{array}{c}0.180^{* *} \\
(0.0863)\end{array}$ & $\begin{array}{c}0.180^{* *} \\
(0.0863)\end{array}$ & $\begin{array}{c}0.180^{* *} \\
(0.0863)\end{array}$ \\
\hline$x_{c}^{25}$ & $\begin{array}{l}-0.104 \\
(0.222)\end{array}$ & $\begin{array}{c}15.00^{* * *} \\
(4.941)\end{array}$ & $\begin{array}{c}-0.425^{*} \\
(0.240)\end{array}$ & $\begin{array}{c}-1.130 * * * \\
(0.264)\end{array}$ & $\begin{array}{c}-1.161^{* * *} \\
(0.271)\end{array}$ & $\begin{array}{c}-1.171^{* * *} \\
(0.273)\end{array}$ \\
\hline$x_{c}^{50}$ & $\begin{array}{c}-1.107^{* * *} \\
(0.252)\end{array}$ & $\begin{array}{c}-1.286^{* * *} \\
(0.274)\end{array}$ & $\begin{array}{c}-1.670^{* * *} \\
(0.309)\end{array}$ & $\begin{array}{c}-1.199^{* * *} \\
(0.343)\end{array}$ & $\begin{array}{c}-1.207^{* * *} \\
(0.346)\end{array}$ & $\begin{array}{c}-1.219^{* * *} \\
(0.349)\end{array}$ \\
\hline$x_{c}^{75}$ & $\begin{array}{c}-3.020^{* * *} \\
(0.299)\end{array}$ & $\begin{array}{c}25.13^{* * *} \\
(5.938)\end{array}$ & $\begin{array}{c}-0.969^{* * *} \\
(0.282)\end{array}$ & $\begin{array}{c}-0.963^{* * *} \\
(0.305)\end{array}$ & $\begin{array}{c}-0.958^{* * *} \\
(0.302)\end{array}$ & $\begin{array}{c}-0.968^{* * *} \\
(0.305)\end{array}$ \\
\hline Constant & $\begin{array}{c}0.828 * * * \\
(0.0946)\end{array}$ & $\begin{array}{l}-0.816 \\
(0.729)\end{array}$ & $\begin{array}{l}-0.0146 \\
(0.0994)\end{array}$ & $\begin{array}{c}-0.269^{* * *} \\
(0.101)\end{array}$ & $\begin{array}{c}0.214^{* *} \\
(0.107)\end{array}$ & $\begin{array}{c}0.200^{*} \\
(0.107)\end{array}$ \\
\hline Observations & 1,953 & 1,953 & 1,953 & 1,953 & 1,953 & 1,953 \\
\hline R-squared & 0.436 & 0.417 & 0.409 & 0.414 & 0.414 & 0.414 \\
\hline
\end{tabular}

This table reports the results for the logit regression using different measures of candidate ideology. Column 1 presents the baseline specification by measuring candidate ideology using Poole and Rosenthal's NOMINATE scores. The second through sixth columns use measures of candidate ideology from other groups. 


\section{Chapter 7}

\section{Empirical Model and Estimation}

I estimate the voter and candidate models presented in Chapter 4 using the advertising and vote share data described in Chapter 5. I estimate the voter side of the model using Generalized Method of Moments (GMM) in the spirit of Berry, Levinsohn, and Pakes (1995) (BLP). Using the voter-side parameters, I calculate the marginal benefit of advertising for each candidate in each DMA and then estimate the marginal cost parameters using ordinary least squares.

\subsection{Econometric Specification: Voters}

I estimate voter preferences for misleading and non-misleading advertising, the transport cost of ideological distance from the candidate, and the parameters that determine the cost of voting. Following BLP, I equate observed vote shares to vote shares predicted by the model. I then solve for the unobservables and create a set of moments that set the unobservable terms orthogonal to instruments. Below, I discuss the econometric specification, the simulation of aggregate county vote shares, 
the calculation of the unobservables, and the moments that I construct.

As described in Chapter 4, the utility a voter receives from a candidate is given by Equation (4.2.1) A voter votes if the difference in utility she receives from the two candidates is greater than the cost of voting. Therefore, the utility to voter $i$ of voting for candidate $j$ is

$$
\begin{aligned}
& V_{i 1 c}\left(\Delta \xi_{c}, e_{c}\right)=u_{i 1 c}-u_{i 2 c}-K\left(X_{c}, e_{c}\right)+\epsilon_{i 1 c} \\
& V_{i 2 c}\left(\Delta \xi_{c}, e_{c}\right)=u_{i 2 c}-u_{i 1 c}-K\left(X_{c}, e_{c}\right)+\epsilon_{i 2 c}
\end{aligned}
$$

where $u_{i j c}$ is defined in Equation (4.2.1), and the cost of voting is $K\left(X_{c}\right)$. The value to voter $i$ of not voting is normalized to mean zero and is

$$
V_{i 0 c}=0+\epsilon_{i 0 c}
$$

$\epsilon_{i j c}$ and $\epsilon_{i 0 c}$ are idiosyncratic error terms that are distributed Type I Extreme Value. Also, let

$K\left(X_{c}, e_{c}\right) \equiv \alpha_{1}\left(1-\right.$ PastTurnout $\left._{s}\right)+\alpha_{2}$ Battle $_{s}+\alpha_{3}$ PopDens $_{c}+\alpha_{4}\left(\text { PopDens }_{c}\right)^{2}+e_{c}$.

PastTurnout $_{s}$ is the percentage of people in state $c$ that voted in the previous presidential election, and this variable captures the tendency of a state to vote in the presidential election. Battle ${ }_{s}$ is an indicator that equals 1 if county $c$, where $c$ belongs to $s$, is in a battleground state. On average, being in a battleground state should decrease the cost of voting. PopDens ${ }_{c}$ is the population density of county $c$ measured in 10,000 people per square mile. There is no constant term in $K(\cdot)$ because, in practice, it is not possible to separately identify the constant term in the cost of voting and the transport cost on ideology. If there were a constant term in $K(\cdot)$, an increase in that constant term and an increase in the absolute value of $t$ would lead 
to similar vote shares observed in the data. Therefore, I do not estimate a constant in the cost of voting; also, I make the identifying assumption that the mean of $e_{c}$ is 0 . This normalizes the cost of voting and allows for identification of the transport cost on ideology.

For ease of notation, let $\Delta w_{c}=w_{1 c}-w_{2 c}$. Then, plugging Equations (4.2.1) and (7.1.3) into Equations (7.1.1) and (7.1.2), it is possible to rewrite the utility to voter $i$ of voting for candidate $j$ as:

$$
\begin{aligned}
V_{i 1 c}= & \Delta \beta_{0}+\beta_{1}\left(\log \left(1+A_{1 m}\right)-\log \left(1+A_{2 m}\right)\right)+\beta_{2}\left(\log \left(1+M_{1 m}\right)-\log \left(1+M_{2 m}\right)\right) \\
& +\beta_{3} \Delta \text { Party }_{s}+\beta_{4} \Delta \text { Poll }_{s}+\Delta \xi_{c} \\
& -\alpha_{1}\left(1-\text { PastTurnout }_{s}\right)-\alpha_{2} \text { Battle }_{s}-\alpha_{3} \text { PopDens }_{c}-\alpha_{4}\left(\text { PopDens }_{c}\right)^{2}-e_{c}+\epsilon_{i 1 c} \\
V_{i 2 c}= & -\Delta \beta_{0}-\beta_{1}\left(\log \left(1+A_{1 m}\right)-\log \left(1+A_{2 m}\right)\right)-\beta_{2}\left(\log \left(1+M_{1 m}\right)-\log \left(1+M_{2 m}\right)\right) \\
& -\beta_{3} \Delta \text { Party }_{s}-\beta_{4} \Delta \text { Poll }_{s}+t\left[\log \left(\left|x_{2}-x_{i}\right|+1\right)-\log \left(\left|x_{1}-x_{i}\right|+1\right)\right]-\Delta \xi_{c} \\
& -\alpha_{1}\left(1-\text { PastTurnout }_{s}\right)-\alpha_{2} \text { Battle }_{s}-\alpha_{3} \text { PopDens }_{c}-\alpha_{4}\left(\text { PopDens }_{c}\right)^{2}-e_{c}+\epsilon_{i 2 c}
\end{aligned}
$$

Adopting the notation used in BLP, let

$$
\begin{aligned}
\delta_{1}\left(\theta_{1}\right)= & \Delta \beta_{0}+\beta_{1}\left(\log \left(1+A_{1 m}\right)-\log \left(1+A_{2 m}\right)\right)+\beta_{2}\left(\log \left(1+M_{1 m}\right)-\log \left(1+M_{2 m}\right)\right) \\
& +\beta_{3} \Delta \text { Party }_{s}+\beta_{4} \Delta \text { Poll }_{s}+\Delta \xi_{c}-\alpha_{1}\left(1-\text { PastTurnout }_{s}\right) \\
& -\alpha_{2} \text { Battle }_{s}-\alpha_{3} \text { PopDens }_{c}-\alpha_{4}\left(\text { PopDens }_{c}\right)^{2}-e_{c} \\
\delta_{2}\left(\theta_{1}\right)= & -\Delta \beta_{0}-\beta_{1}\left(\log \left(1+A_{1 m}\right)-\log \left(1+A_{2 m}\right)\right)-\beta_{2}\left(\log \left(1+M_{1 m}\right)-\log \left(1+M_{2 m}\right)\right) \\
& -\beta_{3} \Delta \text { Party }_{s}-\beta_{4} \Delta \text { Poll }_{s}-\Delta \xi_{c}-\alpha_{1}\left(1-\text { PastTurnout }_{s}\right) \\
& -\alpha_{2} \text { Battle }_{s}-\alpha_{3} \text { PopDens }_{c}-\alpha_{4}\left(\text { PopDens }_{c}\right)^{2}-e_{c}+\epsilon_{i 2 c}
\end{aligned}
$$

and

$$
\begin{aligned}
& \mu_{1}\left(x_{i}, \theta_{2}\right)=t\left(\log \left(\left|x_{1}-x_{i}\right|+1\right)-\log \left(\left|x_{2}-x_{i}\right|+1\right)\right) \\
& \mu_{2}\left(x_{i}, \theta_{2}\right)=t\left(\log \left(\left|x_{2}-x_{i}\right|+1\right)-\log \left(\left|x_{1}-x_{i}\right|+1\right)\right)
\end{aligned}
$$

where $\theta_{1}=(\beta, \alpha)$ are the parameters in the portion of the utility of voting that are 
not individual-specific, and $\theta_{2}=t$ denotes the the transport cost, which is part of the individual-specific portion of the utility of voting. Therefore, I can express the utility of voting for each candidate in terms of $\delta$ and $\mu$, and

$$
\left.V_{i j c}=\delta_{j}\left(\theta_{1}\right)+\mu_{j}\left(x_{i}, \theta_{2}\right)\right)+\epsilon_{i j c} .
$$

Then, the probability that individual $i$ votes for candidate $j$ is given by the standard logit form:

$$
\operatorname{Pr}(i \text { votes for } j)=\frac{\exp \left(\delta_{j}\left(\theta_{1}\right)+\mu_{j}\left(x_{i}, \theta_{2}\right)\right)}{\left.1+\exp \left(\delta_{1}\left(\theta_{1}\right)+\mu_{1}\left(x_{i}, \theta_{2}\right)\right)+\exp \left(\delta_{2}\left(\theta_{1}\right)+\mu_{2}\left(x_{i}, \theta_{2}\right)\right)\right)}
$$

Aggregating over voters, vote share for candidate $j$ in county $c$ is

$$
\mathrm{vs}_{j c}=\int \frac{\exp \left(\delta_{j}\left(\theta_{1}\right)+\mu_{j}\left(x_{i}, \theta_{2}\right)\right)}{\left.1+\exp \left(\delta_{1}\left(\theta_{1}\right)+\mu_{1}\left(x_{i}, \theta_{2}\right)\right)+\exp \left(\delta_{2}\left(\theta_{1}\right)+\mu_{2}\left(x_{i}, \theta_{2}\right)\right)\right)} d H(x)
$$

where $H(\cdot)$ is the distribution of voter ideology. ${ }^{1}$

\section{Simulating Vote Share}

Each voter can be described by one characteristic: her ideology $x_{i}$. I simulate vote share by first simulating individual ideologies and then aggregating individual vote probabilities in each county. To do this, I first draw a person from a county using demographic distributions at the county level provided by the Census. Second, I predict her ideology $x_{i}$ using the estimated ordered probit parameters described in Section 5.2. Then, for a given guess of $\theta_{2}$ and a given guess of $\delta$, I calculate

\footnotetext{
${ }^{1}$ Voter demographics enter the vote share indirectly through the distribution of voter ideology in the county. See Section 5.2 for details.
} 
the individual vote shares. In practice, I draw 500 people from each county, and I aggregate these individual vote shares by each county to obtain county vote shares.

I use the contraction mapping suggested in BLP to solve for the matrix $\hat{\delta}$, which forces the model's predicted shares to equal observed shares under a given guess of $\theta_{2}:$

$$
\hat{\delta}=\hat{\delta}+\log (\mathrm{vs})-\log (\widehat{\mathrm{vs}})
$$

\subsubsection{Recovering $\theta_{1}$}

To recover $\hat{\theta}_{1}$, the linear, non-individual specific voter utility parameters, I use a Generalized Method of Moments (GMM) process. $^{2}$ For each guess of $\theta_{2}$, I solve for the unobservables $\Delta \xi$ and $e$. Let

$$
\nu=\left(\begin{array}{c}
\Delta \xi \\
e
\end{array}\right)
$$

be a $2 n \times 1$ error vector of the two unobservables stacked on top of one another. I then minimize a set of moment conditions that set the errors orthogonal to appropriate instruments. These moment conditions are

$$
\begin{aligned}
D^{(1)}\left(\theta_{1}\right) & \equiv \mathbb{E}\left[\nu \mid Z_{x}\right] \\
D^{(2)}\left(\theta_{1}\right) & \equiv \mathbb{E}\left[\nu \mid Z_{k}\right],
\end{aligned}
$$

where $Z_{x}$ and $Z_{k}$ are block diagonal matrices containing a set of relevant instruments. Specifically,

$$
Z_{x}=\left(\begin{array}{cc}
X & 0 \\
0 & X
\end{array}\right),
$$

\footnotetext{
${ }^{2}$ I cannot use two stage least squares because $\delta_{1}$ and $\delta_{2}$ are functions of sums of the two unobservables.
} 
where $X$ is a matrix containing the instruments described in 7.1.4 and the exogenous variables in Equation (4.2.1), the utility a voter receives from a candidate. Similarly

$$
Z_{k}=\left(\begin{array}{cc}
K & 0 \\
0 & K
\end{array}\right)
$$

where $K$ is a matrix of the exogenous variables in the voter's cost-of-voting function (Equation (7.1.3)). This sets all exogenous variables in a voter's utility of voting orthogonal to both sets of error terms. I stack the moments and choose $\theta_{1}$ to minimize their weighted distance.

$$
\theta_{1}^{*}=\underset{\theta_{1}}{\arg \min } D\left(\theta_{1}\right)^{\prime} \Sigma D\left(\theta_{1}\right)
$$

where

$$
D\left(\theta_{1}\right)=\left(\begin{array}{c}
D^{(1)}\left(\theta_{1}\right) \\
D^{(2)}\left(\theta_{1}\right)
\end{array}\right) .
$$

$\Sigma$ is a positive-definite weighting matrix. I use a two-step GMM method, where the first step finds the optimal weighting matrix to be used in the second step. The weighting matrix is a block diagonal matrix, where each of the two blocks are weighting matrices for the two sets of moment conditions. In the first step, I use $\left(Z_{x}^{\prime} Z_{x}\right)^{-1}$ for the first block and $\left(Z_{k}^{\prime} Z_{k}\right)^{-1}$ for the second block. ${ }^{3}$

\subsubsection{Solving for the Unobservables}

Since the utility of voting is based on the relative differences between the two candidates, the unobservables in this model are different than those in the standard BLP application. Rather than estimating a separate unobserved "quality", $\xi_{j c}$, for

\footnotetext{
${ }^{3}$ This process is slightly different than the one described in BLP; this is because, as shown in Equations (7.1.4) and (7.1.5), both $\delta_{1}$ and $\delta_{2}$ are functions of both error terms $\Delta \xi_{c}$ and $e_{c}$. Therefore, I cannot use two stage least squares.
} 
each candidate, I can only identify the relative difference in their two qualities, $\Delta \xi_{c}$. Adding any constant $a$ to $\xi_{1 c}$ and $\xi_{2 c}$ would result in the same observed vote shares. In the standard BLP application, the product- and DMA-specific unobservable $\xi \mathrm{s}$ account for the difference between the shares of the inside products and accounts for the relative share of the inside products to the outside product. Since I can only estimate the relative preference $\Delta \xi_{c}$, which accounts for the relative share of the two candidates, I also include another error term, $e_{c}$, which is an error term on the county-specific cost of voting and accounts for the relative share of the outside option, which is abstention from voting. Therefore, the unobservables in this model have a different interpretation than BLP, and the arithmetic process to solve for them is also different. In order to solve for $\Delta \xi_{c}$ and $e_{c}$, I rearrange Equations (7.1.4) and (7.1.5), and I define:

$$
\begin{aligned}
\eta_{1} \equiv & \Delta \xi_{c}-e_{c} \\
= & \hat{\delta}_{1}-\Delta \hat{\beta}_{0}-\hat{\beta}_{1}\left(\log \left(1+A_{1 m}\right)-\log \left(1+A_{2 m}\right)\right)-\hat{\beta}_{2}\left(\log \left(1+M_{1 m}\right)-\log \left(1+M_{2 m}\right)\right) \\
& -\hat{\beta}_{3} \Delta \text { Party }_{s}-\hat{\beta}_{4} \Delta \text { Poll }_{s}+\hat{\alpha}_{1}\left(1-\text { PastTurnout }_{s}\right) \\
& +\hat{\alpha}_{2} \text { Battle }_{s}+\hat{\alpha}_{3} \text { PopDens }_{c}+\hat{\alpha}_{4}\left(\text { PopDens }_{c}\right)^{2} \\
\eta_{2} \equiv & \Delta \xi_{c}+e_{c} \\
= & -\delta_{2}-\Delta \hat{\beta}_{0}-\hat{\beta}_{1}\left(\log \left(1+A_{1 m}\right)-\log \left(1+A_{2 m}\right)\right)-\hat{\beta}_{2}\left(\log \left(1+M_{1 m}\right)-\log \left(1+M_{2 m}\right)\right) \\
& -\hat{\beta}_{3} \Delta \text { Party }_{s}-\hat{\beta}_{4} \Delta \text { Poll }_{s}-\hat{\alpha}_{1}\left(1-\text { PastTurnout }_{s}\right)-\hat{\alpha}_{2} \text { Battle }_{s} \\
& -\hat{\alpha}_{3} \text { PopDens }_{c}-\hat{\alpha}_{4}\left(\text { PopDens }_{c}\right)^{2},
\end{aligned}
$$

where $\eta_{1}$ and $\eta_{2}$ are functions of observables, $\hat{\theta}_{1}$, and $\hat{\delta}$. Then, by combining Equations (7.1.7) and (7.1.8), I obtain Equations (7.1.9) and (7.1.10) and am able to solve for the unobservables $\Delta \xi_{c}$ and $e_{c}$ as a function of observables, $\hat{\delta}$, and $\hat{\theta}_{1}$. 


$$
\begin{aligned}
\Delta \xi_{c} & =.5\left(\eta_{1}+\eta_{2}\right) \\
e_{c} & =\eta_{2}-\Delta \xi_{c}
\end{aligned}
$$

\subsubsection{Recovering $\theta_{2}$}

To estimate the parameters, I set the unobservables, $\Delta \xi_{c}$ and $e_{c}$ separately orthogonal to the candidate preference instruments (Z), which are described in Section 7.1.4, and the cost variables $(\mathrm{W})$, respectively. That is, I create the following county-level moment conditions.

$$
\begin{aligned}
& G^{(1)}\left(\theta_{2}\right) \equiv \mathbb{E}\left[\nu \mid Z_{x}\right] \\
& G^{(2)}\left(\theta_{2}\right) \equiv \mathbb{E}\left[\nu \mid Z_{k}\right]
\end{aligned}
$$

Though I do not estimate a constant in the cost of voting, $Z_{k}$ includes a vector of ones;

therefore, I use the identifying assumption that the mean of $e_{c}$ is 0 . This normalizes the cost of voting and allows me to identify the transport cost.

I also create a moment condition based on the predicted individual ideology, which is a function of individual demographics. I assume that the mean ideology by county is not correlated with the errors.

$$
G^{(3)}\left(\theta_{2}\right) \equiv \mathbb{E}\left[\nu \mid \frac{1}{N} \sum_{i=1}^{N} x_{i}\right],
$$

where $N$ is the number of simulated people per county. I stack these three sets of moments choose $\theta_{2}$ to minimize their weighted distance.

$$
\theta_{2}^{*}=\underset{\theta_{2}}{\arg \min } G\left(\theta_{2}\right)^{\prime} \Gamma G\left(\theta_{2}\right)
$$

where 


$$
G\left(\theta_{2}\right)=\left(\begin{array}{c}
G^{(1)}\left(\theta_{2}\right) \\
G^{(2)}\left(\theta_{2}\right) \\
G^{(3)}\left(\theta_{2}\right)
\end{array}\right) .
$$

$\Gamma$ is a positive-definite weighting matrix. I use a two-step GMM method, where the first step finds the optimal weighting matrix to be used in the second step. The weighting matrix is a block diagonal matrix, where each of the three blocks are weighting matrices for the three set of moment conditions. In the first step, I use $\left(Z_{x}^{\prime} Z_{x}\right)^{-1}$ for the first block, $\left(Z_{k}^{\prime} Z_{k}\right)^{-1}$ for the second block, and the identity matrix for the third block.

\subsubsection{Instruments for Advertising}

When candidates decide how to allocate money across types of advertising and across DMAs, there are variables that enter into the candidates' decision-making that the econometrician is unable to observe. This leads to a possible correlation between advertising levels, $A_{j m}$ and $M_{j m}$, and the candidate-preference error, $\Delta \xi_{c}$. For example, misleading advertising may be correlated with the candidate's relative attractiveness in a county or group of counties. To deal with this, I instrument for advertising levels using the three groups of instruments detailed in Table 14, and I describe the instruments below. In Table 15, I show the correlation of the instruments to the endogenous variables by running a regression of the endogenous advertising variables on the instruments.

\section{Congressional Campaign Advertising Measures}

In general, a DMA comprises many counties. Therefore, the advertising levels for each county in the same DMA are the same, since advertising is measured in dollars per eligible voter by DMA, and advertising cannot be run county by county. 
I use spending in congressional elections in 2004 as an instrument for candidate advertising in 2008. I exclude Gubernatorial and Senate spending because not all battleground states have Gubernatorial and Senate races in 2008. Including them would artificially show a greater amount of spending in those states with Gubernatorial and Senate races. The amount spent on advertising in the congressional races in 2004 is correlated with the amount spent in the presidential election in 2008, because the relative strengths of the Republican and Democratic candidate in the 2004 congressional races is correlated with the relative strengths of the Republican and Democratic candidates in the 2008 presidential election. States that traditionally have tight races in the presidential election are also likely to have tight races in the congressional elections, and the costs of advertising for each party in a particular DMA should be correlated across time. Therefore, the advertising behavior in the 2004 congressional elections should be correlated with the advertising behavior in the 2008 presidential election.

However, the error term $\xi_{j c}$ should remain uncorrelated with the advertising level of congressional elections in 2004 in county c. The county's propensity to vote for a particular party is reflected in what percentage of people voted for that party in the previous presidential election, and the county's ideological preference is accounted for by the county ideology. After conditioning on these characteristics, since $\Delta \xi_{c}$ describes the difference in county c's preference for two particular presidential candidates, this error should be uncorrelated with that county's preference for any given two congressional candidates in a previous election cycle and uncorrelated with congressional spending behavior in 2004.

I divide congressional spending into attack and non-attack spending, because the 
2008 presidential data show that spending on attack advertising is correlated with spending on misleading advertising. Therefore, spending on attack advertising in 2004 congressional elections should be a good predictor of spending on misleading advertising in the 2008 presidential election. However, there should not be any systematic strategic correlation between the congressional election decisions in 2004 and the presidential election decisions in 2008, since there are many more candidates in 2004 across many different types of races.

I also use both the same DMA advertising levels and a weighted average of the DMA's surrounding DMAs within the same state. Since Senate and gubernatorial candidates must allocate advertising across the whole state, advertising in one DMA and its surrounding DMAs are correlated; this makes congressional spending in 2004 in the surrounding DMAs a relevant instrument for presidential spending in 2008.

\section{DMA Geography Measures}

Candidates make advertising choices by DMAs, which are geographical areas defined by Nielsen Media Research. I use two measures of DMA geography as instruments. The first is the number of DMAs surrounding the DMA that county $c$ belongs to that also lie within the same state. Similarly to Moshary (2015), the second is the percentage of $c$ 's DMA, $m$, that lies in a non-battleground state. These measures should be exogenous, because they are based on geographical boundaries.

The first measure accounts for how many options a candidate has in using advertising to increase the probability of winning that particular state. Spending in one DMA in a state affects the marginal benefit of spending in another DMA in that same state, since the candidate only cares about winning a plurality in that state. In a state that only has one DMA (like Utah), the candidate faces a different decision 
than a state that has 12 DMAs (like Ohio). In a state with just one DMA, both candidates only have to make one decision, and advertising affects all potential voters in that state.

Now consider a state with 12 DMAs, and suppose one candidate has a higher cost to advertise in that state. ${ }^{4}$ The winner of the state's electoral votes is the candidate with the plurality of votes; moreover, since it does not matter which DMA the voters come from, the candidate with the lower cost of advertising may advertise in all DMAs, while the candidate with the higher cost of advertising may only advertise in DMAs that already lean toward his party. This means that the number of DMAs would change relative spending amounts by each candidate and would serve as a suitable instrument.

The second DMA geography instrument is the percentage of the DMA that lies outside of a battleground state and measures the relative cost of advertising among DMAs. There are some DMAs that cover counties in more than one state. In this case, the economic cost of airing an advertisement increases relative to a DMA that is contained entirely in one state. For example, the Cincinnati DMA covers several counties in both Kentucky and Indiana as well as Cincinnati's state, Ohio. The presidential candidates' dollars are essentially wasted in Kentucky, because the advertisement spending will not change the winner of that state's electoral votes; however, the candidate still must pay something for those viewers because of normal advertising competition in local DMAs. This increases the cost of advertising in Cincinnati relative to a DMA like Columbus, which is completely contained in Ohio.

To measure this overlap, I create a variable that measures the percentage of county

\footnotetext{
${ }^{4}$ This could be because it is more difficult for him to coordinate advertisement purchases in the state's DMAs.
} 
c's DMA that lies outside of county c's state and in a non-battleground state. When a DMA is fully contained in one state, or when a DMA spans more than one states but all of those states are battleground states, this measure is 0 for all counties within that DMA. This instrument should be correlated with advertising because the closer the overlap measure is to 1 , the more viewers in battleground states, and the less advertising candidates air. The exclusion restriction should also be satisfied as long as the overlap is not correlated with the candidate-preference error, which is a reasonable assumption, after accounting for voter ideology by county. ${ }^{5}$

\section{State Laws on Misleading Advertising}

In 2008, there were 17 states with laws that regulate misleading campaign speech (Kruse, 2001). ${ }^{6}$ As an instrument for advertising, I include an indicator variable that equals 1 if the county is in a state that has a law regulating misleading campaign speech and equals 0 otherwise. These laws were enacted between 1979 and 1999, well before the 2008 campaign. These laws change the relative cost of misleading advertising in the relevant states but should have no direct effect on voter behavior.

As a second instrument, I interact the indicator for existence of a state law against misleading advertising with the county being in a battleground state. Being in a battleground state changes the relative costliness of misleading advertising and how much the law affects that cost compared to a non-battleground state. For example, if parties in battleground states are more likely to send cease-and-desist letters in battleground states, that should increase the effectiveness of the law in battleground states.

\footnotetext{
${ }^{5}$ This assumption would fail, for example, if there was some systematic dislike for a particular candidate by voters in non-battleground states.

${ }^{6}$ Alaska, Colorado, Florida, Louisiana, Massachusetts, Minnesota, Mississippi, Montana, Nevada, North Carolina, North Dakota, Ohio, Oregon, Tennessee, Utah, West Virginia, and Wisconsin.
} 
Table 14: Instruments for Misleading and Non-misleading Advertising Levels in 2008

1. Congressional Spending Instruments

(a) Congressional attack advertisement spending in the same DMA in 2004

(b) Congressional non-attack advertisement spending in the same DMA in 2004

(c) Congressional attack advertisement spending in surrounding DMAs in 2004

(d) Congressional non-attack advertisement spending in surrounding DMAs in 2004

2. DMA Geography Instruments

(a) Number of surrounding DMAs in the same state

(b) Percentage of the county's DMA that is not in a battleground state

3. Misleading Law Instrument

(a) County is in a state that has a law against misleading campaign speech

(b) County is in a state that has a law $\times$ county is in a battleground state 
Table 15: Instrument Relevance

\begin{tabular}{|c|c|c|}
\hline VARIABLES & $\begin{array}{c}\text { Non-misleading Advertising } \\
\log \left(1+A_{1}\right)-\log \left(1+A_{2}\right)\end{array}$ & $\begin{array}{c}\text { Misleading Advertising } \\
\log \left(1+M_{1}\right)-\log \left(1+M_{2}\right)\end{array}$ \\
\hline \multirow[t]{2}{*}{$\Delta$ Party } & -0.0778 & $-0.0482^{*}$ \\
\hline & $(0.0875)$ & $(0.0281)$ \\
\hline \multirow[t]{2}{*}{$\Delta$ Poll } & 0.0873 & $-0.139 * * *$ \\
\hline & $(0.0970)$ & $(0.0311)$ \\
\hline \multirow[t]{2}{*}{ Non-Attack Same DMA Cong Ads } & -0.0381 & $0.0313^{* * *}$ \\
\hline & $(0.0240)$ & $(0.00770)$ \\
\hline \multirow[t]{2}{*}{ Attack Same DMA Cong Ads } & $0.417^{* * *}$ & $0.219^{* * *}$ \\
\hline & $(0.0504)$ & $(0.0162)$ \\
\hline \multirow[t]{2}{*}{ Non-Attack Surrounding DMA Cong Ads } & $-0.0863^{* * *}$ & $-0.0341^{* * *}$ \\
\hline & $(0.0187)$ & $(0.00600)$ \\
\hline \multirow[t]{2}{*}{ Attack Surrounding DMA Cong Ads } & $0.298^{* * *}$ & $0.121^{* * *}$ \\
\hline & $(0.0293)$ & $(0.00942)$ \\
\hline \multirow[t]{2}{*}{ \# of Surrounding DMAs } & $0.0262^{* * *}$ & 0.000789 \\
\hline & $(0.00581)$ & $(0.00186)$ \\
\hline \multirow[t]{2}{*}{$\%$ of DMA Outside Battleground State } & $0.0370 * *$ & $0.0238 * * *$ \\
\hline & $(0.0186)$ & $(0.00597)$ \\
\hline \multirow[t]{2}{*}{ Law Against Misleading Campaign Speech } & $-0.175^{* * *}$ & $-0.0184^{* * *}$ \\
\hline & $(0.0164)$ & $(0.00526)$ \\
\hline \multirow[t]{2}{*}{ Law $\times$ Battleground State } & $0.350^{* * *}$ & $-0.0197^{* * *}$ \\
\hline & $(0.0232)$ & $(0.00745)$ \\
\hline \multirow[t]{2}{*}{ Constant } & $0.155^{* * *}$ & $-0.0232^{* * *}$ \\
\hline & $(0.0203)$ & $(0.00651)$ \\
\hline Observations & 1,953 & 1,953 \\
\hline R-squared & 0.248 & 0.283 \\
\hline F-statistic & 63.92 & 76.78 \\
\hline
\end{tabular}

This table shows the results of a regression of the endogenous advertising variables on the instruments. $A_{j}$ is the amount spent on non-misleading advertising by candidate $j$ and $M_{j}$ is the amount spent on misleading advertising by candidate $j$. 


\subsection{Econometric Specification: Candidates}

After estimating the voter-side parameters, I estimate the first order conditions of the candidate model presented in Chapter 4 using ordinary least squares. I take the derivative of the objective function presented in Equation (4.3.1) to obtain first order conditions. I calculate the marginal benefit of advertising as follows. First, I calculate the critical levels of $\Delta \xi_{s}$ that set the number of votes for each candidate equal within each state, usinb observed advertising levels and the estimated voter-side parameters. Then, I increase advertising by a small amount and calculate how that critical value, and the probability of drawing that critical value, changes. I regress marginal benefit on relevant marginal cost variables. The first order conditions (FOCs) that I estimate are:

$$
\underbrace{R_{j} \frac{\partial \text { ElecVotes }_{s} \times \pi_{j s}\left(\mathbf{A}_{\mathbf{s}}, \mathbf{M}_{\mathbf{s}}, \Delta \xi_{c} ; \theta\right)}{\partial \mathrm{Ads}_{j m}}}_{\text {Marginal Benefit }}=\underbrace{N_{m}+W_{j m} \gamma_{j}+\omega_{j m}}_{\text {Marginal Cost }},
$$

where the probability of winning is discussed in section 7.2 and the marginal cost function is given in Section 7.2.

\section{Probability of Winning, $\pi_{j s}$}

The probability of winning is from the candidates' point of view and is a function of the candidates' uncertainty over the state-specific portion of the candidate-preference shock. The probability of winning is

$$
\pi_{j s}=\operatorname{Pr}\left(\operatorname{Votes}_{j s}\left(\mathbf{A d s}_{\mathbf{s}}, \Delta \xi_{c} ; \theta\right)>\operatorname{Votes}_{-j s}\left(\mathbf{A d s}_{\mathbf{s}}, \Delta \xi_{c} ; \theta\right)\right)
$$

and the candidate's beliefs about the candidate-preference shock are 


$$
\Delta \xi_{c}=\Delta \bar{\xi}_{c}+\Delta \xi_{s}, \quad \Delta \xi_{s} \sim N\left(0, \sigma^{2}\right)
$$

There exists a critical level of $\Delta \xi_{s}$ such that the candidates' votes are equal within a state, and the probability that candidate 1 (2) wins is the probability that the realization of $\Delta \xi_{s}^{*}$ is greater than (less than) the critical value. Let $\Delta \xi^{*}$ denote this critical value. Formally, the probability that candidate $j$ wins state $s$ is given by

$$
\begin{aligned}
& \pi_{1 s}=1-\Phi\left(\Delta \xi_{s}^{*}\right) \\
& \pi_{2 s}=\Phi\left(\Delta \xi_{s}^{*}\right)
\end{aligned}
$$

where $\Phi$ is the normal cumulative distribution function, and $\Delta \xi_{s}^{*}$ is such that

$$
\operatorname{Votes}_{j s}\left(\mathbf{A d s}_{\mathbf{s}}, \xi_{c}, \Delta \xi_{s}^{*} ; \theta\right)=\operatorname{Votes}_{-j s}\left(\mathbf{A d s}_{\mathbf{s}}, \Delta \xi_{c}, \Delta \xi_{s}^{*} ; \theta\right)
$$

and

$$
\operatorname{Votes}_{j s}\left(\mathbf{A d s}_{\mathbf{s}}, \xi_{c}, \Delta \xi_{s}^{*} ; \theta\right)=\sum_{c \in s} N_{c} \mathrm{vs}_{j c}\left(\mathbf{A d s}_{\mathbf{s}}, \xi_{c}, \Delta \xi_{s}^{*} ; \theta\right)
$$

$\operatorname{Votes}_{j s}$ is the number of votes for candidate $j$ in state $s . N_{c}$ is the number of potential voters in county $c . \quad \mathrm{vs}_{j c}$ is the vote share for candidate $j$ in county $c$, which is determined by the voter-side model and is defined in Equation (7.1.6).

For a given level of advertising, the probability of winning depends on the critical $\Delta \xi_{s}^{*}$ and the variance of the uncertainty term, $\sigma^{2}$. Holding advertising constant at the observed levels, I calculate the critical $\Delta \xi_{s}^{*}$ values and show, in Table 16, how the probability of winning changes as $\sigma^{2}$ increases.

To calculate the marginal benefit, I perturb each advertising observation, calculate the new critical $\Delta \xi_{s}^{*}$ values and calculate the change in the probability of winning each state and the change in expected electoral votes that result from the change. 
I estimate the marginal cost parameters by setting the calculated marginal benefit equal to marginal cost.

Table 16: Estimated Probabilities of Obama Winning

\begin{tabular}{lccccc} 
& Obama Won & Obama's Actual & \multicolumn{3}{c}{ Estimated $\pi_{\text {obama }}$} \\
\cline { 4 - 6 } State & in 2008 & 2008 Vote Share & $\sigma=.5$ & $\sigma=1$ & $\sigma=1.5$ \\
\hline Colorado & 1 & 0.55 & 0.72 & 0.62 & 0.58 \\
Florida & 1 & 0.51 & 0.56 & 0.54 & 0.52 \\
Indiana & 1 & 0.51 & 0.52 & 0.51 & 0.51 \\
Iowa & 1 & 0.55 & 0.72 & 0.61 & 0.58 \\
Michigan & 1 & 0.58 & 0.83 & 0.68 & 0.62 \\
Missouri & 0 & 0.50 & 0.50 & 0.50 & 0.50 \\
Nevada & 1 & 0.56 & 0.76 & 0.64 & 0.59 \\
New Hampshire & 1 & 0.55 & 0.75 & 0.63 & 0.59 \\
New Jersey & 1 & 0.58 & 0.84 & 0.69 & 0.63 \\
New Mexico & 1 & 0.58 & 0.83 & 0.69 & 0.63 \\
North Carolina & 1 & 0.50 & 0.51 & 0.50 & 0.50 \\
Ohio & 1 & 0.52 & 0.61 & 0.55 & 0.54 \\
Pennsylvania & 1 & 0.55 & 0.74 & 0.62 & 0.59 \\
Virginia & 1 & 0.53 & 0.66 & 0.58 & 0.56 \\
Wisconsin & 1 & 0.57 & 0.82 & 0.68 & 0.62 \\
\hline
\end{tabular}

This table lists the probability of Obama winning each battleground state in 2008 using different measures of $\sigma$. The second column equals 1 if Obama won the plurality of votes in 2008 and won all of the electoral votes in that state. The third column lists Obama's vote share by state. The last three columns list the estimated probability of winning, as a function of candidate uncertainty. The greater the level of uncertainty, the closer the outcomes are to a coin toss.

\section{Marginal Cost}

The marginal cost function is

$$
\begin{aligned}
\text { Marginal }_{\text {Cost }_{j m}=} & N_{m}+W_{j m} \gamma_{j}+\omega_{j m} \\
= & N_{m}\left(1+\gamma_{1 j} \mathbb{1}\left\{\text { Misleading }_{j m}\right\}+\gamma_{2 j} \text { Outside }_{m} * \mathbb{1} \text { Misleading }_{j m}\right\} \\
& \left.+\gamma_{3 j} \text { MisLawPct }_{m} * \mathbb{1}\left\{\text { Misleading }_{j m}\right\}\right) \\
& +\omega_{j m} .
\end{aligned}
$$


where $j$ indexes candidates and $m$ indexes DMAs. $N_{m}$ is the number of potential voters in DMA $m$ that also live in a battleground state. ${ }^{7}$ Since advertising is measured in dollars per voter, multiplying the marginal cost factors by the number of potential voters, $N_{m}$ converts the cost into dollar terms. The interpretation of the $\gamma$ coefficients is the dollar increase in marginal cost. For example, if $\gamma_{1 j}=1$, then this means that the marginal cost of one dollar of misleading advertising is $\$ 1$ greater than the marginal cost of non-misleading advertising for candidate $j$, all else equal. All costs are measured relative to non-misleading advertising aired in a state without a law against misleading advertising.

$\mathbb{1}\left\{\right.$ Misleading $\left._{j m}\right\}$ is an indicator for misleading advertising, allowing the marginal cost of misleading advertising to differ from the marginal cost of non-misleading advertising. A positive $\gamma_{1 j}$ implies that candidate $j$ faces a higher marginal cost to airing any misleading advertising, perhaps due to personal preferences. Outside $m$ measures the percentage of the DMA that is outside of a battleground state and allows the marginal cost of airing advertising for potential battleground voters to differ from the marginal cost of airing advertising for those voters that are not in a battleground state. MisLawPct $m$ is the percentage of that DMA's population that lives in a state with a law against misleading advertising. If $\gamma_{4 j}$ is positive, this means that the marginal cost of misleading advertising is greater in states with laws against misleading campaign advertising. One interpretation of this additional cost is the expected cost of dealing with lawsuits and threats of lawsuits. ${ }^{8} \omega_{j m}$ is a candidateand DMA-specific error term in the marginal cost function. This error term can be

\footnotetext{
${ }^{7}$ Since DMAs can cross borders, $N_{m}$ is weakly less than the number of potential voters in the entire DMA.

${ }^{8}$ Though actual lawsuits are rare, the increased cost could be due to threats of lawsuits, lawyer fees, or responding to cease and desist letters.
} 
interpreted as the cost of coordinating advertisement purchases.

\section{Candidate Side Estimation}

I estimate the candidate-side parameters in three steps. First, I calculate the critical value of $\Delta \xi_{s}^{*}$ that sets the number of votes for each candidate equal within a state. Second, I use a guess of $\sigma$ to calculate the probabilities of winning for each candidate, where the probability that candidate 1 (2) wins is the probability that the realization of $\Delta \xi_{s}^{*}$ is greater than (less than) the critical value. Third, I use ordinary least squares (OLS) to recover $\left(R_{j}, \gamma_{j}\right)$. I repeat this process with different guesses of $\sigma$ and minimize the variance of the marginal cost error term. I assume that the variance of $\omega$ differs by candidate and is scaled by $R_{j}$, where

$$
\frac{\omega_{j m}}{R_{j}} \sim N\left(0, \sigma^{2}\right)
$$

and I estimate $\sigma$ by minimizing the variance of $\omega_{j m}$.

Intuitively, the candidate uncertainty parameter, $\sigma$, is identified by the covariation between polling numbers and advertising dollars. Even within battleground states, some states are closer than others. If there is very little uncertainty, then candidates would not advertise much in the least competitive battleground states. If there is a lot of uncertainty, then candidates would advertise more in the less competitive states. The relative amounts of advertising by polling numbers identify the candidates' uncertainty.

Let the calculated marginal benefit of advertising be denoted

$$
\widetilde{\mathrm{MB}}_{j m}\left(A_{j m}, \sigma\right) \equiv \frac{\partial \text { ElecVotes }_{s} \times \tilde{\pi}_{j s}\left(\mathbf{A}_{\mathbf{s}}, \mathbf{M}_{\mathbf{s}}, \Delta \xi_{c} ; \theta\right)}{\partial A_{j m}},
$$


where $\tilde{\pi}_{j s}$ is the estimated probability that candidate $j$ wins state $s$. Then, I rewrite and transform the FOCs from Equation (7.2.1) by dividing by $R_{j}$ so that the lefthand-side is only a function of $\sigma$. I then use ordinary least squares (OLS) to estimate the following transformed FOCs,

$$
\begin{aligned}
\widetilde{\operatorname{MB}}_{j m}\left(A_{j m}, \sigma\right)= & \frac{1}{R_{j}} N_{m}\left(1+\gamma_{1 j} \mathbb{1}\left\{\text { Misleading }_{j m}\right\}+\gamma_{2 j} \text { Outside }_{m} * \mathbb{1}{\text { \{ } \left.\text { Misleading }_{j m}\right\}}\right. \\
& \left.+\gamma_{3 j} \text { MisLawPct }_{m} * \mathbb{1}\left\{\text { Misleading }_{j m}\right\}\right) \\
& +\omega_{j m}
\end{aligned}
$$

OLS estimates the following parameters,

$$
\begin{aligned}
\lambda_{0 j} & =\frac{1}{R_{j}} \\
\lambda_{i j} & =\frac{\gamma_{i j}}{R_{j}}, \quad i=1, \ldots 4
\end{aligned}
$$

where the variances of the $\lambda \mathrm{s}$ are $\sigma_{\lambda_{i j}}^{2}$. To recover the point estimates and standard errors of $\alpha$ and of $R_{j}$, I use the delta method. Specifically,

$$
\begin{aligned}
\hat{R}_{j} & =\frac{1}{\hat{\lambda}_{0 j}} \\
\hat{\gamma}_{i j} & =\hat{R}_{j} \hat{\lambda}_{i j}, \quad i=1, \ldots 4 .
\end{aligned}
$$

The variances for $\hat{R}_{j}$ are

$$
\hat{\sigma}_{R_{j}}^{2}=\left(\frac{1}{\hat{\lambda}_{0 j}^{4}}\right) \hat{\sigma}_{\lambda_{0 j}}^{2},
$$

and the variances for the $\gamma$ s are

$$
\sigma_{\gamma_{i j}}^{2}=\hat{R}_{j}^{2} \hat{\sigma}_{\lambda_{i j}}^{2}+\hat{\lambda}_{i j}^{2} \hat{\sigma}_{R_{j}}^{2}+2 \hat{R}_{j} \hat{\lambda}_{i j} \widehat{\operatorname{Cov}}\left(R_{j}, \lambda_{i j}\right) .
$$




\section{Chapter 8}

\section{Results}

I report the voter utility parameter estimates in Table 17 and the candidate marginal cost parameters in Table 19. I find that misleading and non-misleading advertising both have positive effects on the utility a voter receives from a candidate, and that the average marginal benefit of misleading advertising is greater than the average marginal benefit of non-misleading advertising. I find that candidates face a positive non-pecuniary cost of misleading advertising and that this cost is even higher in states with laws against misleading campaign advertising.

Table 18 reports the average marginal benefit of both types of advertising at the observed levels of advertising in 2008. The first row shows the preferred specification, using Poole and Rosenthal's NOMINATE score of candidate ideology. I also show the marginal benefit results using candidate ideology measures from other groups.

Figure 8 shows the different candidate ideology measures as determined by various political groups. Non-affiliated groups are denoted with an (N), Democratic groups are denoted with a (D), and Republican groups are denoted with an (R). As 
Figure 8: Candidate Ideology Measures by Various Groups

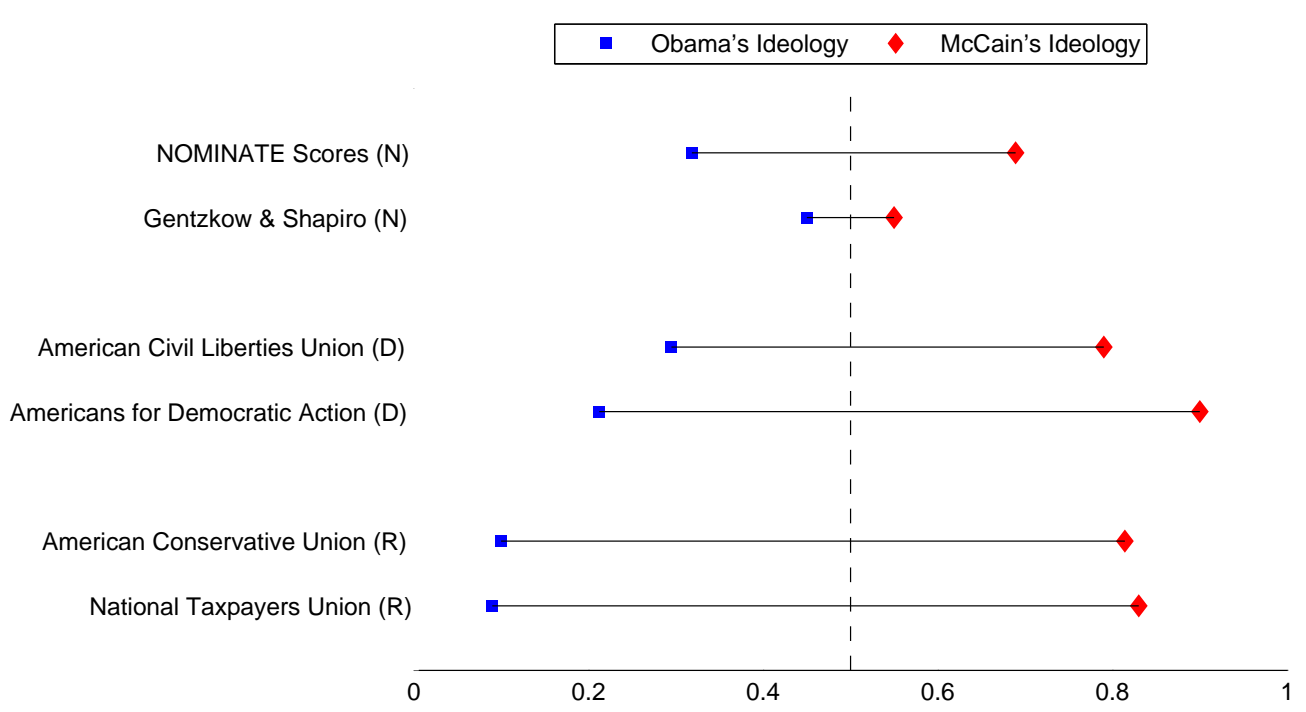

The groups calculate scorecards by taking the percentage of votes by the candidate that agree with the group's aims. Therefore, a score of 1 indicates that the candidate voted in accordance with the group's objectives $100 \%$ of the time. For Democratic groups, I use $(1-$ score $)$ as the ideology to convert scores to level of conservativeness. 
is shown in this figure, the Democratic groups tend to rate Obama as less liberal and McCain as more conservative, relative to the Republican groups. The two nonaffiliated groups rate the two candidates as equidistant from the center. I use Poole and Rosenthal's NOMINATE scores because they are lifetime scores based on the candidate's individual voting behavior in Congress. Note that Gentzkow \& Shapiro's method assigns ideology using the percentage of people in the candidate's district (in this case, state) that voted for the Republican candidate in the previous presidential election. This measure is not based on voting behavior and is not candidate-specific, as two Senators from the same state would receive the same score. The liberal and conservative scorecards are based on candidate-specific voting behavior, but they are calculated using only a subset of votes that the particular group has an interest in.

\subsection{Voters' Utility from Candidates}

The first section in Table 17 show the estimates of the parameters in the candidatepreference portion of voter utility. Both misleading and non-misleading advertising have positive parameters associated with them, indicating that both types of advertising by a candidate increase the voter's utility from that candidate. The parameter on misleading advertising is more than twice that of the parameter on non-misleading advertising; this means that the first dollar spent on misleading advertising increases voter utility by at least twice as much than the first dollar spent on non-misleading advertising. This could be because misleading statements tend to be more "extreme" or "severe" than non-misleading statements. If a candidate can only make nonmisleading statements, his options are limited. When a candidate can make misleading statements, he can make more extreme statements that are, on average, more 
Table 17: Voter Utility Results

\begin{tabular}{lcc}
\hline Variables & Estimate & Standard Error \\
\hline Utility from Candidates & 0.093 & 0.028 \\
$\Delta \beta_{0}$, Constant & 0.335 & 0.081 \\
$\beta_{1}$, Non-Misleading Advertising & 0.818 & 0.372 \\
$\beta_{2}$, Misleading Advertising & 2.838 & 0.277 \\
$\beta_{3}$, Party & 0.692 & 0.196 \\
$\beta_{4}$, Poll & -9.428 & 0.066 \\
$t$, Transport Cost & & \\
Cost of Voting & 3.760 & 0.403 \\
$\alpha_{1}, 1$ - PastTurnout & -0.163 & 0.016 \\
$\alpha_{2}$, Battle & -0.932 & 0.236 \\
$\alpha_{3}$, Population Density & 0.636 & 0.296 \\
$\alpha_{4}$, Population Density Squared & \multicolumn{2}{c}{1934} \\
\hline Observations &
\end{tabular}

This table presents the estimates of the parameters in the voter utility function, which is presented in Equations (7.1.1) and (7.1.2). A voter votes if the difference between the utilities she receives from the candidates is greater than the cost of voting. Misleading and non-misleading advertising increase the utility a voter receives from a candidate. Living in a battleground state decreases the voter's cost of voting.

persuasive, than non-misleading statements.

The parameters on the party and polling variables both have the expected signs, where an increase in the party's vote share in the previous election or an increase in a candidate's poll also increase that candidate's vote share. The transport cost is negative; the further the candidate is from the potential voter's ideology, the lower the utility the voter receives from that candidate. 


\subsubsection{Cost of Voting Parameters}

The second section in Table 17 give the parameter estimates for the cost-of-voting variables. The parameter estimate on 1 - PastTurnout is positive, indicating that there is a positive relationship between the percentage of people that turn out to vote in a state over time. The effect of being in a battleground states decreases the cost of voting. This could be because people in battleground states feel that their vote may be more important. As population density increases, the effect on cost of voting is U-shaped. For low levels of population density, an increase in population density decreases the cost of voting, perhaps because the distance to a voter's polling place decreases. For very high levels of population density, an increase in population density increases the cost of voting. This could be because in a crowded county, even though a voter's polling place is close by, the lines will be longer as population density grows, increasing the cost of voting. ${ }^{1}$

\subsection{Estimated Average Benefit of Advertising}

Given the voter-side parameter estimates and the observed levels of advertising in 2008, I calculate the benefit to each candidate of increasing misleading and nonmisleading advertising. Table 18 shows these results and shows that they are relatively stable across different candidate ideology measures. The numbers in this table are the calculated as a change in electoral votes at the observed levels of advertising for each candidate in 2008. For example, the first entry in Table 18 of 0.487 means that Obama increasing spending by a dollar per voter in an average DMA on misleading advertising

\footnotetext{
${ }^{1}$ The effect of increasing population density is negative only for the five densest counties.
} 
Table 18: Estimated Average Benefit of Advertising

\begin{tabular}{lccccc} 
& \multicolumn{2}{c}{ Obama } & & \multicolumn{2}{c}{ McCain } \\
\cline { 2 - 3 } \cline { 5 - 6 } Candidate Ideology Measure & Misleading & Non-Mis & & Misleading & Non-Mis \\
\hline NOMINATE Scores & 0.487 & 0.092 & & 0.474 & 0.143 \\
Gentzkow \& Shapiro & 0.607 & 0.086 & & 0.592 & 0.133 \\
American Civil Liberties Union & 0.477 & 0.098 & & 0.465 & 0.151 \\
Americans for Democratic Action & 0.406 & 0.097 & & 0.395 & 0.150 \\
American Conservative Union & 0.370 & 0.098 & & 0.360 & 0.152 \\
National Taxpayers Union & 0.370 & 0.999 & & 0.360 & 0.152 \\
\hline
\end{tabular}

This table reports the average marginal benefit of advertising, measured in electoral votes, given different measures of candidate ideology. The baseline specification is given in the first row, using Poole and Rosenthal's NOMINATE score of candidate ideology.

would increase Obama's expected electoral votes by $0.487 .{ }^{2}$ At the observed levels of advertising in the 2008 election, the effect of misleading advertising is greater than the effect of non-misleading advertising. Moreover, the average effect of Obama's misleading advertising is greater than McCain's misleading advertising. Since McCain airs more misleading advertising than Obama, and the marginal effect of advertising diminishes, the average effect of McCain's misleading advertising is less than Obama's. Similarly, Obama airs more non-misleading advertising than McCain, and the average effect of Obama's non-misleading advertising is less than McCain's.

\subsection{Marginal Cost Parameters}

The marginal cost estimates are presented in Table 19. I find that, for both candidates, misleading advertising has a higher marginal cost than non-misleading advertising, and that a law against misleading advertising further increases the marginal cost of misleading advertising. This is true across all measures of candidate ideology.

\footnotetext{
${ }^{2}$ The average DMA size in battleground states is 1.1 million potential voters.
} 
Table 19: Marginal Cost Estimates

\begin{tabular}{|c|c|c|c|c|}
\hline \multirow[b]{2}{*}{ Variable } & \multicolumn{2}{|c|}{ Obama } & \multicolumn{2}{|c|}{ McCain } \\
\hline & Estimate & Std Error & Estimate & Std Error \\
\hline \multicolumn{5}{|l|}{$\overline{\gamma_{1 j}, \text { Misleading }}$} \\
\hline NOMINATE & 7.452 & 0.899 & 4.182 & 0.351 \\
\hline G\&S & 10.299 & 1.515 & 5.937 & 0.585 \\
\hline ACLU & 6.826 & 0.791 & 3.803 & 0.312 \\
\hline ADA & 5.708 & 0.610 & 3.111 & 0.244 \\
\hline $\mathrm{ACU}$ & 5.023 & 0.513 & 2.687 & 0.209 \\
\hline NTU & 5.025 & 0.513 & 2.689 & 0.209 \\
\hline \multicolumn{5}{|c|}{$\gamma_{2 j}$, Misleading, Non-Battle } \\
\hline NOMINATE & -7.981 & 0.976 & -4.848 & 0.414 \\
\hline G\&S & -10.694 & 1.588 & -6.507 & 0.652 \\
\hline ACLU & -7.386 & 0.869 & -4.491 & 0.372 \\
\hline $\mathrm{ADA}$ & -6.320 & 0.687 & -3.837 & 0.302 \\
\hline $\mathrm{ACU}$ & -5.670 & 0.589 & -3.438 & 0.264 \\
\hline NTU & -5.672 & 0.590 & -3.440 & 0.265 \\
\hline \multicolumn{5}{|c|}{$\gamma_{3 j}$, Misleading Statute on $M_{j m}$} \\
\hline NOMINATE & 0.803 & 0.301 & 0.626 & 0.189 \\
\hline G\&S & 1.119 & 0.390 & 0.863 & 0.240 \\
\hline ACLU & 0.735 & 0.284 & 0.574 & 0.179 \\
\hline ADA & 0.620 & 0.255 & 0.487 & 0.161 \\
\hline $\mathrm{ACU}$ & 0.549 & 0.238 & 0.433 & 0.151 \\
\hline NTU & 0.550 & 0.238 & 0.433 & 0.151 \\
\hline \multicolumn{5}{|l|}{$R_{j}($ Million $\$)$} \\
\hline NOMINATE & 15.167 & 1.763 & 9.735 & 0.726 \\
\hline $\mathrm{G} \& \mathrm{~S}$ & 16.336 & 2.357 & 10.473 & 0.969 \\
\hline ACLU & 14.337 & 1.589 & 9.202 & 0.655 \\
\hline $\mathrm{ADA}$ & 14.426 & 1.449 & 9.270 & 0.598 \\
\hline $\mathrm{ACU}$ & 14.169 & 1.337 & 9.109 & 0.553 \\
\hline NTU & 14.155 & 1.337 & 9.101 & 0.553 \\
\hline \multicolumn{5}{|l|}{$\sigma$} \\
\hline NOMINATE & 0.912 & 0.119 & 0.912 & 0.119 \\
\hline G\&S & 0.839 & 0.187 & 0.839 & 0.187 \\
\hline ACLU & 0.931 & 0.115 & 0.931 & 0.115 \\
\hline $\mathrm{ADA}$ & 0.948 & 0.088 & 0.948 & 0.088 \\
\hline $\mathrm{ACU}$ & 0.952 & 0.079 & 0.952 & 0.079 \\
\hline NTU & 1.313 & 0.079 & 1.313 & 0.079 \\
\hline Observations & \multicolumn{2}{|c|}{376} & \multicolumn{2}{|c|}{376} \\
\hline
\end{tabular}

This table lists the parameter estimates in the candidate marginal cost function. The marginal cost is measured in dollars per eligible voter; it is measured relative to the cost of non-misleading advertising in a base DMA that has no surrounding DMAs within the same state, has no areas outside of battleground states, and is not in a state with a law against misleading campaign advertising. 
The marginal cost of advertising is measured in dollars per potential voter and is measured relative to non-misleading advertising aired in a base DMA. This base DMA is a DMA that has no surrounding DMA within that same state, lies completely within the state and does not have a law against misleading advertising. In this base DMA, the marginal cost of spending an additional dollar per voter is exactly the dollar amount spent $\left(N_{m} A_{j m}\right)$. The interpretation of the $\gamma$ parameters is the change in dollars per voter in marginal cost relative to the base DMA.

For example, $\gamma_{1, \text { Obama }}=7.45$ means that the cost to Obama of an additional dollar of misleading advertising per voter in a DMA has a non-pecuniary cost of $\$ 7.45$. This parameter is identified by the amounts of misleading and non-misleading advertising aired by each candidate, relative to the benefit of misleading advertising. That Obama faces a higher cost of airing misleading advertising than McCain is identified by the fact that McCain outspends Obama on misleading advertising in battleground states, on average.

Analogously, in a state with a law against misleading advertising, the cost for Obama (McCain) of airing misleading an additional dollar of misleading advertising is $\$ 0.80$ (\$0.63) more per voter than in a similar state without a law against misleading advertising. This is a $9 \%$ increase in the cost of misleading advertising for Obama and a $15 \%$ increase for McCain, suggesting that laws against misleading advertising affect presidential candidates' airing of misleading advertising.

The cost of airing misleading advertising in battleground states differs from the cost of airing misleading advertising in non-battleground states. In battleground states without laws against misleading advertising, the total cost is $\gamma_{1 j}+\gamma_{2 j}$. Since $\gamma_{2 j}$ is negative for both candidates, the greater the percentage of the DMA outside of 
a battleground state, the less the non-pecuniary cost of airing misleading advertising in that DMA.

The estimated $R_{j}$ values are the estimated shadow prices for each candidate of one electoral vote. I estimate Obama's value of one electoral vote in a battleground state to be $\$ 15.2$ million and McCain's to be $\$ 9.7$ million. These parameters are identified by the amounts spent on advertising (both pecuniary and non-pecuniary) by each candidate; since Obama spent more than McCain did in battleground states, Obama's value of an expected electoral vote is greater than McCain's. Interpreting $\frac{1}{R_{j}}$ as the opportunity cost of a dollar in the campaign chest, this can also be interpreted as McCain's opportunity cost being greater than Obama's.

The uncertainty parameter, $\sigma$ is not estimated separately for each candidate. It is identified by the covariation between advertising and polling. The less uncertainty there is, the more advertising will be concentrated in the battleground states that are closest in the polls. Table 16 shows how the probability of winning changes as the level of uncertainty changes. 


\section{Chapter 9}

\section{Counterfactual Analysis}

I conduct two different sets of counterfactual analysis. In both analyses, I examine two outcome variables: advertising amounts and vote share results. In the first counterfactual analysis, I solve for advertising choices in a world in which misleading advertising does not exist, and I find that total advertising falls by more than the amount of misleading advertising and that three states, Indiana, Missouri, and North Carolina, would have had different electoral outcomes.

Given that Ohio and Massachusetts overturned their state laws against misleading political advertising in 2014 and 2015, respectively, I also conduct a counterfactual where state laws against misleading political advertising are overturned in all battleground states that had them in place as of 2008. ${ }^{1}$ I find that misleading advertising in those states increases by $50 \%$, while non-misleading advertising remains unchanged. This change in advertising leads to a different electoral outcome in North Carolina.

\footnotetext{
${ }^{1}$ Colorado, Florida, Nevada, North Carolina, Ohio, and Wisconsin.
} 
Table 20: Changes in Advertising When Misleading Advertising is Zero

\begin{tabular}{lccc} 
Measure & $\begin{array}{c}\text { Original } \\
\text { Equilibrium }(\mathrm{M} \$)\end{array}$ & $\begin{array}{c}\text { Change in } \\
\text { Advertising }(\mathrm{M} \$)\end{array}$ & $\begin{array}{c}\text { Change in } \\
\text { Advertising }(\%)\end{array}$ \\
\hline Obama, Non-Misleading & 138.6 & -7.7 & $-5.6 \%$ \\
McCain, Non-Misleading & 65.7 & -5.6 & $-8.5 \%$ \\
Obama, Misleading & 17.5 & -17.5 & $-100 \%$ \\
McCain, Misleading & 21.2 & -21.2 & $-100 \%$ \\
Obama, Total & 156.1 & -25.2 & $-16.2 \%$ \\
McCain, Total & 86.9 & -26.8 & $-30.8 \%$ \\
\hline Total Advertising & 243.0 & -52.0 & $-21.4 \%$
\end{tabular}

This table lists the changes in advertising when misleading advertising is forced to be zero. The totals are across all battleground states in the 2008 election.

\subsection{No Misleading Advertising}

The existence of misleading advertising as an option for candidates intensifies the competition between the two candidates. In a counterfactual analysis where misleading advertising by candidates is set to zero, the equilibrium amounts of nonmisleading advertising fall by $7.7 \%$ relative to the observed equilibrium. Table 20 shows what happens to the levels of non-misleading advertising aired by the two candidates when misleading advertising levels are set at zero.

The total amount of advertising falls by $21.4 \%$, where $26 \%$ of the decrease is due to the decrease in non-misleading advertising. The existence of misleading advertising as an option for candidates appears to intensify the competition and lead to higher levels of advertising. This is because there is an implicit complementarity between misleading and non-misleading advertising. As a candidate's opponent airs more misleading advertising, the candidate's probability of winning the state changes; therefore, the candidate's marginal benefit of airing both misleading and non-misleading advertising change, and the candidate airs more of both types of advertising. 


\subsection{Overturn State Laws Against Misleading Advertising}

In 2014 and 2015, Ohio and Massachusetts both overturned their state laws against misleading political advertising. Of the 15 remaining states with laws against misleading political advertising, six were battleground states in the 2008 election: Colorado, Florida, North Carolina, Nevada, Ohio, and Wisconsin. I conduct a counterfactual analysis where the laws in these states are overturned. The resulting changes in advertising for these six states are listed in Table 21.

Changes in non-misleading advertising are small, almost 0, while misleading advertising increases by about $50 \%$ for each candidate. This increases total advertising across those six states by $\$ 10.4$ million dollars $(8.3 \%)$. These results show that laws against misleading advertising are effective in curbing misleading advertising. Moreover, these advertising changes result in a different electoral winner in the state of North Carolina. Since the existence of the law increases McCain's cost of misleading advertising by a greater percentage (14\%) than Obama's (10\%), repealing the law causes McCain to increase his spending on misleading advertising by a greater

percentage as well. This leads to McCain winning North Carolina instead of Obama. 
Table 21: Changes in Advertising When Laws Against Misleading Advertising Are Repealed

\begin{tabular}{lccc} 
Measure & $\begin{array}{c}\text { Original } \\
\text { Equilibrium }(\mathrm{M} \$)\end{array}$ & $\begin{array}{c}\text { Change in } \\
\text { Advertising }(\mathrm{M} \$)\end{array}$ & $\begin{array}{c}\text { Change in } \\
\text { Advertising }(\%)\end{array}$ \\
\hline Obama, Non-Misleading & 74.4 & 0.3 & $0.4 \%$ \\
McCain, Non-Misleading & 31.2 & 0.3 & $0.9 \%$ \\
Obama, Misleading & 9.1 & 4.5 & $49.4 \%$ \\
McCain, Misleading & 10.4 & 5.3 & $51.2 \%$ \\
Obama, Total & 83.4 & 4.8 & $5.8 \%$ \\
McCain, Total & 42.1 & 5.6 & $13.3 \%$ \\
\hline Total Advertising & 125.5 & 10.4 & $8.3 \%$
\end{tabular}

This table lists the changes in advertising when state with laws against misleading advertising repeal those laws. The totals are across the six battleground states in 2008 that had those laws in place: Colorado, Florida, North Carolina, Nevada, Ohio, and Wisconsin. 


\section{Chapter 10}

\section{Conclusion}

I find that misleading and non-misleading advertising differ in substantial ways. On the voter side, I find that misleading advertising has a higher marginal effect than non-misleading advertising, dollar for dollar. On the candidate side, I find that misleading advertising is, dollar for dollar, more costly than non-misleading advertising, and that it is even more costly in states with laws against misleading campaign advertising. Though the media has increasingly reported on the existence of misleading advertising with each presidential campaign, discussion on policies to curb misleading advertising have been limited by the lack of empirical understanding of the quantity and the effectiveness of misleading advertising. I find that state laws against misleading advertising are effective; in a counterfactual analysis where laws against misleading advertising are lifted (as was the case in Ohio in 2014 and Massachusetts in 2015), misleading advertising increases by $50 \%$ in those states, and the electoral winner in North Carolina changes. I also find that misleading advertising distorts voter decisions. In a counterfactual analysis where candidates cannot air misleading 
advertising, total advertising falls by $21 \%$, with $26 \%$ of that due to the decrease in non-misleading advertising.

I develop a model of voter and candidate behavior in the presence of televised candidate advertising. Because voters are forced to live under the regime of the winning candidate, the decision to vote depends on the difference in the utilities the voter receives from each candidate. The voter votes if this differences is greater than the cost of voting. Misleading and non-misleading advertising enter voter utility separately. Candidates choose misleading and non-misleading advertising to maximize expected electoral votes in battleground states.

In order to estimate the model, I use data on misleading advertising. I gathered this data by watching all unique candidate advertisements in the 2008 presidential election and coding each statement in each advertisement as misleading or non-misleading, using the third-party, fact-checking websites FactCheck.org and PolitiFact.com. I separately estimate a model of voter ideology, where voters' characteristics affect their ideology, and I simulate different ideology distributions based on county demographic distributions. I estimate the model according to the methodology of BLP, with modifications because a voter's utility of voting is a function of the difference in utilities the voter receives from each candidate.

There are some caveats that must be addressed in interpreting the results of this model. Firstly, I aggregate advertising over the entire course of the campaign; if the effectiveness of advertising does change over time, then what I estimate is an average effect. Secondly, the estimates from the model are specific to the 2008 election, and it is possible that the results may not easily generalize to other elections; however, I provide a baseline for the effects of misleading and non-misleading advertising on 
vote share.

In this paper, I choose to model advertising as persuasive, rather than informative. There are two main reasons for this. Firstly, there are few theoretical models where misleading advertising exists in equilibrium and also affects consumers. Barigozzi, Garella, and Peitz (2009) allow for misleading advertising, but in their model, misleading advertising never occurs in equilibrium. Rhodes and Wilson (2015) develop a model where misleading advertising occurs in equilibrium and influences rational buyers. However, in this model, firms have different types, and only one type of firm makes misleading claims. This model could not be extended to an election where both candidates ("firms") make misleading statements in equilibrium. Secondly, allowing misleading advertising to be informative and affect candidate ideology would be difficult, and perhaps impossible, to compute empirically. Candidates would essentially be strategically choosing both ideology and valence over 250 markets, which would be very difficult to compute and likely lead to multiple equilibria. If it were possible to estimate advertising effects to be informative, I would expect the resulting estimated relative effects of misleading and non-misleading to be similar to those found in this paper. However, it is possible that I would generally overstate the effect of both types of advertising, since informative advertising would affect voters at the extremes instead of both those at the extreme and those in the middle.

In the 2008 presidential campaign, the two candidates spent over $\$ 38$ million on misleading advertising. I show that this spending on misleading advertising had a significant effect on voter behavior and that the average marginal benefit of misleading advertising was greater than non-misleading advertising. I also show that state laws against misleading political advertising are effective in curbing misleading polit- 
ical advertising, and in a counterfactual analysis where state laws against misleading advertising are repealed, I find that misleading advertising increases by $50 \%$ in those states, which changes the electoral outcome in North Carolina. I find that there is an implicit complementarity between the two advertising types, and I also find that misleading advertising distorts voter decisions relative to a world without misleading advertising. When no misleading advertising is allowed, total advertising falls by $21 \%$, with the change in non-misleading advertising accounting for $26 \%$ of that total. Also, three states (Missouri, Indiana, and North Carolina) would have had different electoral outcomes. These results help provide a context for discussing the importance of potential policies aimed at curbing misleading political advertising and a benchmark for future work on misleading advertising. 


\section{Bibliography}

Adams, James F., Samuel Merrill, and Bernard Groffman. 2005. A Unified Theory of Party Competition: A Cross-National Analysis Integrating Spatial and Behavioral Theories. New York: Cambridge University Press.

Anderson, Simon P., Federico Ciliberto, Jura Liaukonyte, and Regis Renault. 2015. "Push-Me Pull-You: Comparative Advertising in the OTC Analgesics Industry." Forthcoming Rand Journal of Economics.

Anderson, Simon P. and Gerhard Glomm. 1992. "Alienation, Indifference and the Choice of Ideological Position." Social Choice and Welfare 9 (1):17-31.

Andrews, J. Craig, Scot Burton, and Richard G. Netemeyer. 2000. "Are Some Comparative Nutrition Claims Misleading? The Role of Nutrition Knowledge, Ad Claim Type and Disclosure Conditions." Journal of Advertising 29 (3):pp. 29-42.

Andrews, Wilson, Dan Keating, and Karen Yourish. 2012. "Mad Money: TV Ads in the 2012 Presidential Campaign." The Washington Post November 14, 2012.

Annenberg Public Policy Center. 2014. "FactCheck.org." URL http://www . factcheck. org/. 
Ansolabehere, Stephen and James Snyder. 2000. "Valence Politics and Equilibrium in Spatial Election Models." Public Choice 103 (3-4):327-336.

Arceneaux, Kevin and Gregory A. Huber. 2007. "Identifying the Persuasive Effects of Presidential Advertising." American Journal of Political Science 51 (4):957-977.

Barigozzi, Francesca, Paolo G. Garella, and Martin Peitz. 2009. "With a Little Help from My Enemy: Comparative Advertising as a Signal of Quality." Journal of Economics \& Management Strategy 18 (4).

Baron, David P. 1989. "Service-Induced Campaign Contributions and the Electoral Equilibrium." The Quarterly Journal of Economics 104 (1):45-72.

Batz, Dan and Alec Macgillis. 2008. "Battleground States." The Washington Post June 8, 2008.

Berry, Steven, James Levinsohn, and Ariel Pakes. 1995. “Automobile Prices in Market Equilibrium." Econometrica 63 (4):pp. 841-890.

Brams, Steven J. and Morton D. Davis. 1974. "The 3/2's Rule in Presidential Campaigning." The American Political Science Review 68 (1):113-134.

Cawley, John, Rosemary Avery, and Matthew Eisenberg. 2013. "The Effect of Advertising and Deceptive Advertising on Consumption: the Case of Over-the-Counter Weight Loss Products." Working Paper.

Cooper, Michael. 2012. "Campaigns Play Loose With Truth in a Fact-Check Age." New York Times August 31, 2012. 
da Silveira, Bernardo S. and João M.P. De Mello. 2011. "Campaign Advertising and Election Outcomes: Quasi-natural Experimental Evidence from Gubernatorial Elections in Brazil." Review of Economic Studies 78:590-612.

Downs, Anthony. 1957. "An Economic Theory of Political Action in a Democracy." Journal of Political Economy 65 (2):pp. 135-150.

Freedman, Paul, Michael Franz, and Kenneth Goldstein. 2004. "Campaign Advertising and Democratic Citizenship." American Journal of Political Science 48 (4):723741.

Gardner, David M. 1975. "Deception in Advertising: A Conceptual Approach." The Journal of Marketing 39 (1):pp. 40-46.

Geer, John G. 2006. In Defense of Negativity: Attack Ads in Presidential Campaigns. University of Chicago Press.

Gentzkow, Matthew and Jesse M. Shapiro. 2010. "What Drives Media Slant? Evidence From U.S. Daily Newspapers." Econometrica 78 (1):35-71.

Gerber, Alan. 1998. "Estimating the Effect of Campain Spending on Senate Election Outcomes Using Instrumental Variables." The American Political Science Review $92(2): 401-411$.

Goeree, Michelle Sovinsky. 2008. "Limited Information and Advertising in the U.S. Personal Computer Industry." Econometrica 76 (5):1017-1074.

Goldstein, Kenneth and Paul Freedman. 2002. "Campaign Advertising and Voter 
Turnout: New Evidence for a Stimulation Effect." The Journal of Politics $64(3): 721-740$.

Goldstein, Kenneth and Travis N. Ridout. 2004. "Measuring the Effects of Televised Political Advertising in the United States." Annual Review of Political Science $7: 205-226$.

Gordon, Brett and Wesley Hartmann. 2013. "Advertising Effects in Presidential Elections." Marketing Science 32 (1):19-35.

—. 2015. "Advertising Competition in Presidential Elections." Forthcoming Quantitative Marketing and Economics.

Gordon, Brett R., Mitchell J. Lovett, Ron Schachar, Kevin Arceneaux, Sridhar Moorthy, Michael Peress, Akshay Rao, Subrata Sen, David Soberman, and Oleg Uminsky. 2012. "Marketing and Politics: Models, Behavior, and Policy Implications." Marketing Letters 23 (2):391-403.

Hillygus, D. Sunshine. 2005. "Campaign Effects and the Dynamics of Turnout Intention in Election 2000." Journal of Politics 67 (1):50-68.

Holan, Angie Drobnic. 2015. "All Politicians Lie. Some Lie More Than Others." The New York Times .

Johnston, Richard, Michael G. Hagen, and Kathleen Hall Jamieson. 2004. The 2000 Presidential Election and the Foundation of Party Politics. Cambridge: Cambridge University Press. 
Kruse, Becky. 2001. "The Truth in Masquerade: Regulating False Ballot Proposition Ads through State Anti-False Speech Statutes." California Law Review 89 (1).

Lau, Richard R., Lee Sigelman, and Ivy Brown Rovner. 2007. "The Effects of Negative Political Campaigns: A Meta-Analytic Reassessment." The Journal of Politics $69(4)$.

Levitt, Steven D. 1994. "Using Repeat Challengers to Estimate the Effect of Campaign Spending on Election Outcomes in the U.S. House." Journal of Political Economy 102 (4):777-798.

Liep, Dave. 2014. "Atlas of U.S. Presidential Elections." URL http:// uselectionatlas.org.

McDonald, Michael P. 2014. "United States Election Project." URL http://www . electproject.org.

Moshary, Sarah. 2015. "Price Discrimination across PACs and the Consequences of Political Advertising Regulation." Working Paper.

Nelson, Phillip. 1974. "Advertising as Information." Journal of Political Economy $82(4)$ :pp. $729-754$.

Nevo, Aviv. 2001. "Measuring Market Power in the Ready-to-Eat Cereal Industry." Econometrica 69 (2):307-342.

Poole, Ketih T. and Howard Rosenthal. 1997. Congress: A Political-Economic History of Roll Call Voting. Oxford University Press.

Rhodes, Andrew and Chris M. Wilson. 2015. "False Advertising." Working Paper. 
Russo, J. Edward, Barbara L. Metcalf, and Debra Stephens. 1981. "Identifying Misleading Advertising." Journal of Consumer Research 8 (2):pp. 119-131.

Shaw, Daron R. 2006. The Race to 270: The Electoral College and the Campaign Strategies of 2000 and 2004. Chicago: University of Chicago Press.

Silver, Nate. 2008. "Swing State Analysis." June 9, 2008. URL http://www. fivethirtyeight.com.

Snyder, James M. 1989. "Election Goals and the Allocation of Campaign Resources." Econometrica 57 (3):637-660.

Stephen Ansolabehere, Adam Simon, Shanto Iyengar and Nicholas Valentino. 1994. "Does Attack Advertising Demobilize the Electorate?" American Political Science Review 88 (4).

Stigler, George J. and Gary S. Becker. 1977. "De Gustibus Non Est Disputandum." The American Economic Review 67 (2):76-90.

Stokes, Donald E. 1963. "Spatial Models of Party Competition." American Political Science Review 57 (2):368-377.

—. 1992. Valence Politics. New York: Oxford Univeristy Press.

Stone, Walter J. and Elizabeth N. Simas. 2010. "Candidate Valence and Ideological Positions in U.S. House Elections." American Journal of Political Science $54(2): 371-388$.

Stromberg, David. 2008. "How the Electoral College Influences Campaigns and Policy: The Probability of Being Florida." American Economic Review 98 (3):769-807. 
Szidarovszky, Ferenc and Koji Okuguchi. 1997. "On the Existence and Uniqueness of Pure Nash Equilibrium in Rent-Seeking Games." Games and Economic Behavior $18: 135-140$.

Tampa Bay Times. 2014. "Politifact.com." URL http://www.politifact.com/.

The Federal Election Commission. 2008. "Federal Election Campaign Laws." Washington, D.C. 20463.

The New York Times. 2008. "The Electoral Map." May 11, 2008. URL http: //politics.nytimes.com/election-guide/2008/electoralmap/.

Winneg, Kenneth, Kate Kenski, and Kathleen Hall Jamieson. 2005. "Detecting the Effects of Deceptive Presidential Advertisements in the Spring of 2004." American Behavioral Scientist 49 (1). 